\title{
LOW CYCLE FATIGUE PROPERTIES OF A LOW RARE EARTH-CONTAINING ME20 MAGNESIUM ALLOY
}

\author{
by \\ Ke Wang \\ Bachelor of Engineering in Materials Science and Engineering \\ China University of Mining and Technology, Beijing, China, 2011 \\ A thesis \\ presented to Ryerson University \\ in partial fulfillment of the \\ requirements for the degree of \\ Master of Applied Science \\ in the Program of \\ Mechanical Engineering
}

Toronto, Ontario, Canada, 2015

(C) Ke Wang 2015 


\section{AUTHOR'S DECLARATION FOR ELECTRONIC SUBMISSION OF A THESIS}

I hereby declare that I am the sole author of this thesis. This is a true copy of the thesis, including any required final revisions, as accepted by my examiners.

I authorize Ryerson University to lend this thesis to other institutions or individuals for the purpose of scholarly research.

I further authorize Ryerson University to reproduce this thesis by photocopying or by other means, in total or in part, at the request of other institutions or individuals for the purpose of scholarly research.

I understand that my thesis may be made electronically available to the public. 


\title{
LOW CYCLE FATIGUE PROPERTIES OF A LOW RARE EARTH-CONTAINING ME20 MAGNESIUM ALLOYS
}

\author{
(C) Ke Wang, 2015 \\ Master of Applied Science \\ Department of Mechanical \& Industrial Engineering \\ Ryerson University
}

\begin{abstract}
A newly-developed rare earth-containing ME20 magnesium alloy was studied in this thesis. As a potential structural material for applications in automotive industry, low cycle fatigue properties are inevitably required. Strain-controlled low cycle fatigue tests were conducted on this wrought alloy with different specimen orientations. Microstructure, tensile behaviors and low cycle fatigue properties were studied. The effect of different specimen orientations on microstructures and mechanical properties were also discussed. Results show that rare earth element addition in this alloy helped weaken the texture and specimen orientations had little influence over microstructure and fatigue properties of this magnesium alloy.
\end{abstract}




\section{ACKNOWLEDGEMENTS}

I would like to express my sincere gratitude to Dr. Daolun Chen for giving me this opportunity to work on this project. I would like to also show my deep appreciation to Dr. Jacob Friedman for checking and correcting my thesis.

I would like to thank Dr. Ahmad Ghasempoor and Dr. Donatus Oguamanam for serving on my thesis supervisory committee.

The assistance of J. Amankrah, R. Churaman, Q. Li, and A. Machin is gratefully acknowledged for the aid in performing the experiments. I would also like to thank all my colleagues and friends at Ryerson University for their constant support and help.

All praise, honor and glory to my heavenly father, the almighty God, who is the maker of heaven and earth. I thank my Lord and savior Jesus Christ for His richest grace and mercy for the accomplishment of this thesis.

Surely your goodness and love will follow me all the days of my life, and I will dwell in the house of the Lord forever. - Psalm 23 
To

My Parents

Kaoshan Wang and Yanying Yang

My fiancée

Emily Zhou 


\section{Table of Contents}

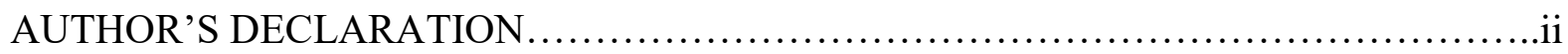

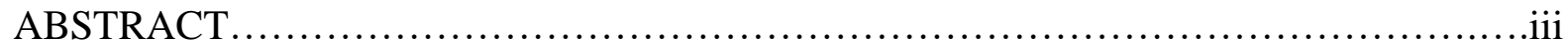

ACKNOWLEDGEMENTS .................................................... iv

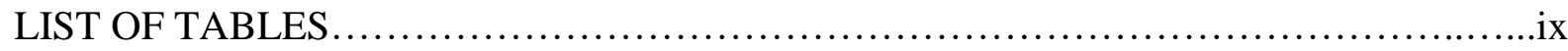

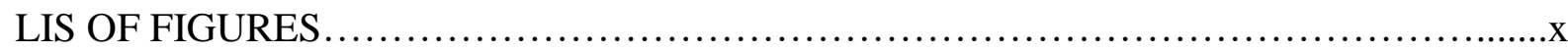

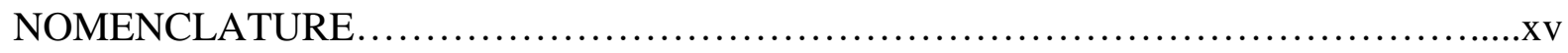

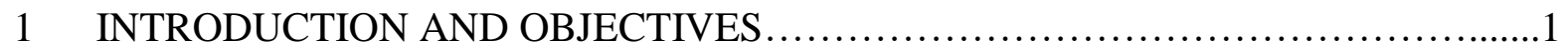

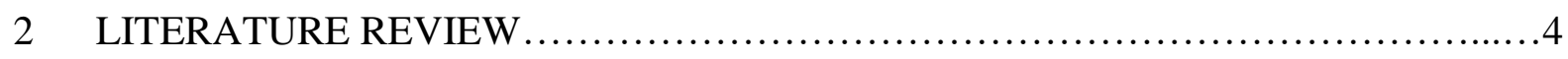

2.1 Recent research work of magnesium alloys and their development ......................4

2.2 Microstructures of rare earth element containing $\mathrm{Mg}$ alloys ..................................5

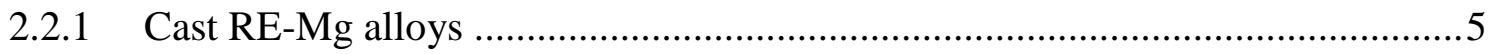

2.2.2 Extruded RE-Mg alloys .................................................................

2.3 Crystallographic textures of RE-Mg alloys ...................................................5

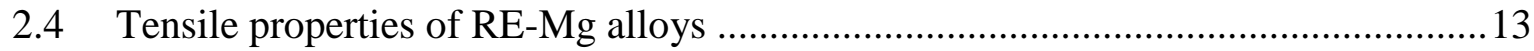

2.5 Fatigue behavior of RE-Mg alloys ............................................................ 14

2.5.1 Stress-controlled fatigue behavior ...................................................... 15

2.5.2 Strain-controlled fatigue behavior ....................................................... 18

2.5.2.1 Stress-strain hysteresis loops ........................................................ 19

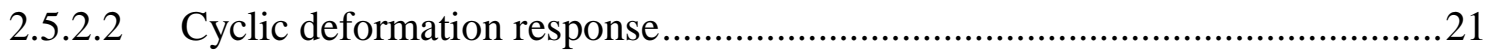

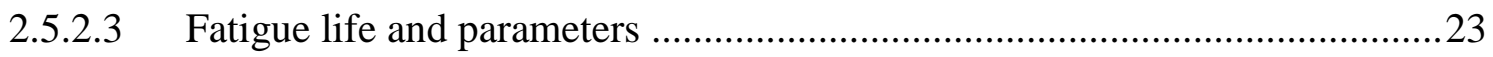




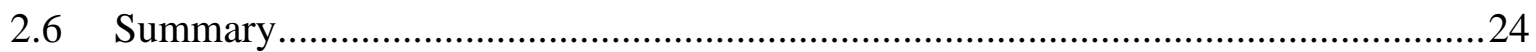

3 EXPERIMENTAL PROCEDURES........................................... 25

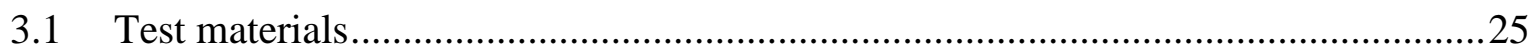

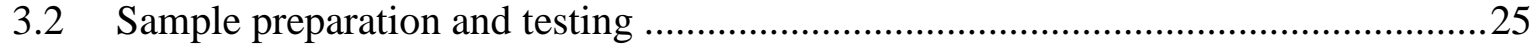

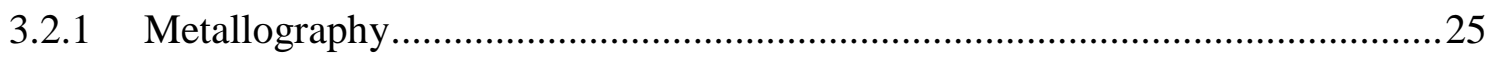

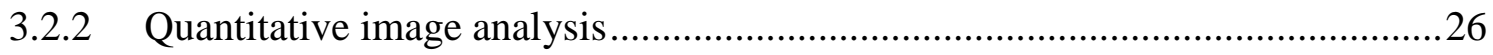

3.2.3 Texture measurements by X-ray diffraction...........................................27

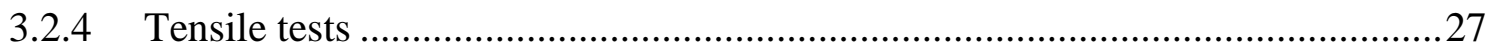

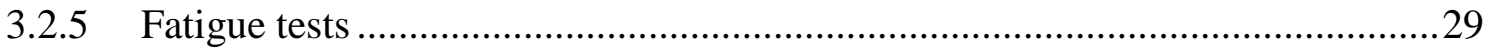

$4 \quad$ RESULTS AND DISCUSSION .............................................

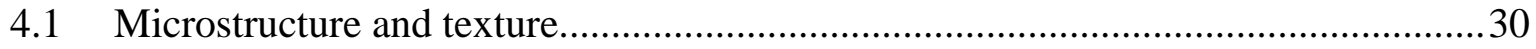

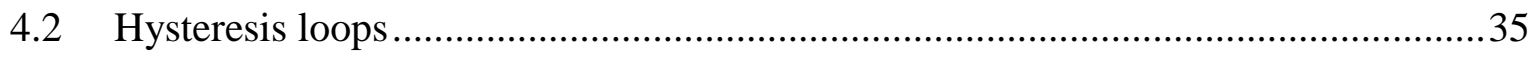

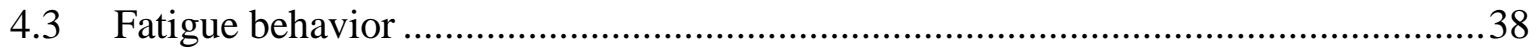

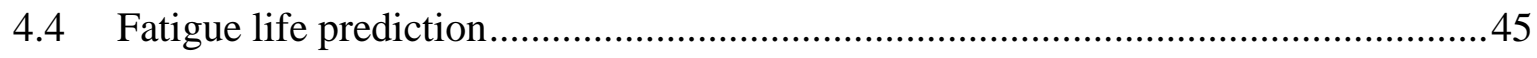

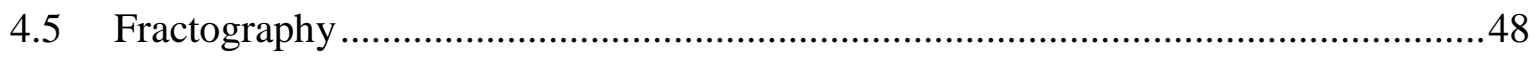

5 COMPARISON WITH SAMPLES CUT ALONG TRASVERSE DIRECION.........51

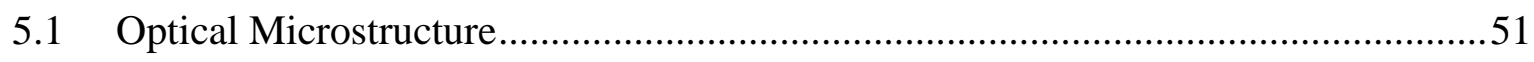

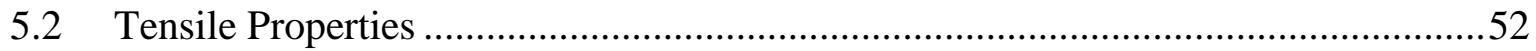

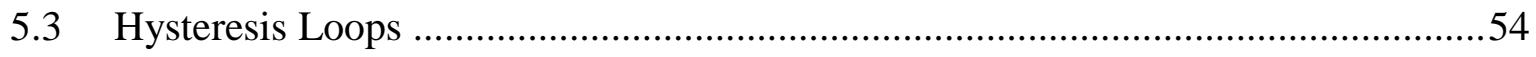

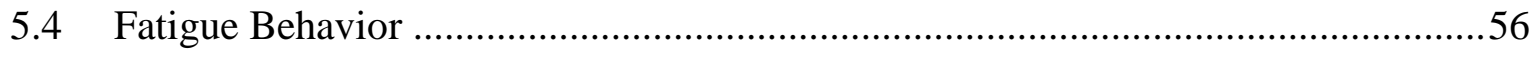

6 SUMMARY, CONCLUSIONS AND FUTURE WORK ..........................65 


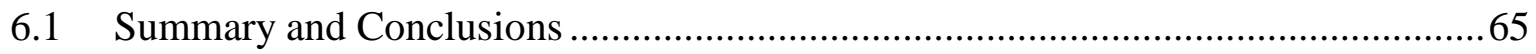

6.2 Recommendations for Future Work .............................................................66

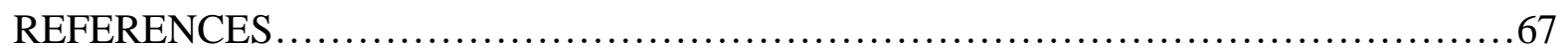




\section{LIST OF TABLES}

Table 3.1: Chemical composition (in wt. \%) of ME20 alloy............................................. 25

Table 4.1: Tensile properties of rolled ME20 alloy (RD). ................................................ 34

Table 4.2: Low cycle fatigue parameters for the rolled ME20 alloy (Rolling direction)......... 44

Table 5.1: Tensile properties of rolled ME20 alloy (Transverse orientation)....................... 53

Table 5.2: Low cycle fatigue parameters for the rolled ME20 alloy (TD).......................... 64 


\section{LIST OF FIGURES}

Figure 2.1: (a) Typical SEM micrographs of an as-cast Mg-15Gd-5Y-0.5Zr alloy [77] and (b) as-cast Mg-8Gd-0.6Zr-xNd-yY alloys, $(x+y=3$, mass \%) [70].

Figure 2.2: SEM image of as-cast sample and the corresponding EDS spectra of the points indicated in the image [57].

Figure 2.3: Optical images of the as-extruded specimens: (a) and (b) Mg-8Gd-0.4Zr alloy, (c) and (d) Mg-8Gd-1Zn-0.4Zr alloy, and (e) and (f) Mg-8Gd-3Zn-0.4Zr alloy [78]. .9

Figure 2.4: Effect of Gd content on the recrystallization texture intensity in an Mg-Gd binary alloy [115]. 11

Figure 2.5: (0001) and 110-10\}pole figures of the as-received (a) AZ31 and (b) ZE10 sheets, where density profiles of the basal pole along different sheet directions are shown for (c) AZ31 and (d) ZE10 sheets (RD: rolling direction, TD: transverse direction, $45^{\circ}: 45^{\circ}$ from the RD) [123]. 12

Figure 2.6: Uniaxial tensile and compressive stress-strain curves for (a) GW123k alloy and (b) AZ31 alloy [37]. 14

Figure 2.7: S-N curves for an AZ91D alloy with different amounts of Ce addition. (a) 0\% Ce, (b) $1 \% \mathrm{Ce}$, and (c) $2 \% \mathrm{Ce}[86,142]$. 16

Figure 2.8: S-N curve of an extruded Mg-12Gd-3Y-0.5Zr (GW123K) alloy [37]. 17

Figure 2.9: Stress-strain hysteresis loops of an extruded GW83 alloy fatigued at (a) $\Delta \varepsilon / 2=4.0 \%$, (b) $\Delta \varepsilon / 2=0.77 \%$, and (c) $\Delta \varepsilon / 2=0.30 \%[58]$. 20 
Figure 2.10: Hysteresis loops of a GW123K alloy fatigued at varying total strain amplitudes $[148]$. 21

Figure 2.11: Variation of stress amplitude with increasing number of cycles at varying strain amplitudes from $0.275 \%$ to $5.0 \%$ for an extruded GW83 alloys [58]. 22

Figure 2.12: Total strain amplitude-fatigue life curves for GW102K and AZ31 alloys [149].23

Figure 3.1: Geometry and dimensions of the sub-sized tensile/fatigue test specimens according to ASTM E8 [164]. 28

Figure 4.1: (a) Microstructures of a ME20 base material observed from rolling direction, (b) SEM back-scattered electron image of rolled ME2O base metal observed from rolling direction. (c) SEM back-scattered electron image indicating an EDS line scan position, and (d) the corresponding EDS line scan results. 31

Figure 4.2: (0002) pole figure of rolled ME20 alloy, where RD stands for the rolling direction, and TD stands for transverse direction. 33

Figure 4.3: Typical tensile stress-strain curves of ME20 alloys at a strain rate of $1 \times 10^{-3} \mathrm{~s}^{-1}$. (Rolling orientation) 34

Figure 4.4: Typical stress-strain hysteresis loops of different cycles at a total strain amplitude of $1.2 \%$ and strain ratio of $R_{S}=-1$ for the rolled ME20 alloy (Rolling orientation)..... 36

Figure 4.5: Optical micrograph in the area near the fracture surface at total strain amplitude of $1.2 \%$, showing the distribution of residual twins in the fatigued sample of the rolled ME20 alloy (Rolling orientation). 37 
Figure 4.6: Stress amplitude vs. the number of cycles at different total strain amplitudes applied (Rolling orientation). 39

Figure 4.7: Plastic strain amplitude vs. the number of cycles at different total strain amplitudes applied (Rolling orientation). 41

Figure 4.8: Cyclic stress-strain curve for the ME2O alloy, where the corresponding monotonic stress-strain curve is also potted for comparison (Rolling orientation). 41

Figure 4.9: Total strain amplitude as a function of the number of cycles to failure for the rolled ME20 alloy (Rolling orientation), in comparison with the data reported in the literature for various $\mathrm{Mg}$ alloys .43

Figure 4.10: Evaluation of fatigue parameters in the form of log elastic, plastic and total strain amplitudes vs. log number of reversals to failure, respectively (Rolling orientation)..44 Figure 4.11: Life prediction with the energy-based models based on plastic strain energy density (a) and based on total strain (b).....

Figure 4.12: SEM images of overall fracture surfaces of the rolled specimens fatigue data total strain amplitude of (a) $0.2 \%$ and $(b) 1.0 \%$. .49

Figure 4.13: SEM micrographs of the fracture surface near crack initiation of the rolled specimens fatigued at a total strain amplitude of $0.2 \%((a)$ secondary electron image and (b) $1.0 \%$ ( secondary electron image). .49

Figure 4.14: SEM micrographs of the fatigue crack propagation region of the rolled specimens fatigued at total strain amplitude of (a) $0.2 \%$ and $(b) 1.0 \%$ 50 
Figure 5.1: Microstructures of a ME20 base material observed from transverse direction (a)

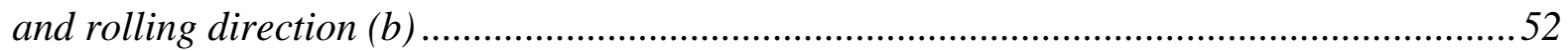

Figure 5.2: Typical tensile stress-strain curves of ME20 alloys at a strain rate of $1 \times 10^{-3} \mathrm{~s}^{-1}$. (Transverse and rolling direction) 53

Figure 5.3 : Typical stress-strain hysteresis loops of different cycles at a total strain amplitude of $1.2 \%$ and strain ratio of $R_{s}=-1$ for the rolled ME20 alloy. (Transverse direction and comparison with rolling direction under different cycles) 55

Figure 5.4: Optical micrograph in the area near the fracture surface at a total strain amplitude of $1.2 \%$, showing the distribution of residual twins in the fatigued sample of the rolled ME20 alloy. (Transverse direction) 56

Figure 5.5: Stress amplitude vs. the number of cycles at different total strain amplitudes applied (Transverse and rolling direction). 57

Figure 5.6: Plastic strain amplitude vs. the number of cycles at different total strain amplitudes applied (Transverse and rolling direction) 60

Figure 5.7: Cyclic stress-strain curve for the ME20 alloy, where the corresponding monotonic stress-strain curve is also potted for comparison. (Transverse orientation) 61

Figure 5.8: Total strain amplitude as a function of the number of cycles to failure for the rolled ME20 alloy of different specimen orientation, in comparison with the data reported in the literature for various $\mathrm{Mg}$ alloys. 
Figure 5.9: Evaluation of fatigue parameters in the form of log elastic, plastic and total strain amplitudes vs. log number of reversals to failure, respectively (Transverse orientation)......64 


\section{NOMENCLATURE}

\section{Acronym}

ASTM

USAMP

bcc

fcc

hcp

$\mathrm{HCF}$

LCF

$\mathrm{Mg}$

Al

$\mathrm{Mn}$

$\mathrm{Cu}$

$\mathrm{Zn}$

$\mathrm{Fe}$

$\mathrm{Ni}$

Ce

RT

SEM

EDS

$\% \mathrm{El}$

\section{Definition}

American Society for Testing of Materials

United States Automotive Materials Partnership

Body centered cubic

Face centered cubic

Hexagonal closed packed

High cycle fatigue

Low cycle fatigue

Magnesium

Aluminum

Manganese

Copper

Zinc

Iron

Nickel

Cerium

Room temperature

Scanning electron microscope

Energy dispersive X-ray spectroscopy

$\%$ Elongation 
UTS

YS

RE

LD

RD

TD

ND

\section{Symbol}

$\sigma$

$\varepsilon$

$\dot{\varepsilon}$

$n$

K

E

$\theta$

$$
\begin{aligned}
& \left(\frac{\Delta \varepsilon_{t}}{2}\right) \\
& \left(\frac{\Delta \varepsilon_{e}}{2}\right)
\end{aligned}
$$

Ultimate tensile strength

Yield strength

Rare-earth

Longitudinal direction

Rolling direction

Transverse direction

Normal direction

\section{Definition}

Stress, MPa

Strain

Strain rate, $\mathrm{s}^{-1}$

Strain hardening exponent

Strength coefficient, $\mathrm{MPa}$

Young's modulus or modulus of elasticity, MPa

Strain or work hardening rate, $\mathrm{MPa}$

Total strain amplitude

Elastic strain amplitude 


$\begin{array}{ll}\left(\frac{\Delta \varepsilon_{\mathrm{p}}}{2}\right) & \text { Plastic strain amplitude } \\ N & \text { Number of cycles } \\ N_{f} & \text { Number of cycles to failure } \\ n^{\prime} & \text { Cyclic strain hardening exponent } \\ K^{\prime} & \text { Cyclic strength coefficient, MPa } \\ \sigma_{f}^{\prime} & \text { Fatigue strength coefficient, MPa } \\ b & \text { Fatigue strength exponent } \\ \varepsilon_{f}^{\prime} & \text { Fatigue ductility coefficient, \% } \\ c & \text { Fatigue ductility exponent } \\ R & \text { Stress ratio }\end{array}$




\section{INTRODUCTION AND OBJECTIVES}

Due to the increasing global energy demand and great cognizance of human-caused pollution such as $\mathrm{CO}_{2}$ emissions in recent years [1,2], light weighting has turned into a crucial approach in the automotive and aerospace industries [1, 3-4]. It has been reported that for each $10 \%$ reduction in weight, the fuel efficiency of passenger vehicles can be boosted by $6-$ 8\% [5]. Being the lightest structural metallic material, magnesium alloys have been more and more applied in the auto industry for motor vehicle weight reduction [6]. The application of magnesium alloys into structural materials in the automotive and aerospace industry would thus inevitably drive engineers to evaluate the fatigue and cyclic deformation features, owing that structural components would unavoidably experience dynamic loading in vehicles and aeroplanes, which leads to the occurrence of fatigue failure [7-9]. Hereafter, in order to design and evaluate the durability of such engineering components, it is essential to understand the fatigue and cyclic deformation behavior of magnesium alloys. As there are growing significant applications of magnesium alloys in powertrain, chassis and body areas, developing wrought magnesium components which show improved mechanical properties is a necessity [10]. Indeed, wrought alloys exhibit superior fatigue properties such as fatigue resistance, as compared to cast counterparts; they are suitable for studying the intrinsic fatigue mechanisms of magnesium alloys [10-13]. However, only very limited work on the strain-controlled low cycle fatigue behavior of rolled magnesium alloy ME20 has been 
reported in the literature. The objective of the present work was to evaluate the cyclic deformation behavior of a rolled ME20 magnesium alloy, determine the fatigue life under varying strain amplitudes, obtain cyclic parameters such as cyclic strain hardening exponent, and verify the fatigue life behavior based on the energy density model. Influence of specimen orientation, tensile and low cycle fatigue properties along the transverse and rolling directions were also studied.

The general objective of this thesis is to achieve an understanding of the cyclic deformation behavior of ME20 alloys. As mentioned above, studies on the cyclic deformation behavior of this newly developed RE-Mg alloy are limited to date. Thus microstructure, mechanical properties such as tensile and cyclic deformation behavior of ME20 was studied. The specific objectives of this thesis include the following:

- To evaluate the cyclic deformation behavior of rolled ME20 alloy under varying strain amplitudes.

- To investigate the effect of the addition of RE-Element on the cyclic deformation behavior of this material.

- To study the sample orientation effect on microstructure and mechanical properties of this rolled alloy.

The approach that was taken for achieving these goals was mostly experimental work. This thesis has been structured as follows: 
In Chapter 2, a literature survey is presented on the recent developments and trends of research on RE-Mg alloys. As well as microstructural characterization and mechanical properties of different RE-Mg alloys, both under monotonic and cyclic deformation tests. Experimental procedure is presented in Chapter 3. Chapters 4-5 present the experimental results along with the discussion of results obtained from the low cycle fatigue tests subjected to different strain amplitudes of rolled ME20 alloy. The conclusions arising from the thesis and direct to the potential future for continuing with this research are specified in Chapter 6. 


\section{LITERATURE REVIEW}

\subsection{Recent research work on magnesium alloys and their development}

Magnesium $(\mathrm{Mg})$, which was discovered in 1774 , is ranked $6^{\text {th }}$ in terms of abundance in the earth as it constitutes nearly $2 \%$ of the earth's crust total mass [14]. The density of magnesium is $1.74 \mathrm{~g} / \mathrm{cm}^{3}$. Compared with other materials, the density of $\mathrm{Mg}$ is two-thirds of Aluminum, around $20 \%$ of steel and is comparable to many polymers, making $\mathrm{Mg}$ the lightest structural metallic material available [15-16]. Compared with Aluminum, the Young's modulus and shear modulus of magnesium are around two-thirds of $\mathrm{Al}$, and the melting point and specific heat of $\mathrm{Mg}$ are also similar. There are some other striking properties such as good machinability and recyclability, dimensional stability and electromagnetic shielding [17]. In the past decade, there has been a remarkable growing demand in the magnesium alloy development for use in structural, automotive, household as well as sports equipment applications. This is largely due to their light weight structure and a good potential for weight reduction and thus the cutting of $\mathrm{CO}_{2}$ emission [17-19]. $\mathrm{Mg}$ is also an alloying element in different alloys. Magnesium could be alloyed with aluminum, manganese, rare-earths, thorium, zinc or zirconium to increase the strength to weight ratio. Applications can be found in weight reduction of materials and the reduction of inertial forces. Therefore denser materials such as steels, cast irons and copper base alloys, as well as even aluminum alloys may be replaced by Mg alloys [20-21].

Moreover, a report released from United States Automotive Materials Partnership conveyed that by the year 2020, the use of Magnesium alloys will increase by $340 \mathrm{lbs}$ per car, which 
would make possible a significant vehicle weight reduction (about 15\%) [22]. It was reported in a recent (October 2013) press release at the WWJ Auto Summit that "Vehicle lightweighting is auto industry's best opportunity to achieve CAFE (Corporate Average Fuel Economy) standard" and it was also stated that the weight of each vehicle could achieve a reduction of more than 209 pounds with the application of modern technologies with lightweight materials, and this is essentially the equivalent of planting about 19 trees in terms of environmental consideration per vehicle. Consequently, the application of $\mathrm{Mg}$ alloys brings about weight reduction, energy-saving, and environmental protection benefits.

\subsection{Microstructures of rare earth element containing Mg alloys}

\subsubsection{Cast RE-Mg alloys}

Numerous research activities have recently been conducted on the cast Mg alloys with the addition of RE elements [23-48]. These studies have indicated that RE elements' function to adjust the mechanical properties of bulk metals with a wide range of alloy composition and heat treatment, because of their fairly large solubility at the eutectic temperature and the formation of precipitates like $\mathrm{Mg}_{5} \mathrm{RE}(\mathrm{Gd}, \mathrm{Y})$. Figure 2.1 shows the microstructure of an ascast Mg-15Gd-5Y-0.5Zr alloy [33] and as-cast Mg-8Gd-0.6Zr-xNd-yY alloys, (x+y=3, wt.\%) [26] respectively. The as-cast alloy is primarily composed of continuous rosette-shaped equiaxed dendrites, and partially interdendritic eutectic co-exists in the alloy. Many dark petal-like Zr-rich regions were also dispersed in the $\alpha-\mathrm{Mg}$. As noted in the literature [36, 38, $39,49,50]$, the main intermetallic compounds were $\mathrm{Mg}_{5} \mathrm{RE}, \mathrm{Mg}_{24} \mathrm{RE}_{5}$, and $\mathrm{Mg}_{41} \mathrm{RE}_{5}$. The 
average equiaxed interdendritic arm spacing was about $30 \mu \mathrm{m}$ in the as-cast $\mathrm{Mg}-15 \mathrm{Gd}-5 \mathrm{Y}$ $0.5 \mathrm{Zr}$ alloy [26], and this is fairly small if compared with the common magnesium alloys such as AZ31 and AM30 [51-55]. This was owing to the role of RE elements and zirconium addition, where $\mathrm{Zr}$ principally restricted the grain growth [56]. Furthermore, as stated in the work of $\mathrm{He}$ et al. [24], the as-cast $\mathrm{Mg}-10 \mathrm{Gd}-2 \mathrm{Y}-0.5 \mathrm{Zr}$ alloy contains three different phases: $\alpha-\mathrm{Mg}$ solid solution matrix phase with supersaturated $\mathrm{Gd}+\mathrm{Y}$ elements, a $(\mathrm{Gd}+\mathrm{Y})$-rich eutectic compound which had a higher $\mathrm{Gd}+\mathrm{Y}$ content than the matrix, and intracrystalline $\mathrm{Zr}$ rich cores (Figure 2.2).
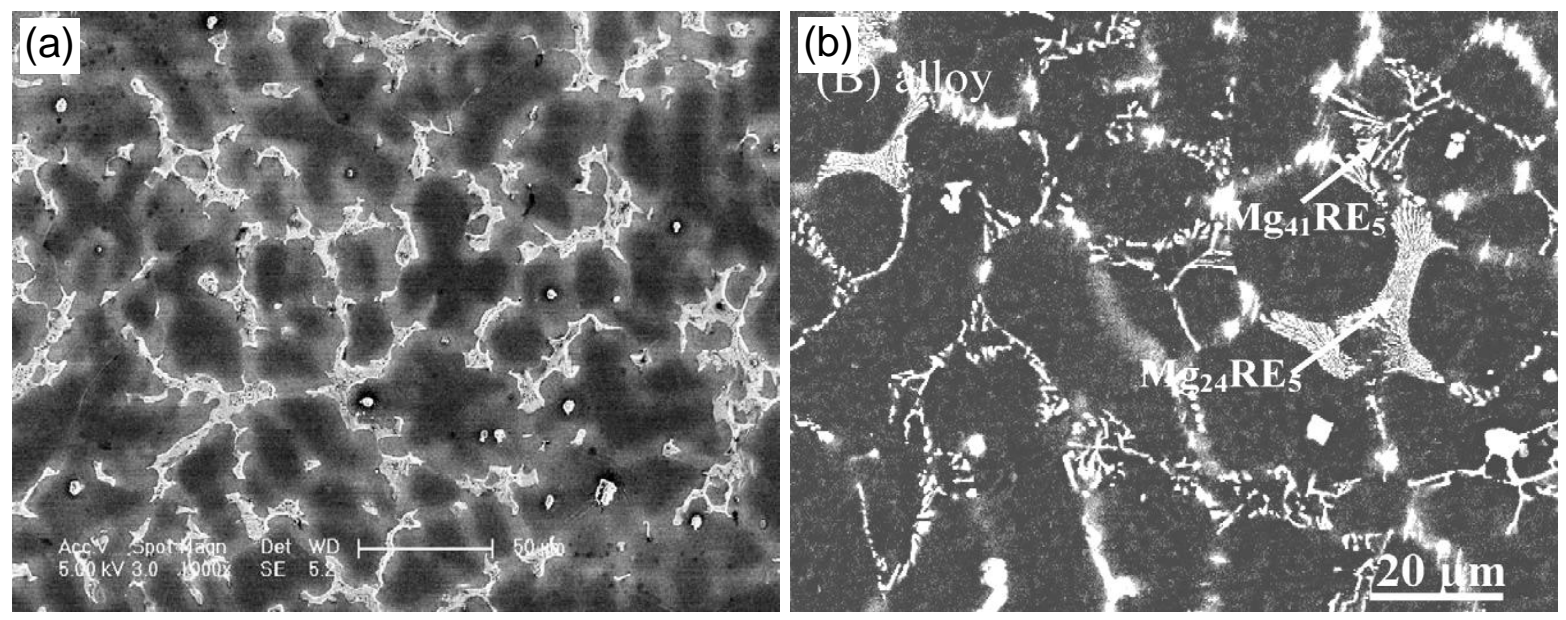

Figure 2.1: (a) Typical SEM micrographs of an as-cast Mg-15Gd-5Y-0.5Zr alloy [33] and (b) as-cast Mg-8Gd-0.6Zr-xNd-yY alloys, $(x+y=3$, mass \%) [26]. 

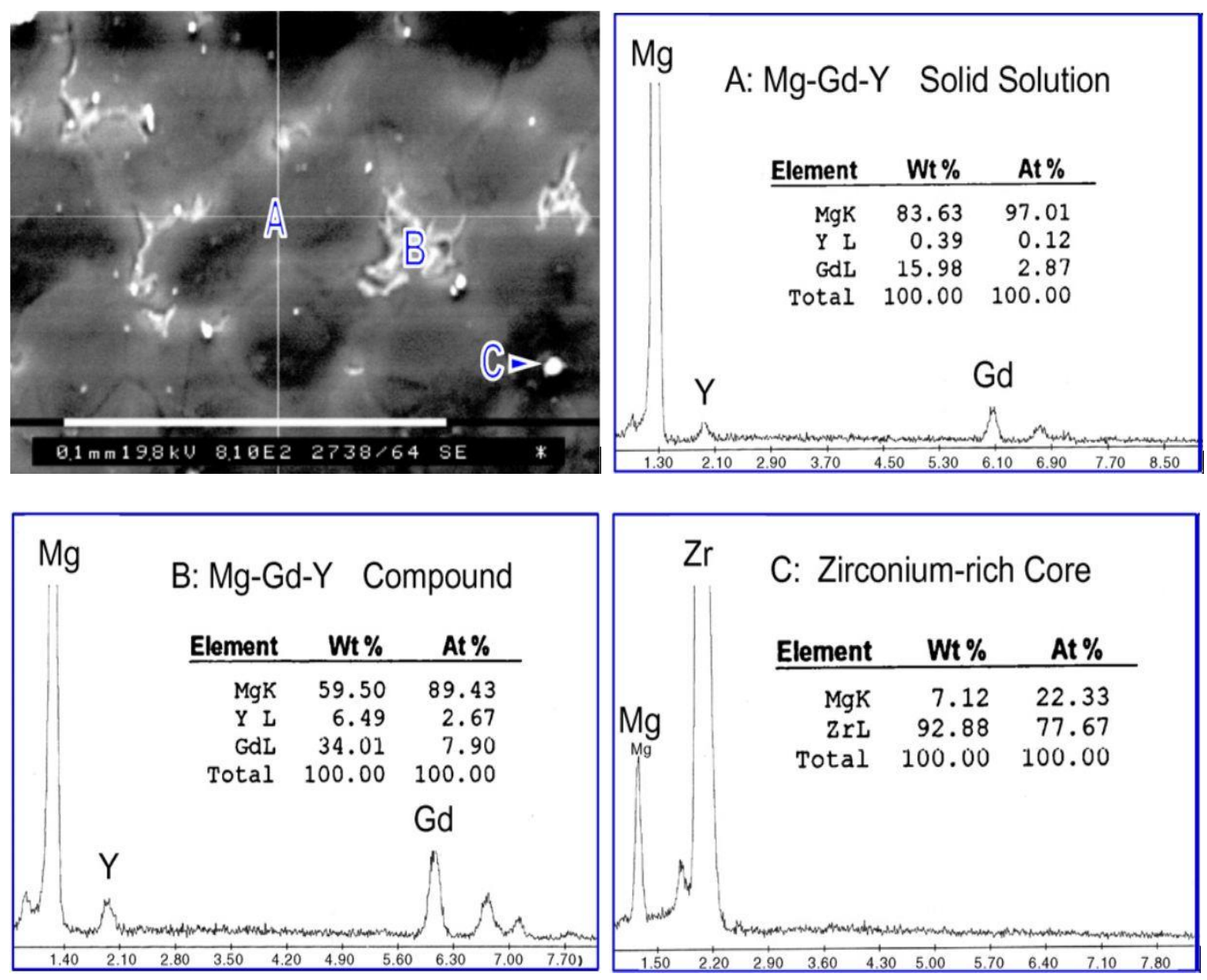

Figure 2.2: SEM image of the as-cast sample and the corresponding EDS spectra of the points indicated in the image [24].

\subsubsection{Extruded RE-Mg alloys}

Compared with cast alloys, wrought $\mathrm{Mg}$ alloys exhibit superior mechanical properties because during extrusion, rolling or forging processes hot deformation occurred. These parts 
are free of porosities or cavities and meanwhile the mechanical properties were enhanced through a thermomechanical treatment resulting in a close to perfect microstructure $[51,52$, 57-62]. For instance, the microstructures of the alloys which were extruded showed a greatly refined grain structure due to dynamic recrystallization (DRX) in the hot extrusion process, when compared with the alloys in the as-cast condition [34]. Some characteristic optical micrographs of hot-extruded Mg-8Gd-xZn-0.4Zr (x=0, 1, and 3 wt. \%) alloys are displayed in Figure 2.3 [34]. The Gd-containing intermetallic compounds in Mg-8Gd-xZn-0.4Zr alloys were fragmented through the hot extrusion process, and were dispersed along the hot extrusion direction. The average recrystallized grain sizes of $\mathrm{Mg}-8 \mathrm{Gd}-0.4 \mathrm{Zr}, \mathrm{Mg}-8 \mathrm{Gd}-1 \mathrm{Zn}-$ $0.4 \mathrm{Zr}$, and $\mathrm{Mg}-8 \mathrm{Gd}-3 \mathrm{Zn}-0.4 \mathrm{Zr}$ alloys were about 8,6 , and $3 \mu \mathrm{m}$, respectively. Recrystallized grains were formed on the original grain boundaries during the hot extrusion process, which suggests that the DRX process was stimulated from the accumulation of dislocations at grain boundaries [34], and also indicates the function of RE elements addition [56]. A similar type of extruded magnesium alloy microstructures was also reported by Liu et al. [43]. 


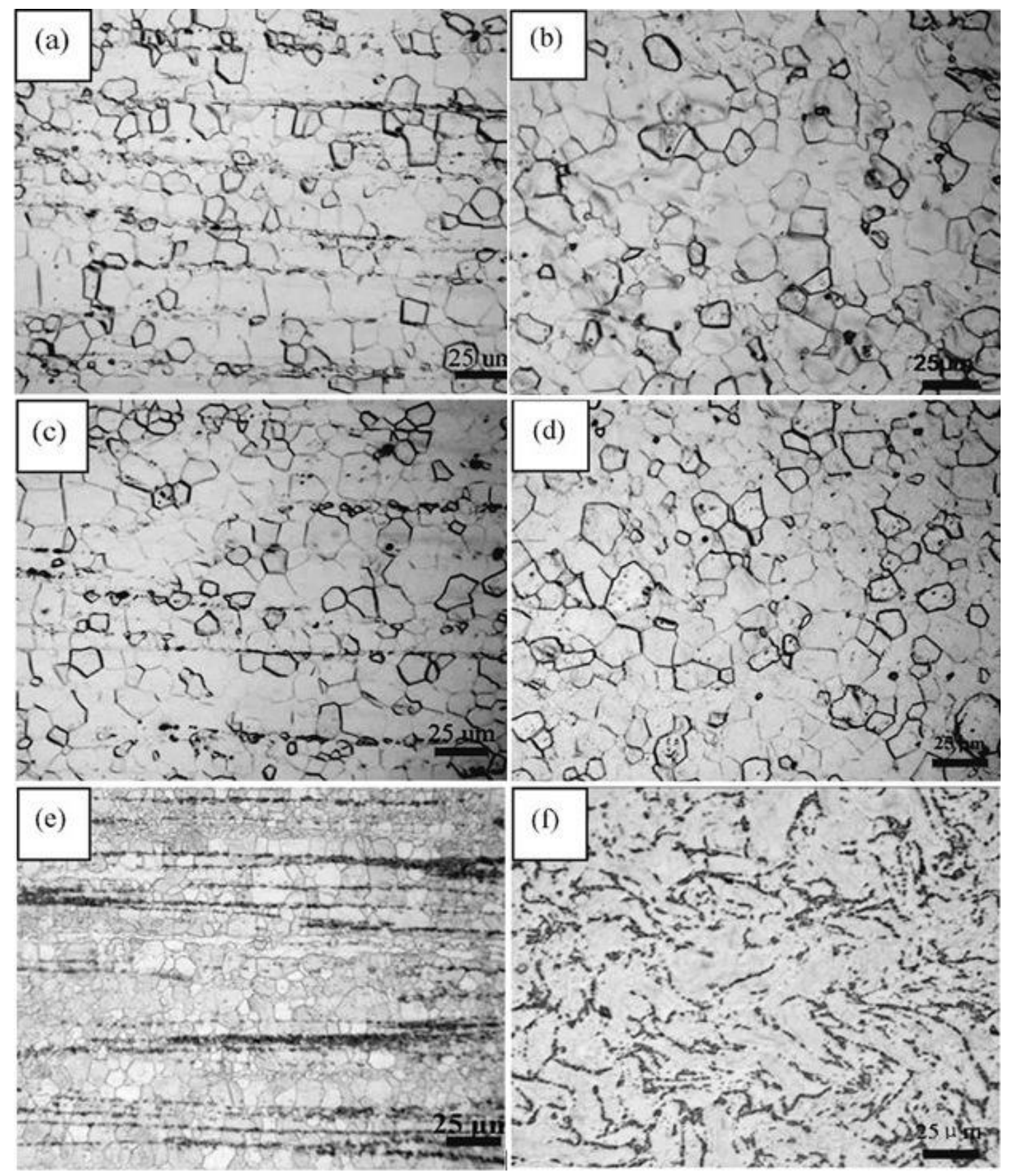

Figure 2.3: Optical images of the as-extruded specimens: (a) and (b) Mg-8Gd-0.4Zr alloy,

(c) and (d) Mg-8Gd-1Zn-0.4Zr alloy, and (e) and (f) Mg-8Gd-3Zn-0.4Zr alloy [34]. 


\subsection{Crystallographic textures of RE-Mg alloys}

Wrought Mg alloys normally exhibit strong basal-type textures which means basal planes of most grains are aligned parallel to the rolling or extrusion direction [14, 63-65]. It has lately been reported that with RE elements alloyed with magnesium alloys, the resulting alloy can develop weaker textures which were different than typical textures that were observed in conventional $\mathrm{Mg}$ alloy sheets during deformation processing [66] or subsequent annealing $[67,68]$. This incited great interest in RE elements, which are considered as effective texture modifiers for Mg alloys, such as Gd [24,31,64,69-82], Y [24,31,64,70,72,77-80,82,83], Ce $[64,74,82-84]$, La [71,74,82,83], and $\mathrm{Nd}[64,83,85-87]$. Even under low alloying concentrations an alteration occurred in the orientation peak of the extrusion textures in the RE-Mg alloys. It shifted from $<10 \overline{1} 0>$ to $<11 \overline{2} 1>,<11 \overline{2} 2>$ or $<20 \overline{2} 1>$ that were parallel to the extruded direction, and they have been expressed as "RE texture components" $[64,67,70,73,74,82,84,88]$. For instance, an addition of a small amount of Gd $(0.22$ wt.\%) [81] and Ce (0.5 wt.\%) [89] to $\mathrm{Mg}$ alloys could considerably reduce the texture of the extruded alloy and the addition of $\mathrm{Y}$ had a similar effect on the texture alteration.[90,91] As seen from Figure 2.4, the texture sharpness decreased in a Mg-Gd binary alloy when the Gd content increased [81]. The major change in texture happened within the first $\sim 1$ wt. \% concentration of $\mathrm{Gd}$, and the change of texture with $\mathrm{Gd}$ concentration was less prominent after $1 \mathrm{wt} \%$. In addition, when the sample was tested in proper orientations these "RE texture components" were well oriented for basal slip, which gives rise to a considerable increase of ductility and a decrease in the tension-compression asymmetry which were observed in conventional wrought $\mathrm{Mg}$ alloys [51-54,64]. Bohlen et al. [83] stated that the basal pole intensity aligned with the sheet normal direction and the overall texture intensity, when 
compared with conventional Mg alloys, was lower for RE-containing alloys, and the typical character of the sheet texture was also changed. It was reported that for many RE elementscontaining-Mg alloys a greater tilt of basal poles towards the sheet transverse direction was exhibited, rather than in the rolling direction (as shown in Figure 2.5). More activation of basal slip would be promoted during loading in the transverse direction than in the rolling direction [92].

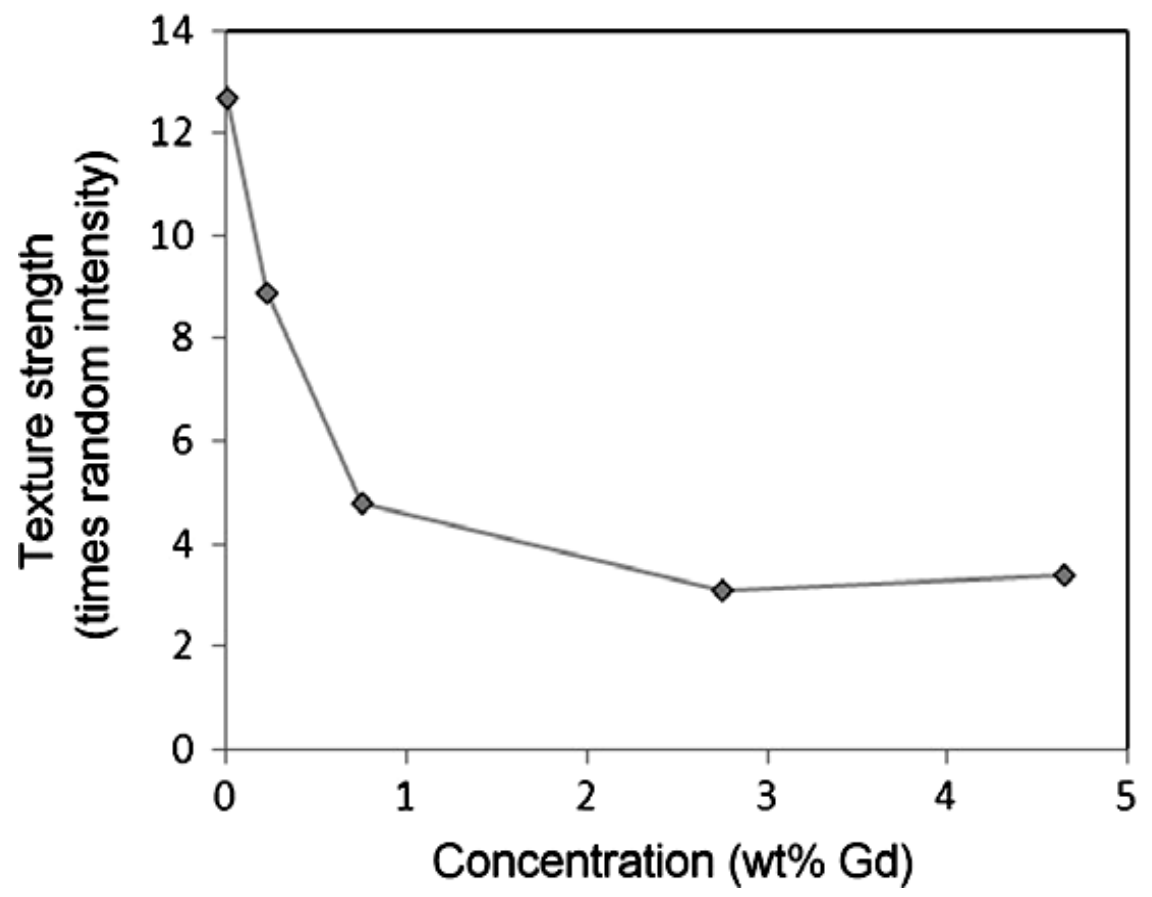

Figure 2.4: Effect of $G d$ content on the recrystallization texture intensity in an Mg-Gd binary alloy [81]. 
(a)
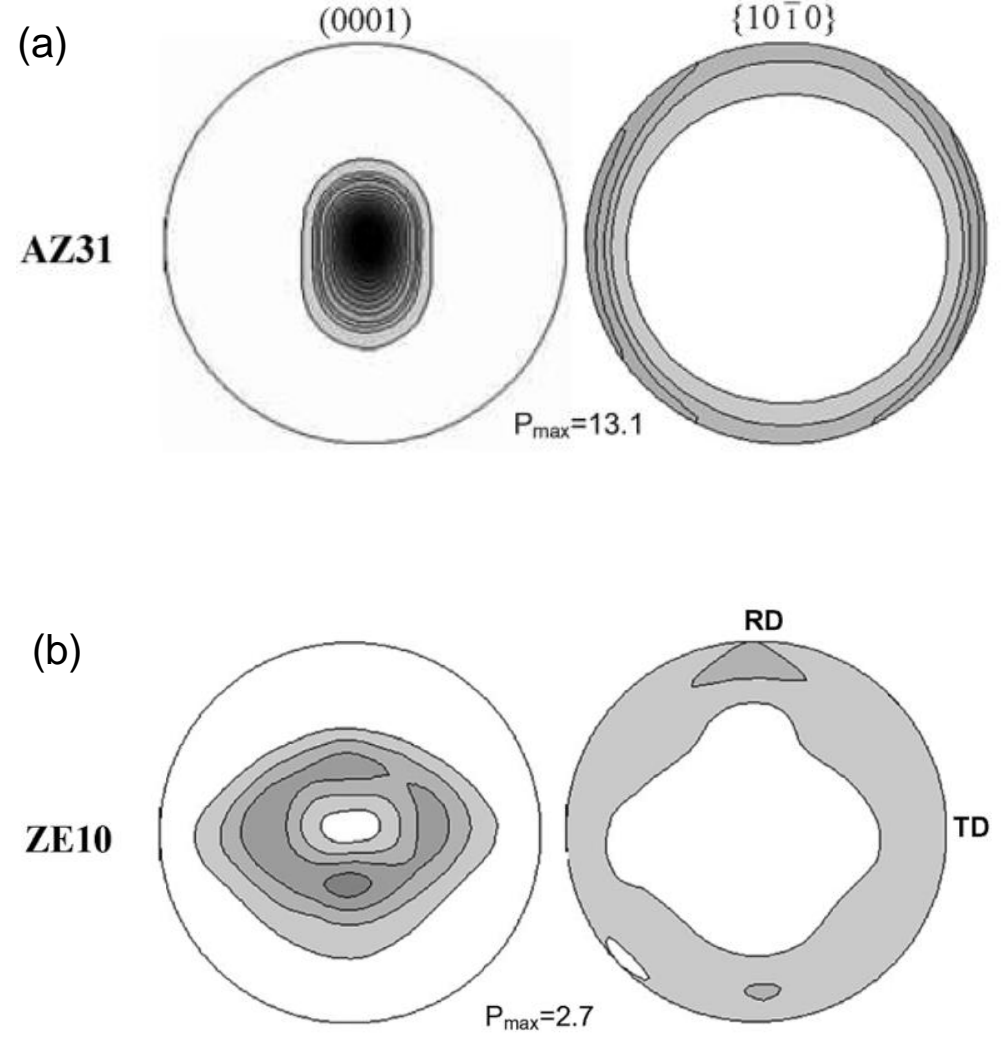

(c)

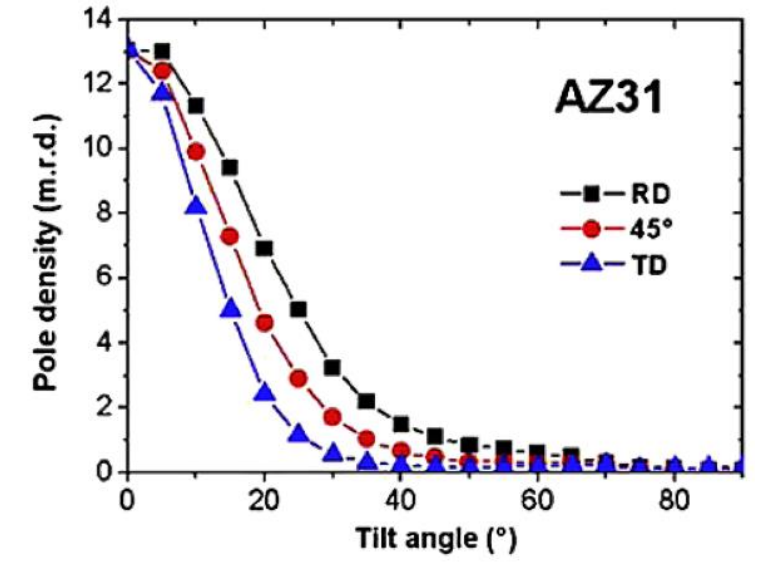

(d)

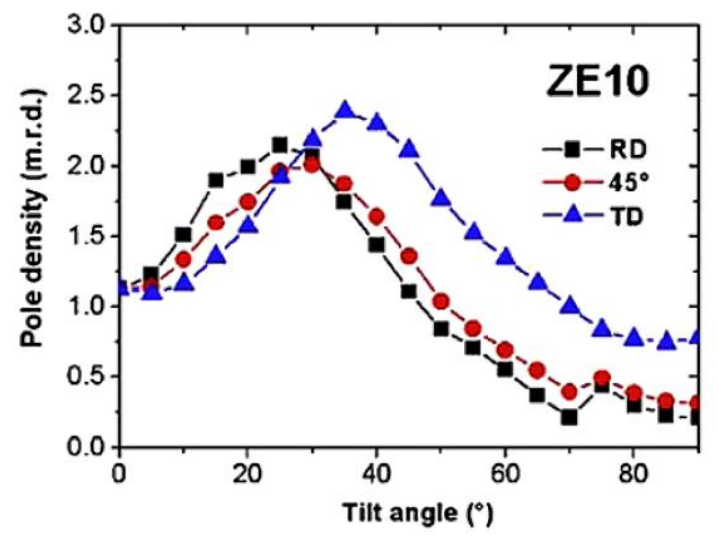

Figure 2.5: (0001) and \{10-10\}pole figures of the as-received (a) AZ31 and (b) ZE10 sheets, where density profiles of the basal pole along different sheet directions are shown for $(c)$ $A Z 31$ and $(d) Z E 10$ sheets (RD: rolling direction, TD: transverse direction, $45^{\circ}: 45^{\circ}$ from the RD) [92]. 


\subsection{Tensile properties of RE-Mg alloys}

Up to now, numerous studies have investigated the mechanical properties of different RE-Mg alloys [26, 34, 36-38, 66, 79, 84, 93]. Mg alloys display high mechanical property anisotropy owing to the HCP structure, which is one of the chief obstacles to the broader application of wrought Mg alloys. However, it was reported that the addition of RE elements could overcome the problems of anisotropy by means of the texture weakening, which could make possible broader applications for RE-Mg alloys [64,71,84]. Different investigations showed experimental results on RE-Mg alloys that the dependence of tensile/compressive properties, for example yield strength (YS), ultimate tensile strength (UTS), elongation (EL) and strain hardening exponent (n), on microstructure and crystallographic textures $[93,94]$. For instance, the uniaxial tensile and compressive stress-strain curves of a RE-Mg alloy (GW123k) are presented in Figure 2.6 [93]. Compared with the conventional extruded AZ31 $\mathrm{Mg}$ alloy, the GW123k alloy shows a deficiency in strong texture which results in a reduced tension-compression yield asymmetry. Moreover, with the grain refinement through the extrusion process, the fine precipitated particles dispersion and the high content of solute rare-earth elements might bring about sufficient barriers for the slip of dislocations, therefore improving both the compressive and tensile yield strengths. Similar results have been reported elsewhere in [66, 84, and 94]. 

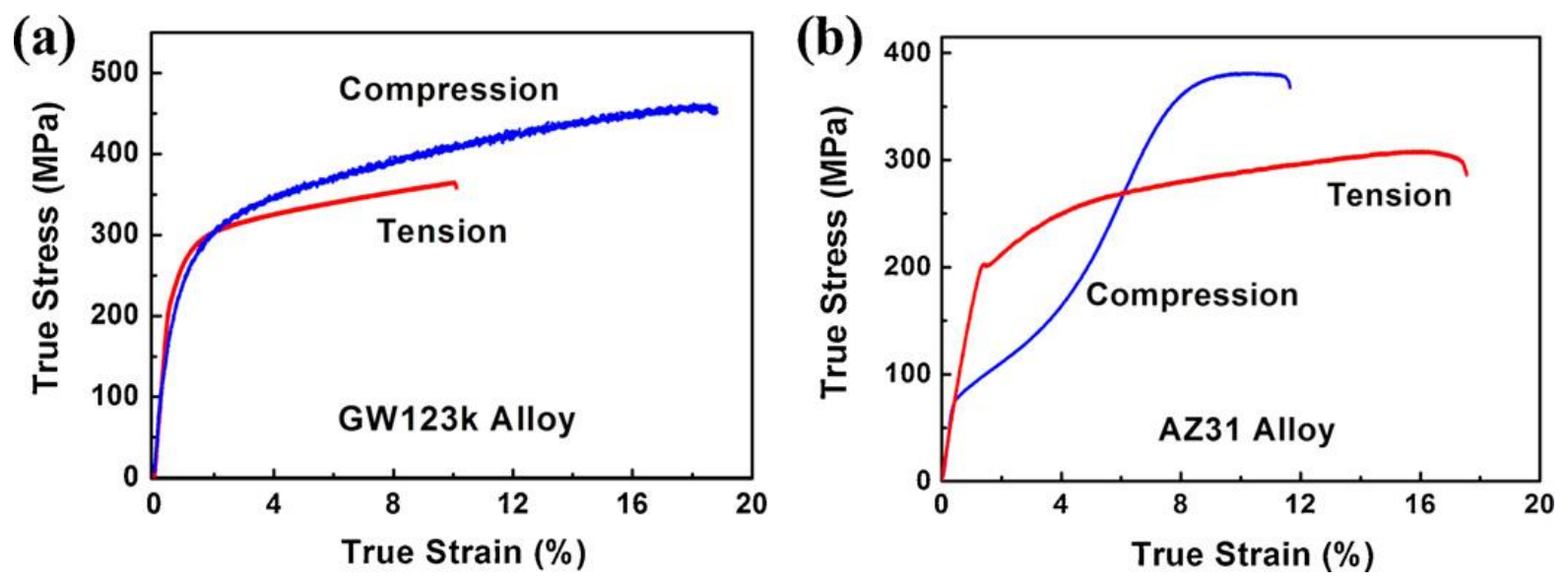

Figure 2.6: Uniaxial tensile and compressive stress-strain curves for (a) GW123k alloy and

$$
\text { (b) AZ31 alloy [93]. }
$$

\subsection{Fatigue behavior of RE-Mg alloys}

During the past decade or so, many studies have been conducted on the cyclic deformation behavior of Mg alloys that included cast alloys, i.e., AZ91 [95-98], AM60 [99-102], AM50 [103-105], and wrought alloys i.e., AZ31 [51-53, 106-110], AM30 [54, 55], ZK60 [111,112]. Some results on this part of research could be seen in a recent review paper [14]. The fatigue properties of RE-containing Mg alloys have also been studied in recent times [93, 72, 42, 4447, 113, 114-121], which will be discussed in the next few paragraphs. 


\subsubsection{Stress-controlled fatigue behavior}

The stress-controlled fatigue results are mainly presented by way of stress-life $(S-N)$ curves, which is a plot of stress $(S)$ against the number of cycles to failure $(N)$ in a log scale. The $S-N$ curve method represents the most thoroughly examined fatigue characteristics of $\mathrm{Mg}$ alloys as well as other materials $[122,133]$. Yang et al. $[42,114]$ examined the stress-controlled fatigue properties of an AZ91D alloy with different concentrations of Cerium, which is a rare earth element, by the use of a high-frequency fatigue testing machine. Figure 2.7 demonstrates the typical $S-N$ curves for an AZ91D alloy with varying concentrations of Ce addition ( 1 wt. $\%$ and 2 wt. $\%$ ) [42,114]. It can be seen that there was an increase of $20.3 \%$ and $9.1 \%$ in the fatigue strength of AZ91D alloy with the addition of 1 wt. $\%$ and 2 wt. $\%$ Ce, respectively. Similar results of fatigue strength improvements were also reported in the diecast AZ91D Mg alloy in the high cycle fatigue (HCF) properties, after the addition of different amounts $(1.5 \%, 1.0 \%$, and $0.5 \%)$ of $\mathrm{Nd}$ by Yang and $\mathrm{Li}$ [46], in the die-cast AZ91D alloys by the addition of $1 \%$ mischmetal $(50 \% \mathrm{Ce}, 30 \% \mathrm{La}, 12 \% \mathrm{Nd}$, and $6 \% \mathrm{Pr}$ ) by $\mathrm{Xu}$ et al. [44], in the die-cast AZ91D alloy with or without 1wt.\% Ce by Yang and Liu [45], and in the gravity cast AZ91 alloy by the addition of $1 \%$ mischmetal $(67 \% \mathrm{Ce}, 23 \% \mathrm{La}, 7 \% \mathrm{Pr}$ and $2 \%$ Nd) by Mokhtarishirazabad et al. [47]. The factors influencing the HCF properties of die-cast AZ91D alloy include grain size, inclusions distribution and size, porosity as well as $\mathrm{Mg}_{17} \mathrm{Al}_{12}$ intermetallic particles, as stated in refs. [42, 45, 47, 114]. 


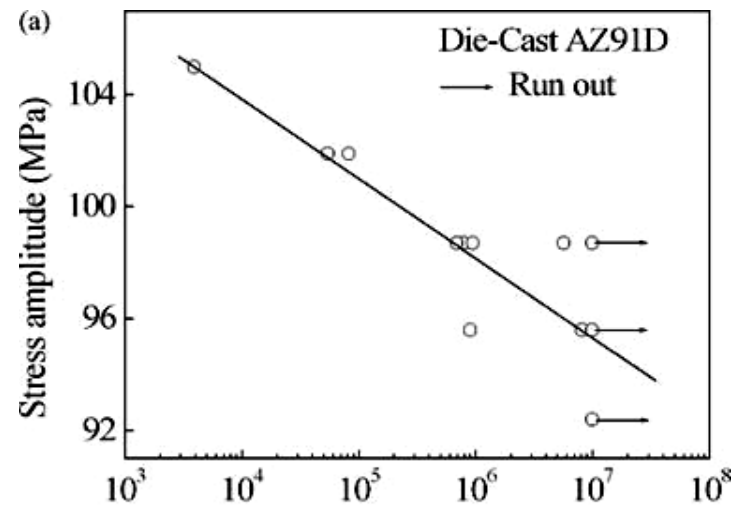

Number of cycles to failure, $N$,

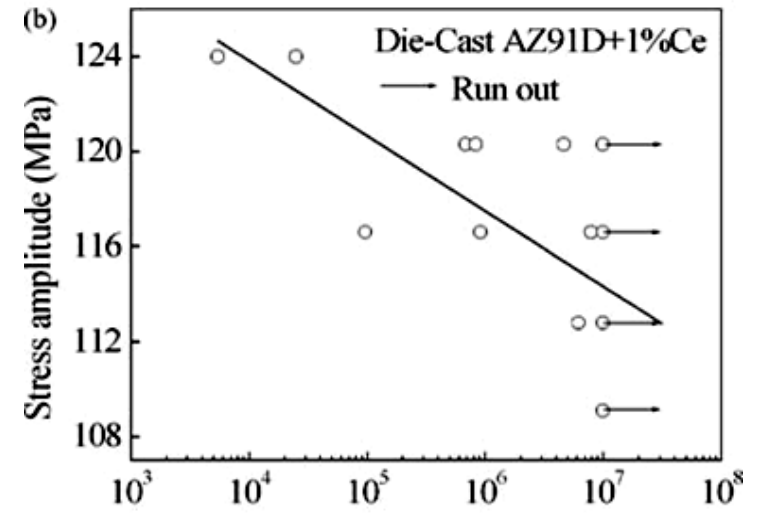

Number of cycles to failure, $N$,

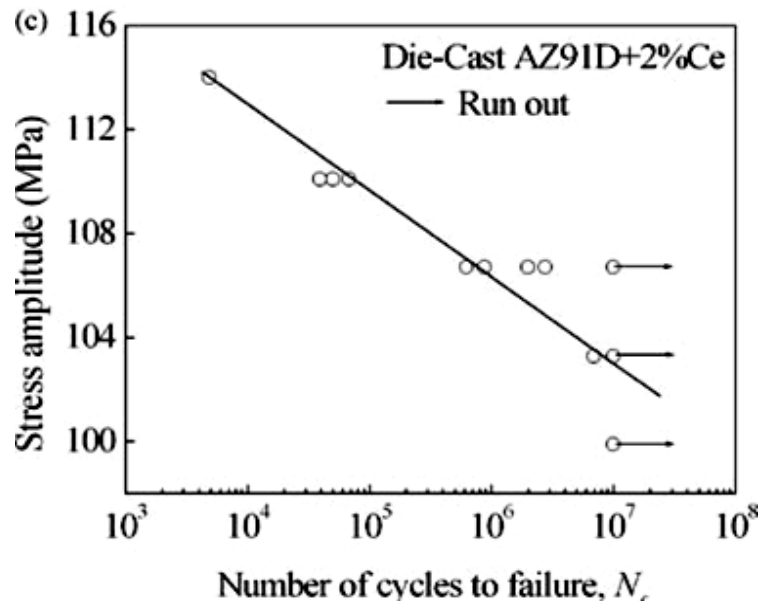

Figure 2.7: S-N curves for an AZ91D alloy with different amounts of Ce addition. (a) 0\% Ce, (b) $1 \% \mathrm{Ce}$, and (c) $2 \% \mathrm{Ce}[42,114]$.

Remarkable grain size refinement can be achieved through the addition of RE elements (e.g., Ce and Nd). This also brought about upgraded HCF properties of the die-cast AZ91D alloy, as the sum of grain boundary area rises with the reduction of grain size, and therefore increasing the resistance to dislocation movement for the duration of plastic deformation. In addition, Ce addition was seen to lead to reducing the size and amount of porosity and inclusions (evenly distributed), and the fatigue strength of the Mg alloy was improved [45]. 
Some other investigations were also related to the HCF behavior of Gd-containing and Ycontaining Mg alloys $[93,113,116,117]$. The HCF resistance of conventional extruded AZ31 alloy was compared with an extruded Mg-12Gd-3Y-0.5Zr (GW123K) alloy by Yang et al. [93]. The GW123K alloy seems to show a continuous decreasing $S-N$ curve, as can be seen from Figure 2.8 [93] and it exhibited a better fatigue strength than the AZ31 alloy [124]. The elimination of the tension-compression yield asymmetry in the conventional wrought Mg alloys can be achieved with addition of Gd and Y. Similar phenomena of fatigue properties improvement were also described in an as-extruded and aged Mg-10Gd-3Y alloy (GW103) by Song et al. [117].

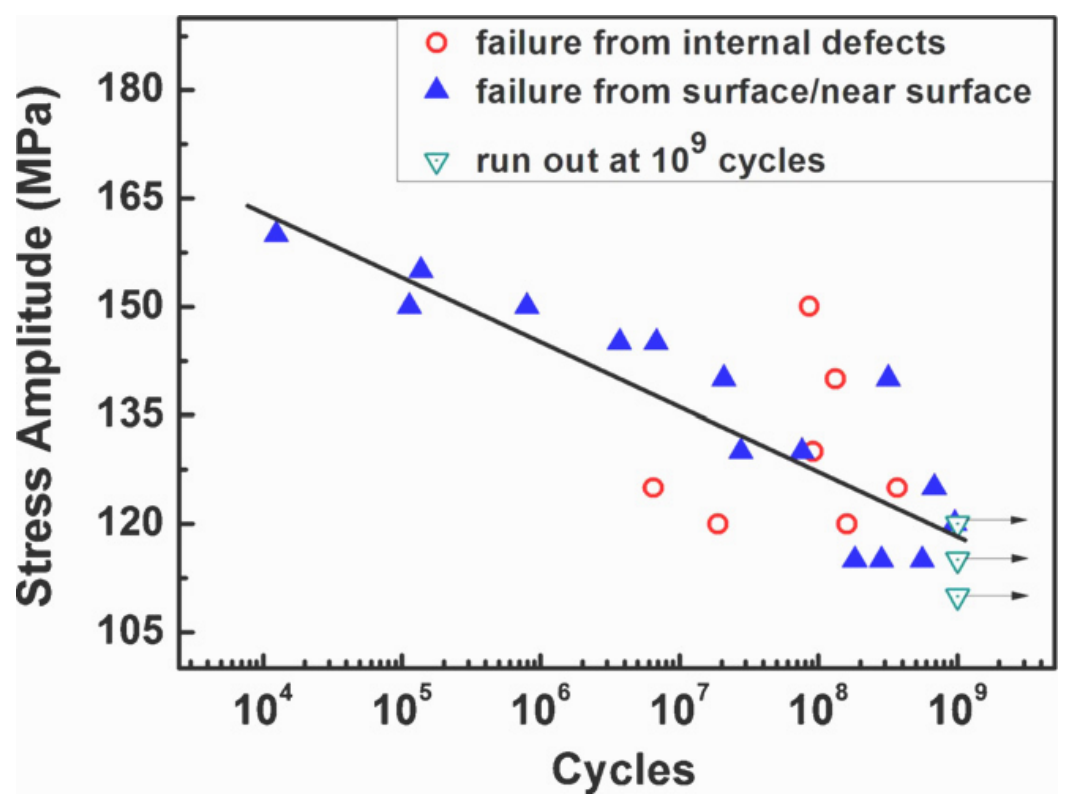

Figure 2.8: S-N curve of an extruded Mg-12Gd-3Y-0.5Zr (GW123K) alloy [93]. 


\subsubsection{Strain-controlled fatigue behavior}

The condition of strain-controlled low cycle fatigue (LCF) are often seen where the repeated stresses are of thermal origin and at the notch root $[122,125]$. LCF features a high stress level and fairly low numbers of cycles. The related low cycle fatigue of strain-life data are essential for structural component design, particularly in the automotive industry. There are numerous studies on the fully reversed $\left(R_{\varepsilon}=-1\right)$ strain-controlled fatigue behavior of RE-free Mg alloys, e.g., AZ31 [51-53,107,108], ZK60 [111], AM50 [58], AM60B [126,127], and AZ91 [128,129], as well as some other works which have been finished lately on the straincontrolled LCF behavior of RE-Mg alloys [72,119-121]. The majority of these works involved the strain-controlled low cycle fatigue behavior of Mg-Gd-Y alloys. Wang et al. [72] studied the fully reversed strain-controlled tension-compression tests of an extruded $\mathrm{Mg}$ 8.0Gd-3.0Y-0.5Zr (GW83) alloy along the extrusion direction, with the strain amplitudes varying from $0.275 \%$ to $5.0 \%$. Their results showed that the GW83 alloy had some closesymmetric stress-strain hysteresis loops as well as marginal cyclic hardening having nearly zero mean stress. There were some other studies such as the LCF behavior of an extruded Mg-12Gd-3Y-0.5Zr by Yin and Li [120], an extruded Mg-10Gd-2Y-0.5Zr by Zhu et al. [121], and an as-cast Mg-10Gd-2.0Y-0.46Zr alloy by $\mathrm{Wu}$ et al. [119]. Fu et al. [118] also described the work of the strain-controlled LCF behavior of AZ91D+0.3\%Ce alloy with varying strain amplitudes and tested at room temperature. 


\subsubsection{Stress-strain hysteresis loops}

In order to better understand the cyclic deformation behavior of the Mg alloys under LCF conditions, the analysis of the stress-strain hysteresis loops is needed. Figure 2.9 illustrates the stress-strain hysteresis loops of an extruded Mg-8.0Gd-3.0Y-0.5Zr (GW83) alloy. Results were obtained from fully reversed strain-controlled fatigue experiments that were under different total strain amplitudes [72]. As for the conventional extruded $\mathrm{Mg}$ alloy, the compression division of the stress-strain hysteresis loop shows a concave-up shape, but the lower division of GW83 stress-strain hysteresis loop exhibits a sigmoidal shape instead which is similar to the upper part of curve. While total strain amplitude decreased, the hysteresis loops become contracted and shrank [72]. Figure 2.10 demonstrates the closesymmetric stress-strain hysteresis loops of an extruded GW123K alloy which were fatigued at varying total strain amplitudes from $0.2 \%$ to $1.0 \%$ [120]. Similar results of near-symmetric hysteresis loops were also reported for AZ91D+0.3\%Ce alloy by $\mathrm{Fu}$ et al. [118] and GW102K alloys by Zhu et al. [121]. 

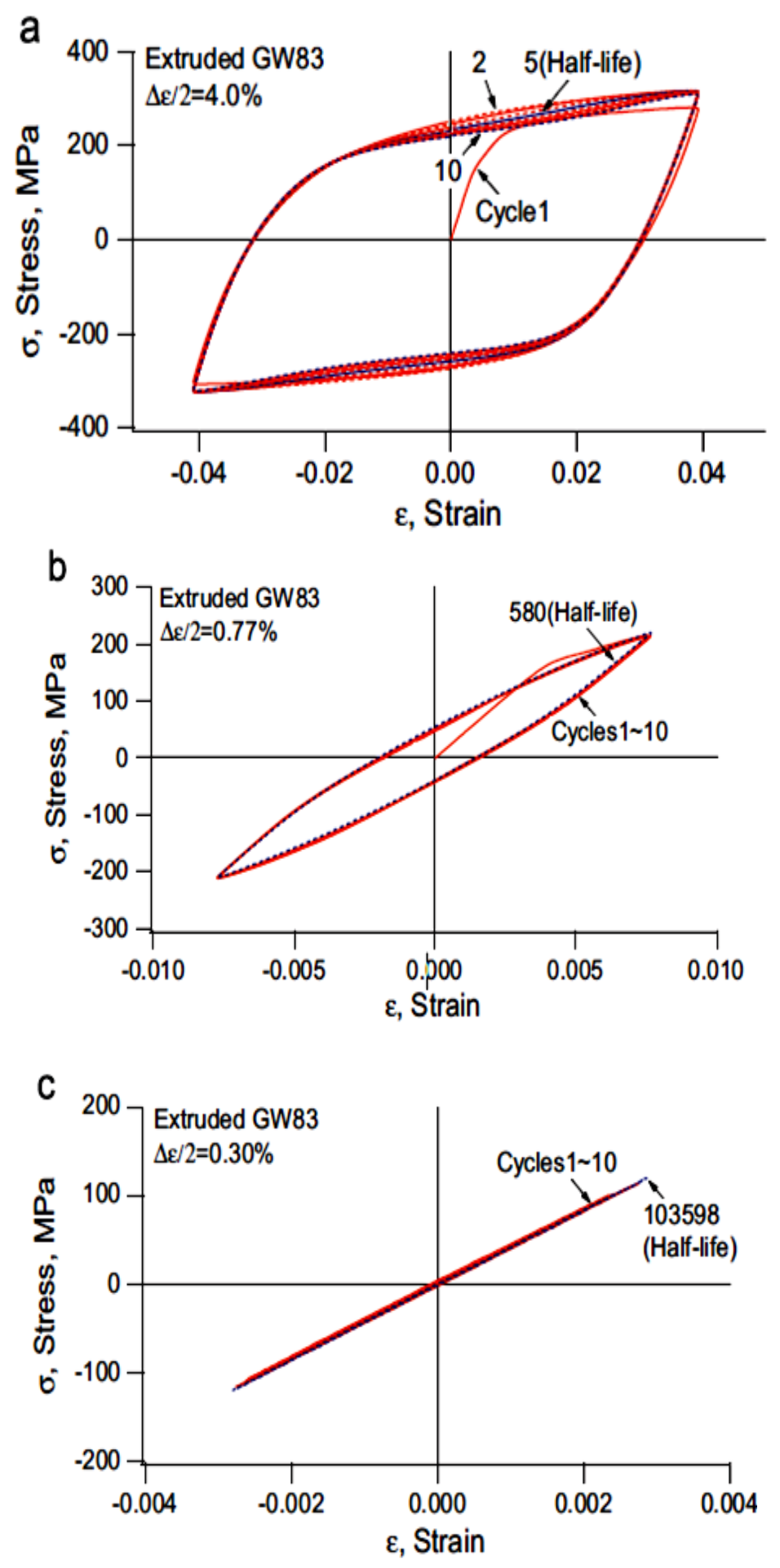

Figure 2.9: Stress-strain hysteresis loops of an extruded GW83 alloy fatigued at (a) $\Delta \varepsilon / 2=4.0 \%$, (b) $\Delta \varepsilon / 2=0.77 \%$, and (c) $\Delta \varepsilon / 2=0.30 \%$ [72]. 


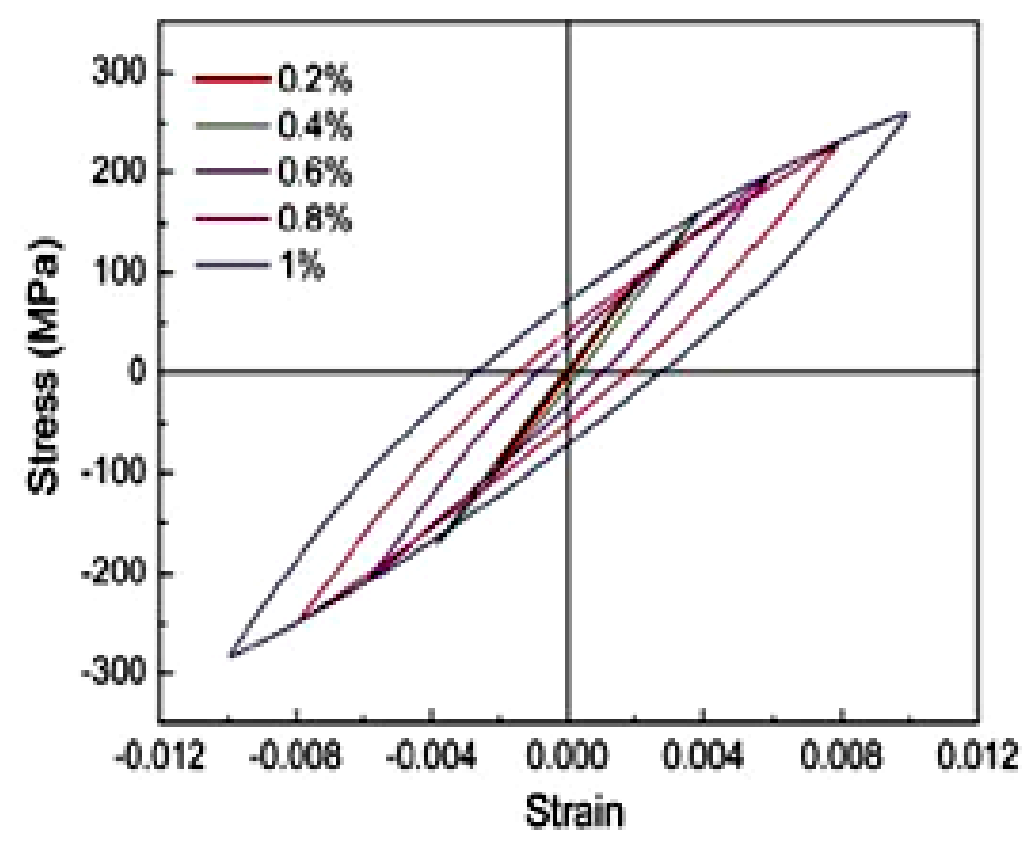

Figure 2.10: Hysteresis loops of a GW123K alloy fatigued at varying total strain amplitudes [120].

\subsubsection{Cyclic deformation response}

In terms of the total strain-controlled fatigue tests, the cyclic stress response of a material during cyclic deformation is a representation of the change of the stress amplitude with uninterrupted cycles. It can also demonstrate the track that the tested sample reaches its ultimate stress level. Figure 2.11 displays the stress amplitude evolution in regard to the number of cycles under different applied strain amplitude levels in an extruded Mg-8.0Gd3.0Y-0.5Zr (GW83) alloy [72]. It can be seen that the stress amplitude increased and the fatigue life of the material decreased as the total strain amplitude increased. It also shows that 
approximately stable or slightly cyclic hardening behavior occurred once the strain amplitude is below $1.0 \%$, and this might be credited to the dislocation transformation effects due to the increased slip of dislocations [130]. Alternatively, the alloy shows the hardening effect of the first cyclic and then cyclic softening until failure as soon as the strain amplitude is greater than $1.0 \%$. Other investigations also reported that the cyclic stress response for the REcontaining Mg alloys is moderately stable, and this is particularly true for an extruded GW123K alloy at a low strain amplitude of $0.2 \%$ [120].

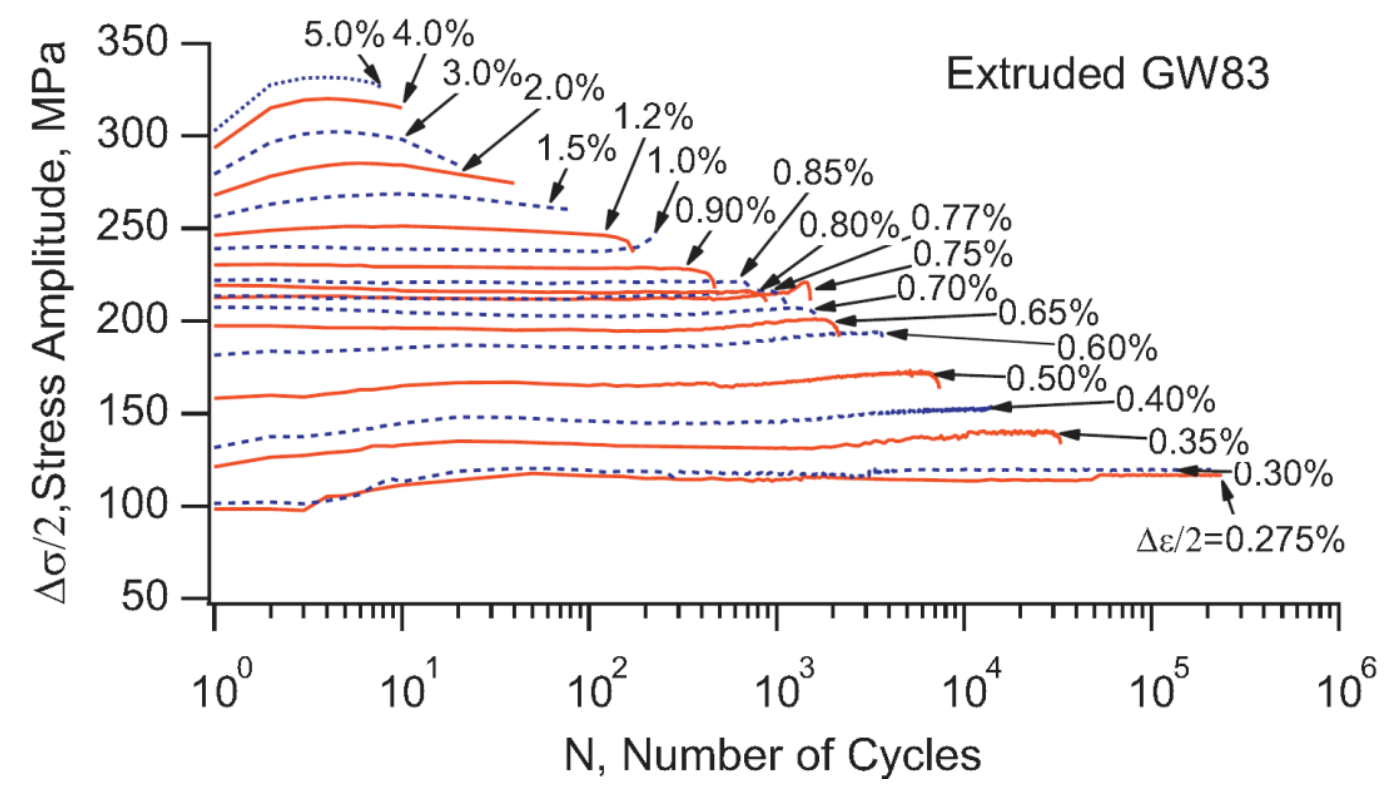

Figure 2.11: Variation of stress amplitude with increasing number of cycles at varying strain amplitudes from $0.275 \%$ to $5.0 \%$ for an extruded GW83 alloys [72]. 


\subsubsection{Fatigue life and parameters}

The RE-Mg alloys showed a superior fatigue life when they were compared with RE-free wrought Mg alloys [52, 54, 120, 121, 130-133]. Zhu et al. [121] stated that at the same total strain amplitude the Mg-10Gd-2Y-0.5Zr (GW102K) alloy presented a greater fatigue resistance than the AZ31 alloy, which can be seen in Figure 2.12. Similarly, Yin and Li [120] made the comparison of GW123K alloy with some RE-free wrought Mg alloys, e.g., AM60 [134], AZ31 [52], and Al-Mg-Sc alloy [135] regarding fatigue life, and noticed that the GW123K alloy showed decent low-cycle fatigue properties. The relation between the fatigue life and total strain amplitude can be related by the Coffin-Manson and Basquin equations. It was also reported in Fu et al. [118] that the fatigue life of an AZ91D+Ce alloy could be described by the Manson-Coffin equations.

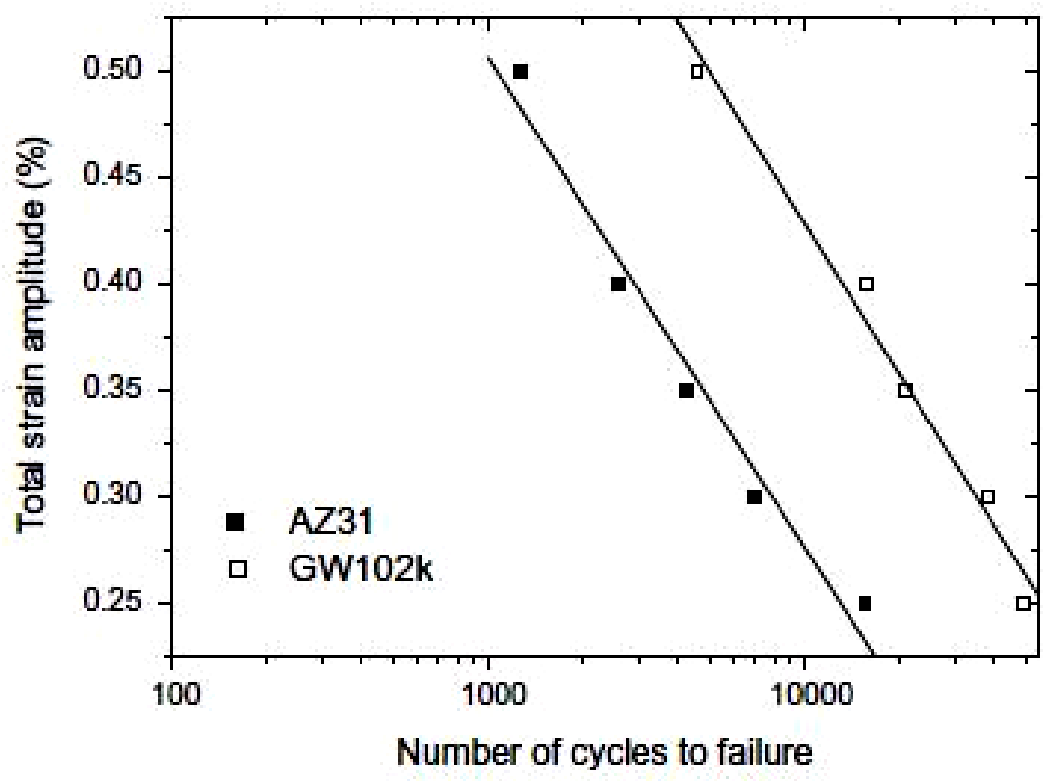

Figure 2.12: Total strain amplitude-fatigue life curves for GW102K and AZ31 alloys [121]. 


\subsection{Summary}

There is general agreement that the addition of RE elements into magnesium alloys can weaken the mechanical anisotropy and relieve the unfavorable and undesirable tensioncompression yield asymmetry of such alloys. The microstructures, crystallographic textures, as well as mechanical properties such as tensile and compressive strength and fatigue life with respect to the RE elements addition have been earlier investigated and reported. RE-Mg alloys are fairly new, and there is very limited data on the cyclic deformation behavior (especially strain-controlled low cycle fatigue) for such $\mathrm{Mg}$ alloys that has been reported publicly. Hence, our understanding is still limited regarding the cyclic deformation mechanisms of such alloys. Substantial efforts of research work are needed to understand to the cyclic deformation behavior, stress response, as well as improved life prediction approaches for the RE-Mg alloys.

Besides, none of work on the strain-controlled low cycle fatigue behavior of this rolled magnesium alloy ME20 has been reported so far. Therefore, it is necessary to evaluate the low cycle fatigue behavior of this material to determine the fatigue life under varying strain amplitudes, obtain cyclic parameters such as cyclic strain hardening exponent and etc., verify the fatigue life behavior based on the energy density model, and compare the fatigue properties of samples with different sample orientation as texture leads to anisotropy in their mechanical properties. 


\section{EXPERIMENTAL PROCEDURES}

\subsection{Test materials}

The material studied in this thesis is a rare-earth element $(\mathrm{Ce})$-containing magnesium alloy that was processed by hot rolling and H112 tempered. The rolled plate was received from the Institute of Metal Research Chinese Academy of Sciences. The detailed chemical composition of this material is shown in Table 3.1 .

Table 3.1: Chemical composition (in wt. \%) of ME20 alloy.

\begin{tabular}{lcccccccccc}
\hline Element & $\mathrm{Al}$ & $\mathrm{Zn}$ & $\mathrm{Mn}$ & $\mathrm{Ce}$ & $\mathrm{Si}$ & $\mathrm{Fe}$ & $\mathrm{Cu}$ & $\mathrm{Ni}$ & $\mathrm{Be}$ & $\mathrm{Mg}$ \\
\hline $\begin{array}{l}\text { Content } \\
\text { (wt. \%) }\end{array}$ & $<0.2$ & $<0.3$ & $1.69 \sim 1.81$ & $0.29 \sim 0.33$ & $<0.10$ & $<0.05$ & $<0.05$ & $<0.007$ & $<0.01$ & Balance \\
\hline
\end{tabular}

\subsection{Sample preparation and testing}

The preparation of samples for metallography and mechanical testing used the following procedures.

\subsubsection{Metallography}

All metallographic samples (approx. $5 \mathrm{~mm} \times 5 \mathrm{~mm}$ in the cross section) for the microstructural characterization were cut from ME20 alloy plate (14 mm in thickness). The samples were cold mounted using LECO 7007 resin powder and liquid (mixing ratio: 2 parts of resin added to 1 part of catalyst). Hot mounting was avoided to prevent any possible 
microstructural change due to the effect of temperature during sample preparation. The mounted samples were manually ground with $\mathrm{SiC}$ sand papers with a grit number of 320, 600, and 1200, respectively. Water was used as lubricant in each grinding step. Polishing was carried out with $6 \mu \mathrm{m}, 3 \mu \mathrm{m}$, and $1 \mu \mathrm{m}$ diamond paste using diamond extender (a mixture of rust inhibiting solution with distilled water - $10 \%$ solution by volume) as lubricant. Cleaning of the mount after polishing involved dipping in and spraying ethanol, ultrasonic cleaning in ethanol, followed by drying with compressed air. After the final polishing with $0.05 \mu \mathrm{m}$ alumina paste (master prep), the polished samples were etched with Acetic-Picral (10 ml acetic acid, $4.2 \mathrm{~g}$ picric acid, $10 \mathrm{ml}$ distilled water, and $70 \mathrm{ml}$ ethanol) for the ME20 alloy to reveal the macroscopic structure (grain boundaries).

\subsubsection{Quantitative image analysis}

Microstructural examinations were performed using an optical microscope (OM) equipped with Clemex quantitative image analysis software, and a scanning electron microscope (SEM) JSM-6380LV equipped with an Oxford energy dispersive X-ray spectroscopy (EDS) system. The average grain size was measured via the linear intercept method. Overall, at least 15 locations for each sample were examined and the average values will be reported in this report. The Clemex image analysis system was comprised of a Clemex CMT software adaptable to ASTM standards, a Nikon optical microscope (10× eye piece, five different object lenses with magnifications of $5 \times, 10 \times, 20 \times, 40 \times$, and $100 \times$ ), a high-resolution digital camera, and a high performance computer to carry out the detailed analysis. 


\subsubsection{Texture measurements by $X$-ray diffraction}

Texture measurements were performed on the as-received samples of ME20 alloy. The polishing procedure was the same as the one employed for microstructural observations and image analysis but without etching. The texture was determined by measuring incomplete pole figures between $\Psi=0$ to $75^{\circ}$ in the back reflection mode using a PANalytical X'Pert PRO X-ray diffractometer with $\mathrm{Cu} K_{\alpha}$ radiation at $45 \mathrm{kV}$ and $40 \mathrm{~mA}$. The texture measurements were designed to determine the intensity variation of a certain diffraction peak, indexed $\boldsymbol{h}=(h k l)$, as a function of the measurement direction $(\boldsymbol{y})$ relative to the samplereference frame. After corrections and normalizations, the probability maps, $P(\boldsymbol{h}, \boldsymbol{y})$, or pole figures were constructed to describe the distribution of different crystal directions in the sample space using MTEX software [136]. Defocusing due to the rotation of XRD sample holder was corrected using experimentally determined data obtained from the diffraction of $\mathrm{Mg}$ powders received from Magnesium Elektron.

\subsubsection{Tensile tests}

The tensile samples in accordance with ASTM E8 standard [137] were machined with the loading axis parallel to the rolling direction (RD) as well as parallel to the transverse direction (TD). The sample geometry and dimensions are shown in Figure 3.1. The samples had a gauge length of $25 \mathrm{~mm}$ (or a parallel length of $32 \mathrm{~mm}$ ) and a width of $6 \mathrm{~mm}$. The thickness of the samples was $6 \mathrm{~mm}$ as well. The specimens were hand-ground progressively along the loading direction with $1 / 0,2 / 0,3 / 0,4 / 0$ emery papers to remove machining marks 
and to achieve a smooth surface. The gage section of fatigue samples was ground progressively along the loading direction with emery papers up to a grit number of 600 to remove machining marks and to achieve a consistent surface. The tests were carried out using a computerized United tensile testing machine at a strain rate of $1 \times 10^{-3} \mathrm{~s}^{-1}$ for the ME20 Mg alloy at room temperature. At least two samples were tested to ensure reproducibility. The strain was measured using an extensometer with a gauge length of 25 $\mathrm{mm}$.

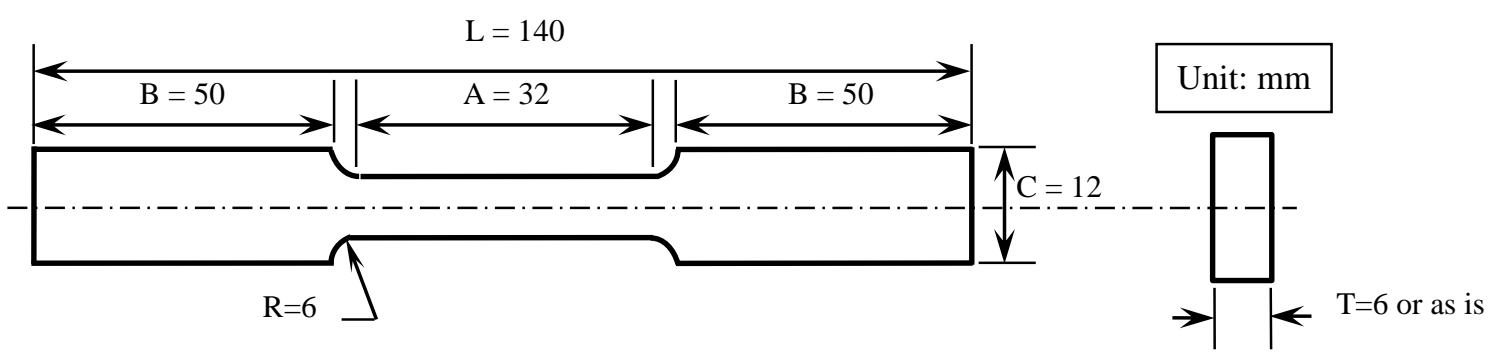

Figure 3.1: Geometry and dimensions of the tensile/fatigue test specimens according to ASTM E8 [137].

The tensile properties, including $0.2 \%$ yield strength (YS), ultimate tensile strength (UTS) and percent elongation to failure $(\% \mathrm{El})$ were evaluated from the engineering stress-strain curves. The strain (or work) hardening exponent $(n)$ and the strength coefficient $(K)$ were determined using the Hollomon equation $\left(\sigma=K \varepsilon^{n}\right)$ by plotting $\log \sigma$ vs. $\log \varepsilon$. 


\subsubsection{Fatigue tests}

Strain-controlled, pull-push type fatigue tests were conducted using a computerized servohydraulic Instron 8801 fatigue testing system via a Fast Track Low Cycle Fatigue (LCF) program at a constant strain rate of $1 \times 10^{-2} \mathrm{~s}^{-1}$ and room temperature of $25^{\circ} \mathrm{C}$. The tests were carried out in a strain control mode according to the ASTM E606 standard [138]. A triangular strain waveform was applied during the tests. Low cycle fatigue tests were performed at zero mean strain $\left(R_{\varepsilon}=-1\right.$, completely reversed strain cycle), at total strain amplitudes of $0.1 \%, 0.2 \%, 0.4 \%, 0.6 \%, 0.8 \%, 1.0 \%$, and $1.2 \%$, and at least two samples were tested at each level of the strain amplitudes. The calibration of both load and strain channels was performed for each individual sample prior to testing. The strain-controlled tests at lower strain amplitude levels were continued up to 10,000 cycles, then the tests were changed to load control at a frequency of $50 \mathrm{~Hz}$ using a sinusoidal waveform. The fracture surfaces of fatigued specimens were examined via scanning electron microscope (SEM) to identify fatigue crack initiation sites and propagation characteristics. The residual twins in the region near the fracture surface were observed as well. 


\section{RESULTS AND DISCUSSION}

\subsection{Microstructure and texture}

Figure 4.1 (a) shows an optical image of the microstructure of the as-rolled ME20 alloy which was observed along the rolling direction. Uniform equiaxed grains with an average grain size about $15 \mu \mathrm{m}$ were seen in the alloy due to the dynamic recrystallization that occurred in the rolling process. Grain size was slightly larger than GW103K [145] which contains 10 wt.\% of RE element, but was greatly refined compared with other common wrought magnesium alloys that are without rare earth elements, such as AZ31and AM30 [8, 10, 12-13, 139]. The composition (wt.\%) of GW103K is $10 \mathrm{Gd}, 3 \mathrm{Y}, 0.5 \mathrm{Zr}$, and $\mathrm{Mg}$ (balance) and for $\mathrm{AM} 30$ it is $3.4 \mathrm{Al}, 0.33 \mathrm{Mn}, 0.16 \mathrm{Zn}, 0.0026 \mathrm{Fe}, 0.0006 \mathrm{Ni}, 0.0008 \mathrm{Cu}$ and $\mathrm{Mg}$ (balance). This grain refinement was due to the rare earth element addition in this alloy. The grains can be prevented from coarsening during the hot deformation process as cerium can form some dispersed and thermally stable particles [140]. Besides, no twin was found in the non-deformed samples. Figure 4.1 (b) is a SEM back-scattered electron image of this alloy and some particles can be seen on the sample surface. An EDS line scan was performed to confirm the rare earth element presence in the particle as shown in Figure 4.1 (c) and (d), where some particles were Ce-rich precipitates containing $\mathrm{Mn}$ and some second phase particles containing $\mathrm{Mg}$ and $\mathrm{Ce}$ were confirmed to be $\mathrm{Mg}_{12} \mathrm{Ce}$ [141]. As a flammable solids,

Ce should be handled under dry protective gas such as argon and handled in an enclosed, controlled process. 

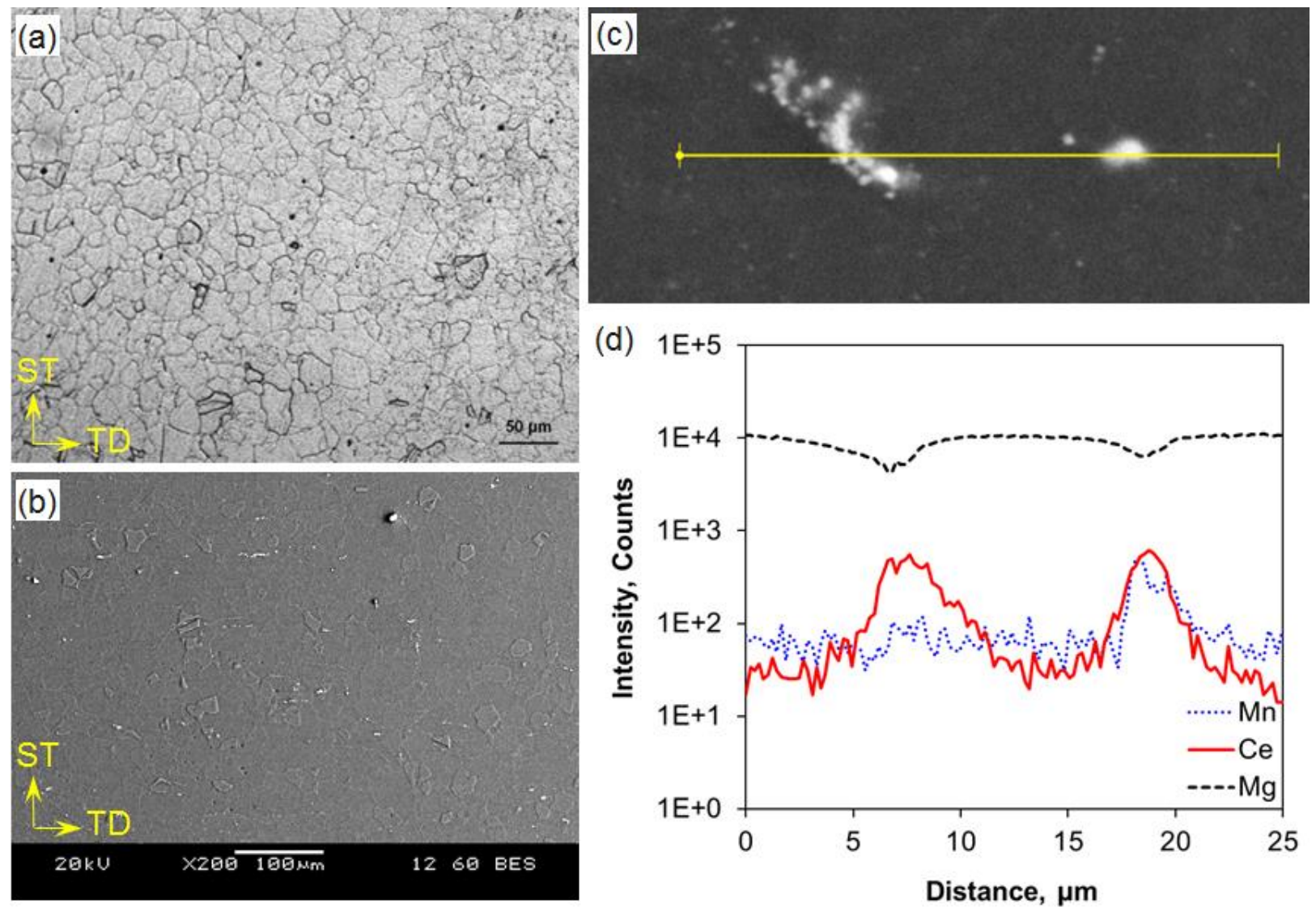

Figure 4.1: (a) Microstructures of a ME20 base material observed from rolling direction, (b) SEM back-scattered electron image of rolled ME20 base metal observed from rolling direction. (c) SEM back-scattered electron image indicating an EDS line scan position, and (d) the corresponding EDS line scan results. 
Figure 4.2 shows a (0002) pole figure of the as-rolled ME20 alloy which was evaluated by MTEX software. A relatively strong basal texture with a maximum intensity of 4.8 m.r.d.(multiples of random distribution) was seen after de-focusing correction, where the caxes of many grains were aligned perpendicular to the $\mathrm{RD}$ and tilted toward the ND. Compared with extruded AM30 [142] and rolled AZ31 [143] this ME20 alloy presented a weaker texture. A maximum intensity of 8.6 m.r.d.for the (0002) pole figure of a RE free extruded AM30 was reported from our research group. This is probably another benefit of rare earth element addition into magnesium alloys, as also reported by Stanford and Barnett [144] and Mirza and et al. [145] that rare earth element microalloying leads to texture weakening in the forming process. Strong crystallographic texture would lead to yield asymmetry in the hysteresis loop, as texture is related with the orientation of slip or twinning plane under external applied forces [146]. Typically, cast magnesium alloys have no such yield asymmetry because of their weak or no texture, while wrought alloys have a strong texture [144]. The ratio of the compressive-to-tensile yield stress was $\sim 0.79$ for the ME20 alloy in the mid-life cycle of hysteresis loop. This indicates that yield asymmetry is not very prominent as compared with other wrought magnesium alloys, and this is probably because of the light addition of rare earth elements. While there was almost no yield asymmetry for GW103K during cyclic loading as reported by Mirza et al. [145], the rare earth-content is over $10 \mathrm{wt} \%$ for this alloy as compared with merely 0.29 0.33 wt\% for ME20. The tensile stress-strain curve for the samples cut along rolling direction determined at a strain rate of $1 \times 10^{-3} \mathrm{~s}^{-1}$ (room temperature) is shown in Figure 4.3, and the tensile properties obtained are listed in Table 4.1. 

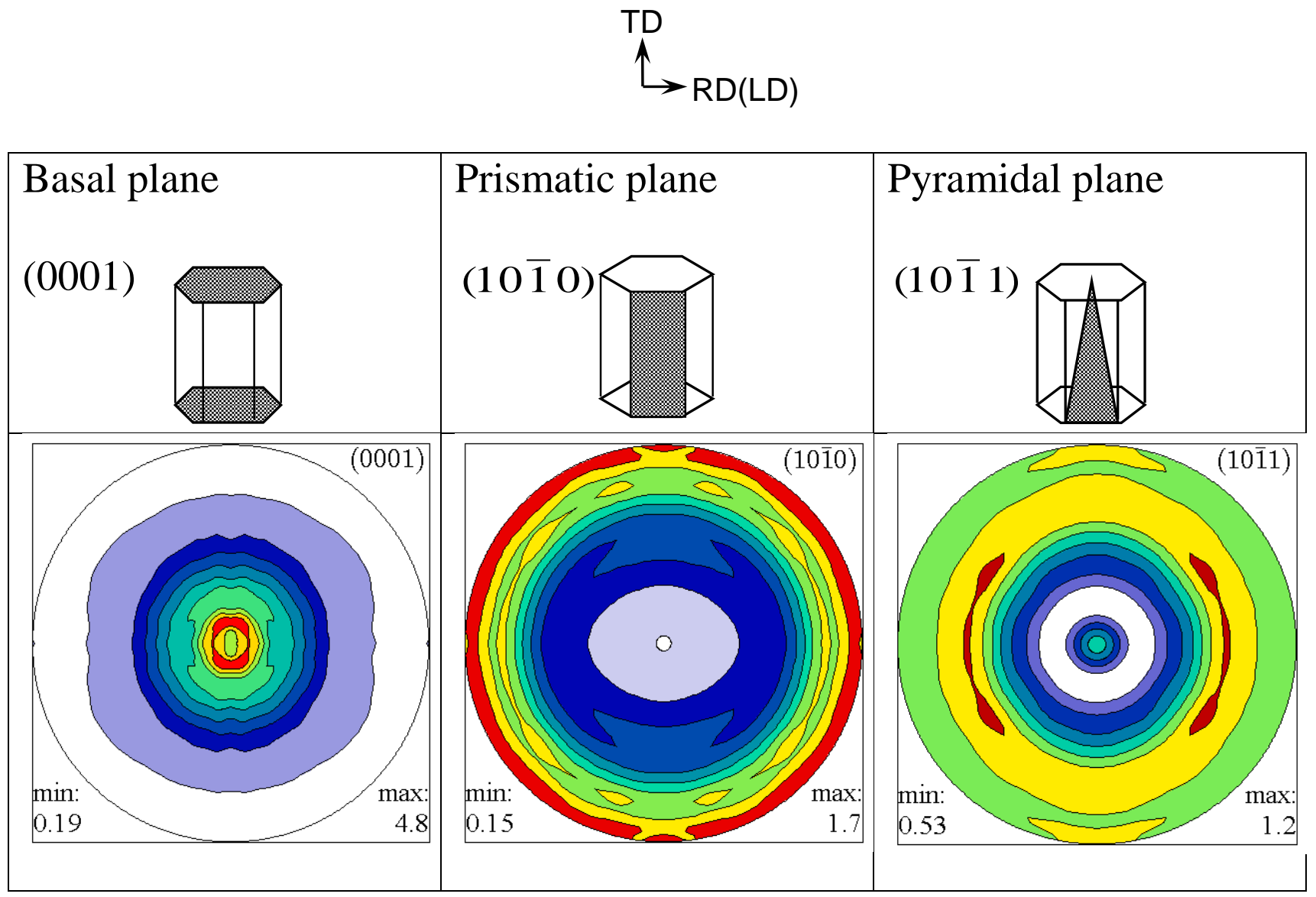

Figure 4.2: (0002) pole figure of rolled ME20 alloy, where RD/LD stands for the rolling/longitudinal direction, and TD stands for transverse direction. 


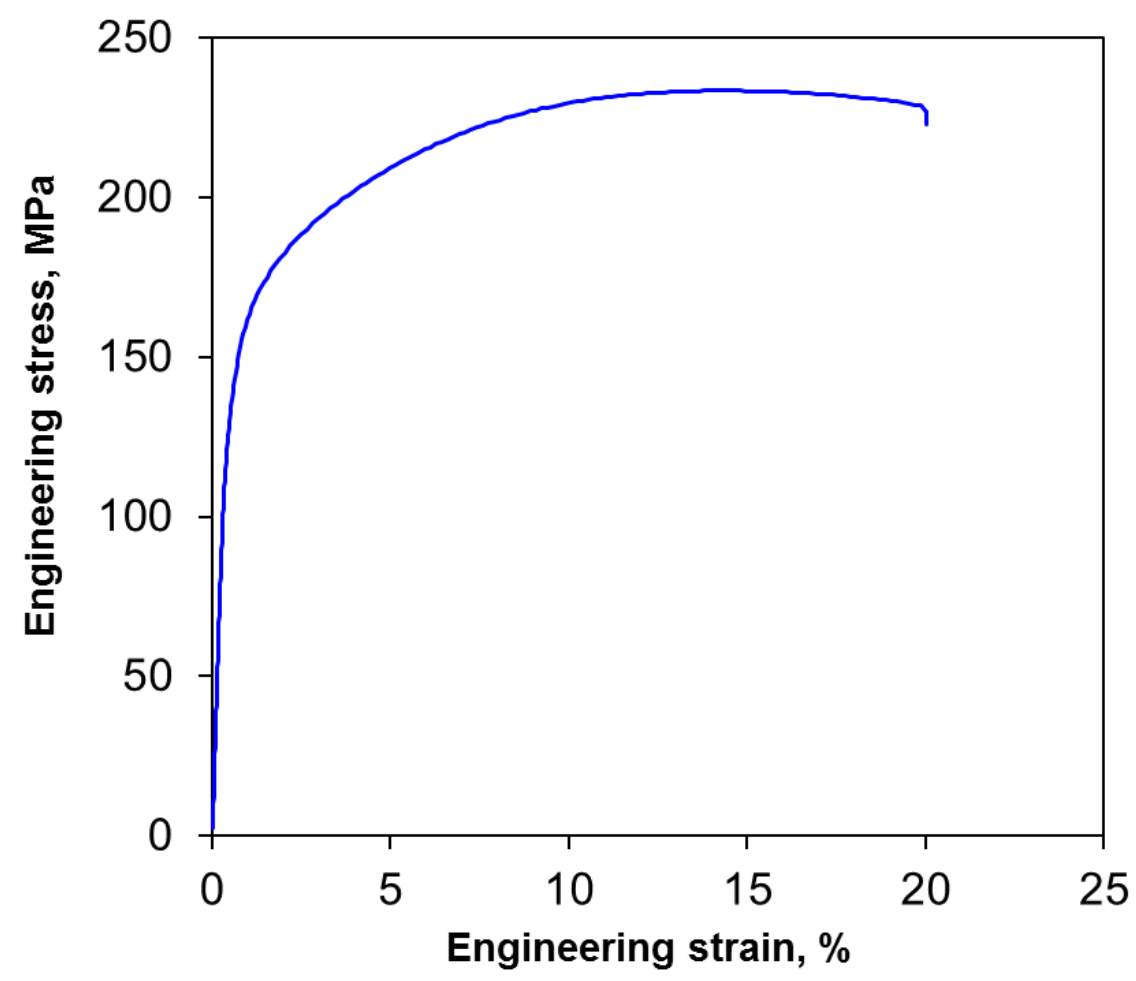

Figure 4.3: Typical tensile stress-strain curves of ME20 alloys at a strain rate of $1 \times 10^{-3} \mathrm{~s}^{-1}$ $(R D)$.

Table 4.1: Tensile properties of rolled ME20 alloy (RD).

\begin{tabular}{cccccc}
\hline $\begin{array}{c}\text { Yield strength, } \\
\mathrm{MPa}\end{array}$ & $\begin{array}{c}\text { Ultimate } \\
\text { tensile } \\
\text { strength, } \\
\mathrm{MPa}\end{array}$ & Elongation, \% & $\begin{array}{c}\text { Young's } \\
\text { modulus, } \\
\mathrm{GPa}\end{array}$ & $\begin{array}{c}\text { Strain } \\
\text { hardening } \\
\text { exponent } \\
(n)\end{array}$ & $K, \mathrm{MPa}$ \\
\hline 139.2 & 233.6 & 23.6 & 37.7 & 0.19 & 391 \\
\hline
\end{tabular}




\subsection{Hysteresis loops}

Figure 4.4 shows typical stress-strain hysteresis loops of the first, second, and mid-life cycles at a total strain amplitude of $1.2 \%$ and strain ratio of $R_{\mathrm{s}}=-1$ for the as-rolled ME20 alloy (samples cut along rolling direction). This alloy exhibited an unsymmetrical hysteresis loop in shape as a result of twinning in compressive loading and detwinning in tensile loading deformation [111]. Low yield strength and a strain hardening plateau in the compression phase is a characteristic of materials deformed by twinning [111]. The low yield strength and low strain hardening rate phenomena due to the deformation by detwinning [111] can be seen in the subsequent tensile loading. Exhaustion of detwinning happened at around $0.3 \%$ total strain which is shown by the occurrence of an inflection point beyond which the hardening rate rapidly increased [111]. Plastic strain imposed in the twinning can be completely recovered during detwinning, however. Detwinning finished at the early stage of tensile loading because of its lower critical resolved shear stress [147]. Thus, activation of slip systems is needed to accommodate the strain applied in the following stages in tensile loading, and this would cause a significant increase in the tensile stress curve [148]. A pseudo-elastic behavior is observed in the unloading phase starting from compressive peak stress because of detwinning [148]. The maximum and minimum peak stress also changed for the mid-life cycle loops compared with the first and second cycle loops. This situation is similar to the extruded AM30 alloy where the hysteresis loops were skewed. The mid-life cycle loop is less distorted than the first and second hysteresis loops. This phenomenon is 
also mainly due to the activity of twinning in compression in the descending phase and detwinning in the ascending phase in the hysteresis loop [8, 9, 11-13, 107, 108, 111, 139].

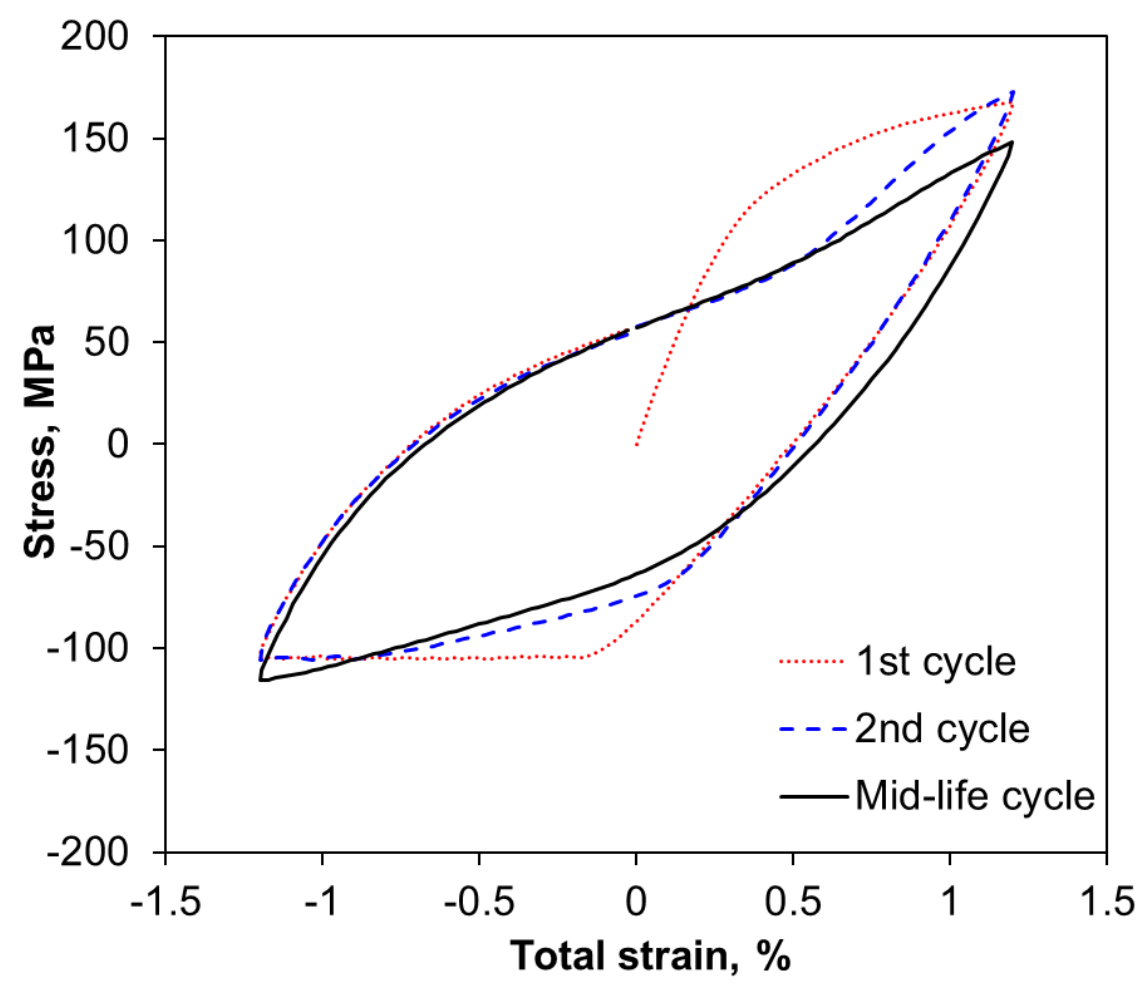

Figure 4.4: Typical stress-strain hysteresis loops of different cycles at a total strain amplitude of $1.2 \%$ and strain ratio of $R_{s}=-1$ for the rolled ME20 alloy $(R D)$.

Twinning plays an important role in the deformation process of magnesium alloys [8-13, 66, $129,139,142]$. For wrought magnesium alloys, most grains would orient in such a matter that their c-axis tilted toward the ND and the basal plane aligned parallel with the rolling or extrusion direction [145]. The loading applied in this fatigue test is along the rolling direction. In this test, extension twinning (in compression) and basal slip (in tension) occur more easily compared with the prismatic and pyramidal slip system which require a much higher 
activation stress at room temperature [149]. Intensive twinning and detwinning would be expected to happen for the sample tested under cyclic loading $[10,11]$. However, only a small amount of residual twins can be seen near the fracture surface on Figure 4.5. The twin formation is because of the insufficient slip systems for hcp-structured $\mathrm{Mg}$ alloys under cyclic deformation at room temperature, as well as the presence of relatively strong texture. Since the addition of RE-elements weakened the texture, intensive twin formation did not occur.

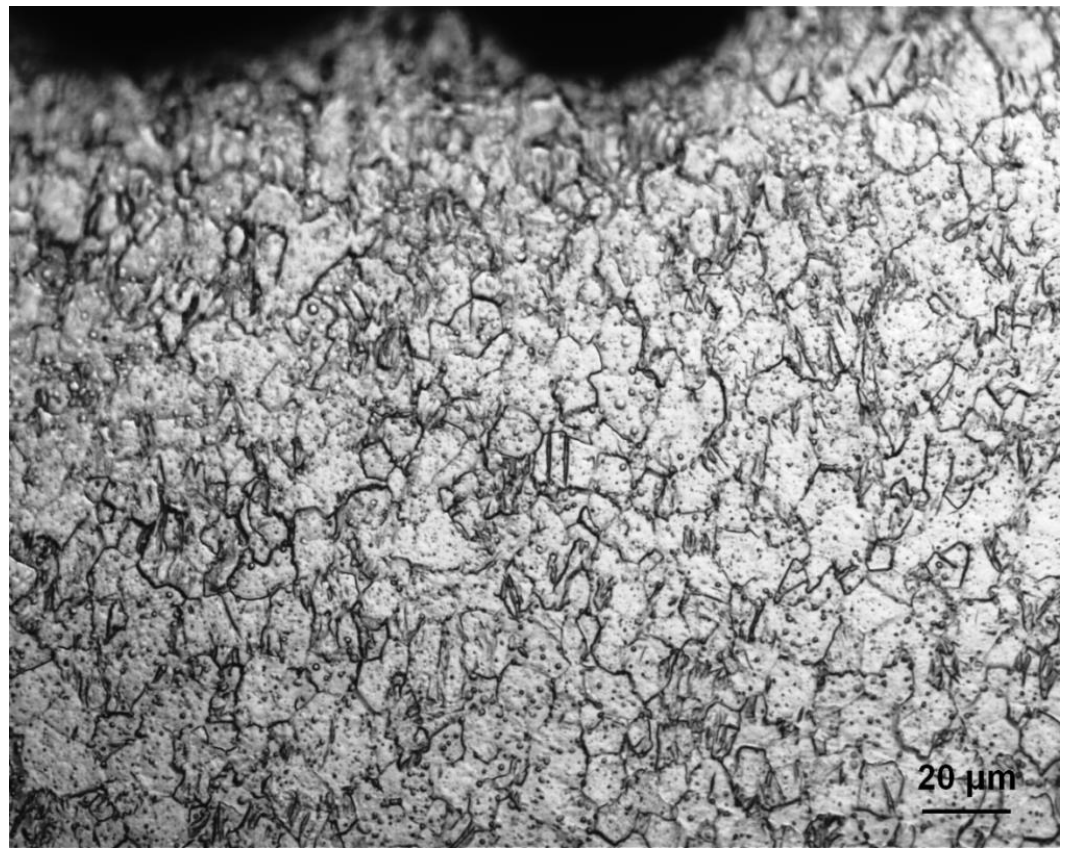

Figure 4.5: Optical micrograph in the area near the fracture surface at total strain amplitude of $1.2 \%$, showing the distribution of residual twins in the fatigued sample of the rolled ME20 alloy $(R D)$. 


\subsection{Fatigue behavior}

Figure 4.6 shows the trend of stress amplitude with regard to the number of cycles at different applied strain amplitudes on a semi-log scale. The stress amplitude increased as the strain amplitude increased, while the fatigue life decreased. This ME20 alloy (Rolling direction) showed a similar response as the extruded rare earth element-free AM30 [11] and AZ31 $[8,10,11,13]$, in that the cyclic stabilization occurred only at the lowest strain amplitudes of $0.1 \%$. Even under a strain amplitude of $0.1 \%$, slight cyclic hardening started at the fifth cycle until at around 30 cycles slight cyclic softening started to occur and continued up to failure. Cyclic softening occurred all the way to failure for samples tested under the strain amplitude of both $0.2 \%$ and $0.4 \%$. As for the sample tested at the strain amplitude of $0.6 \%$, the first cycle of the test experienced hardening followed by cyclic softening from the second to the twentieth cycles; From 20 to 60 cycles cyclic hardening occurred and fluctuating of the stress amplitude occurred all the way until 800 cycles. This fluctuation of results was probably because of disturbance and noise caused by the machine. However, the overall trend for stress amplitude is softening for the testing condition of $0.6 \%$ strain amplitude. As for the sample tested under the strain amplitude of $0.8 \%$, the stress amplitude was very stable from the beginning to 800 cycles, with cyclic softening beginning from this point. While cyclic hardening occurred for the first 3 cycles for samples tested under a strain amplitude of $1.0 \%$, and $1.2 \%$, cyclic softening kept going on until failure occurred. Overall, cyclic softening basically happened for samples tested under all the different strain amplitude: $0.1 \%, 0.2 \%, 0.4 \%, 0.6 \%, 0.8 \%, 1.0 \%$ and $1.2 \%$. Strain hardening [150] and strain softening [151] can be caused by twin formation, depending on grain size, material crystal structure, 
tensile and compressive asymmetry etc. [10] The cyclic strain softening behavior for ME20 may be explained by the twin softening mechanism that is caused by the reorientation of the lattice in the twinned area to provide an easier orientation for slip to occur $[151,152]$.

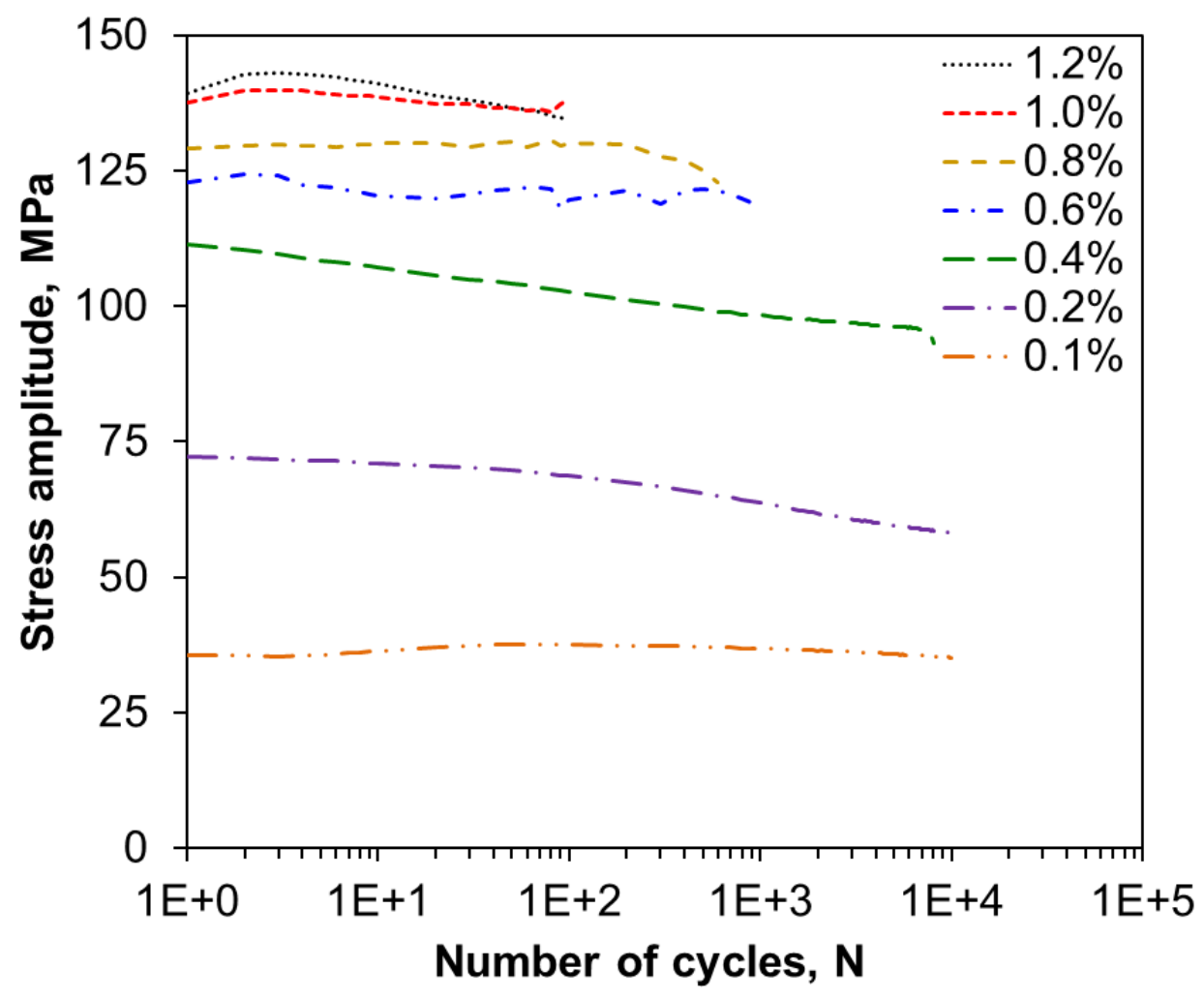

Figure 4.6: Stress amplitude vs. the number of cycles at different total strain amplitudes applied (Rolling direction).

Plastic strain amplitude is considered as an important physical quantity in low cycle fatigue. It is related to several damaging processes and it influences the internal microstructure that is closely related to the strain resistance and eventually the fatigue life [10]. Figure 4.7 shows the change of plastic strain amplitude with cycles of fatigue and it is seen that as the total 
strain amplitude increased the plastic strain amplitude also increased but fatigue life decreased. Stabilization of plastic strain amplitude occurred at the strain amplitude of $0.1 \%$. However, a slight increase of plastic strain amplitude can be observed over the entire fatigue life for samples tested under the strain amplitude of $0.2 \%$ and $0.4 \%$. At 20-200 cycles plastic strain amplitude decreased for samples tested under a strain amplitude of $0.8 \%$ and plastic strain amplitude started to increase at 200 cycles until failure occurred. For samples tested under the high strain amplitude of $1.0 \%$ and $1.2 \%$, a clear trend of increase of plastic strain amplitude over the full course of cyclic loading can be noticed. Under all of the different strain amplitudes the plastic strain amplitude generally showed a trend of increase with the number of cycles, which is further proof of cyclic softening, that occurred in all the tested samples.

Figure 4.8 shows the cyclic stress-strain curve corresponding to the mid-life of ME20 alloy (RD) in comparison with the monotonic tensile stress-strain curve. At a strain amplitude $0.1 \%$ the cyclic stress-strain curve is consistent with the monotonic ones. However, under higher strain amplitude the stress amplitude for cyclic loading is lower than that for monotonic loading. Thus this alloy showed a cyclic softening under the rest of strain amplitudes except for the lowest strain amplitude of $0.1 \%$, which is in agreement with the results shown in Figure 4.6 and Figure 4.7. 


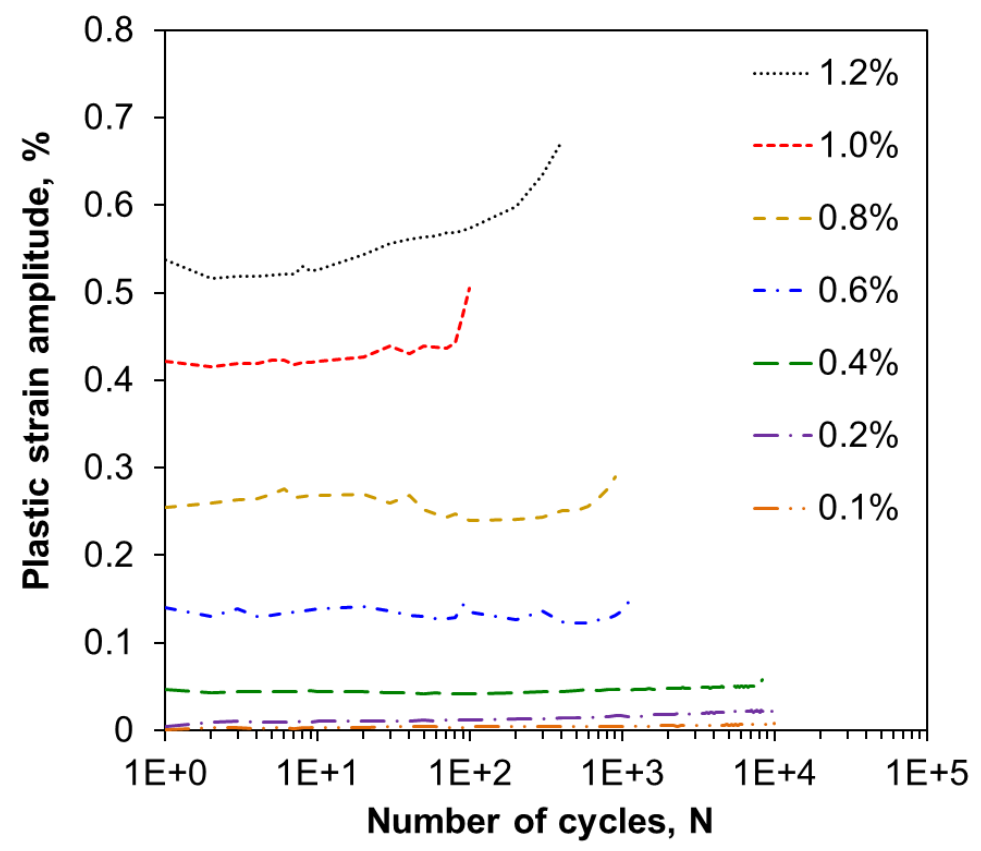

Figure 4.7: Plastic strain amplitude vs. the number of cycles at different total strain amplitudes applied (Rolling direction).

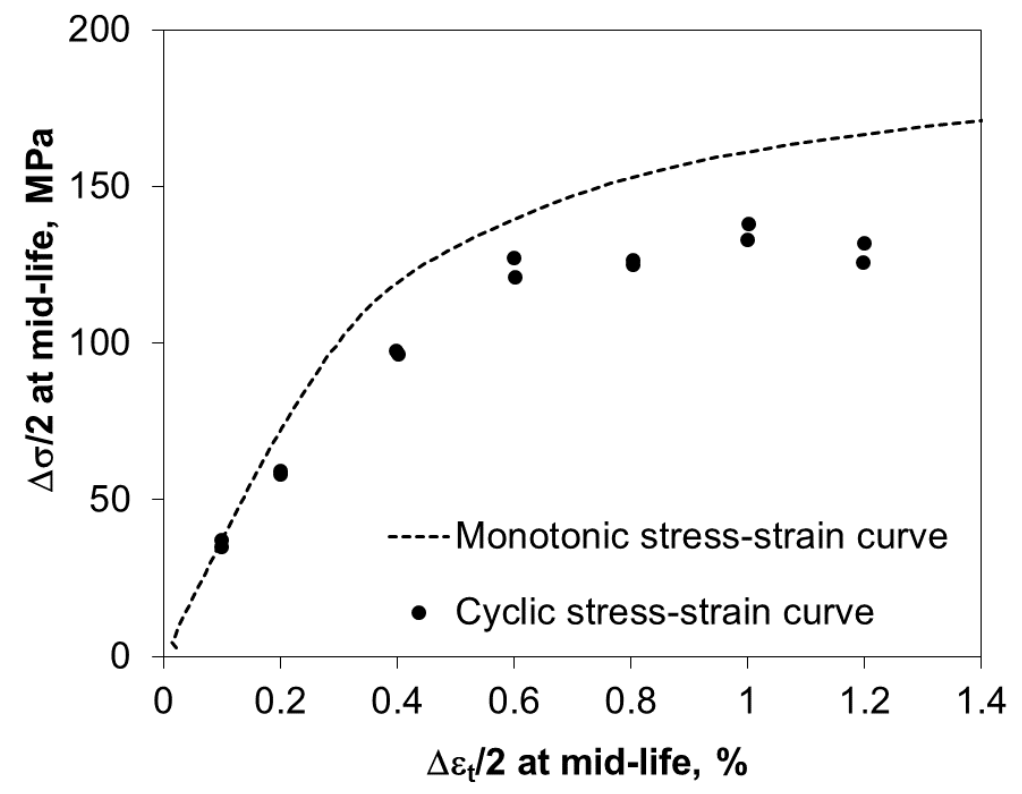

Figure 4.8: Cyclic stress-strain curve for the ME20 alloy (RD), where the corresponding monotonic stress-strain curve is also potted for comparison. 
In Figure 4.9, the number of cycles to failure $\left(N_{f}\right)$ as a function of the applied total strain amplitudes $\left(\Delta \varepsilon_{\mathrm{t}} / 2\right)$ ME20 is plotted, as well as data for some other reported wrought magnesium alloys $[10,12,145]$ for comparison. Arrows are used to point out data where the cycles of fatigue was at or over $10^{7}$. This ME20 alloy (RD) showed a better fatigue life than other wrought magnesium alloys at higher strain amplitudes, such as $0.8 \%, 1.0 \%$ and $1.2 \%$. However, at a lower strain amplitude of $0.2 \%$ the ME20 alloy showed the shortest fatigue life. This phenomenon is closely related with material strength and ductility. ME20 alloys showed a higher ductility and lower strength compared with other alloys and this resulted in better fatigue resistance at larger strain amplitudes.

The total strain amplitude is the combination of elastic strain amplitude and plastic strain amplitude from refs. [8-11, 98, 122, 129, and 153] and it can be expressed in the following equation:

$$
\frac{\Delta \varepsilon_{t}}{2}=\frac{\Delta \varepsilon_{e}}{2}+\frac{\Delta \varepsilon_{p}}{2}=\frac{\sigma_{f}^{\prime}\left(2 N_{f}\right)^{b}}{E}+\varepsilon_{f}^{\prime}\left(2 N_{f}\right)^{c}
$$

where $E$ is the Young's modulus (for the present alloy the average value obtained during fatigue testing was $\sim 42.0 \mathrm{GPa}$ ), $N_{f}$ is the fatigue life or the number of cycles to failure, $\sigma_{f}^{\prime}$ is the fatigue strength coefficient, $b$ is the fatigue strength exponent, $\varepsilon_{f}^{\prime}$ is the fatigue ductility coefficient, and $c$ is the fatigue ductility exponent. The elastic strain component is known as Basquin's equation and the plastic strain component is known as the Coffin-Manson relation. Figure 4.10 shows the elastic, plastic, and total strain amplitudes plotted as a function of the 
number of reversals to failure. The values of the strain amplitudes were taken from the midlife cycles. The fatigue life parameters obtained on the basis of Equation (1) were summarized in Table 4.2.

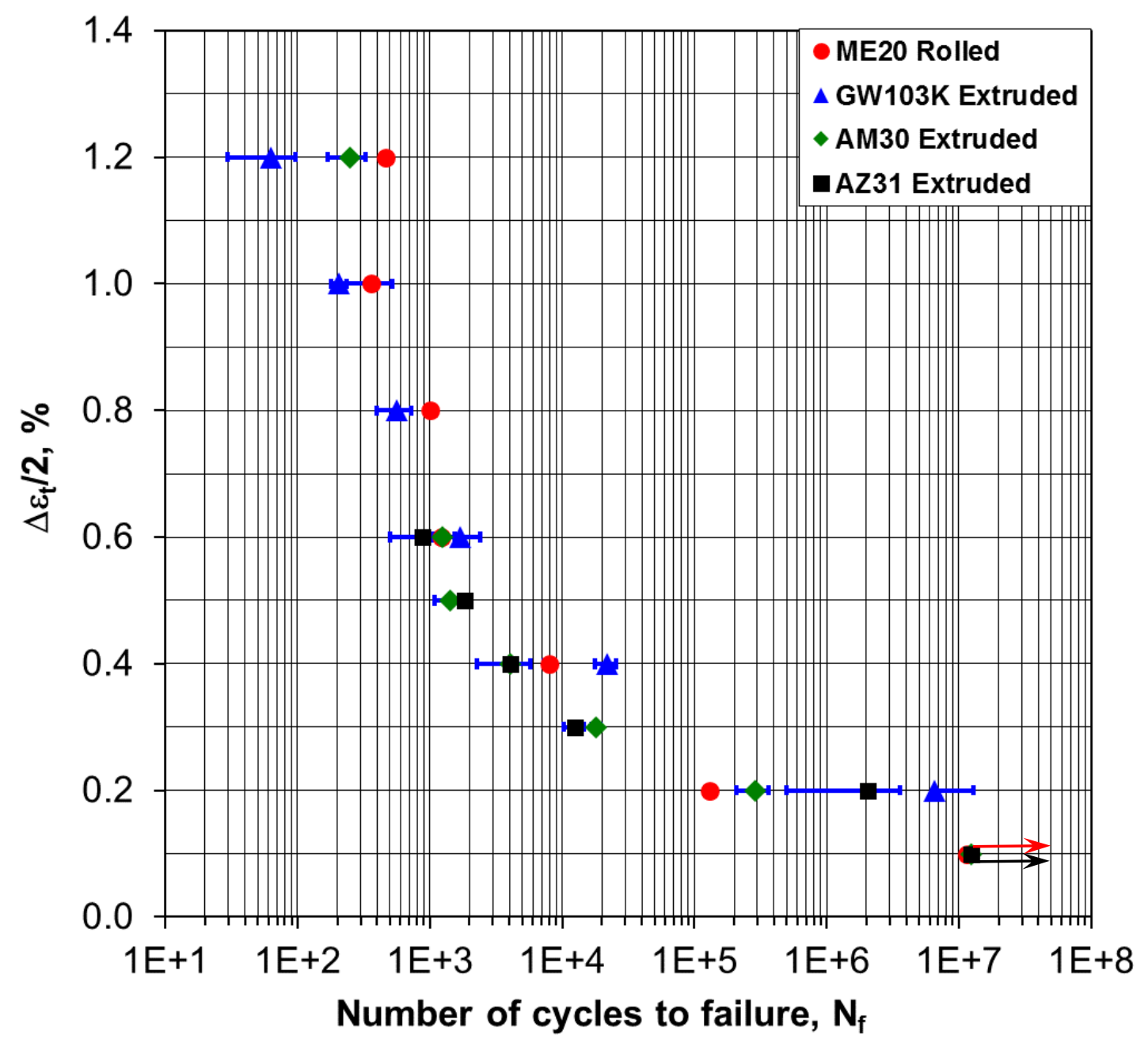

Figure 4.9: Total strain amplitude as a function of the number of cycles to failure for the rolled ME20 alloy (RD), in comparison with the data reported in the literature for various Mg alloys. 


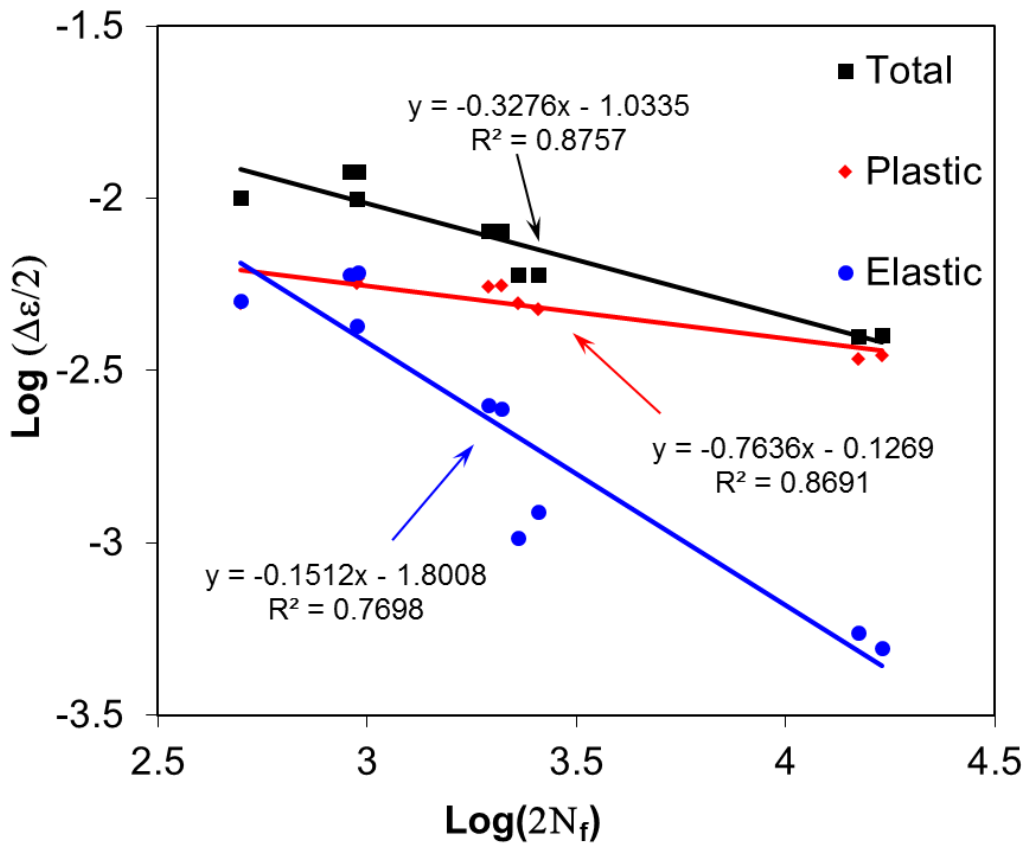

Figure 4.10: Evaluation of fatigue parameters in the form of log elastic, plastic and total strain amplitudes vs. log number of reversals to failure, respectively (Rolling direction).

Table 4.2: Low cycle fatigue parameters for the rolled ME20 alloy (Rolling direction).

\begin{tabular}{|c|c|}
\hline Low cycle fatigue parameters & \\
\hline Cyclic yield strength, $\sigma^{\prime}, \mathrm{MPa}$ & 115 \\
\hline Cyclic strain hardening exponent, $\mathrm{n}^{\prime}$ & 0.11 \\
\hline Cyclic strength coefficient, $\mathrm{K}^{\prime}, \mathrm{MPa}$ & 240 \\
\hline Fatigue strength coefficient, $\sigma^{\prime} \mathrm{f}, \mathrm{MPa}$ & 665 \\
\hline Fatigue strength exponent, $\mathrm{b}$ & -0.15 \\
\hline Fatigue ductility coefficient, $\boldsymbol{\varepsilon}^{\prime} \mathrm{f}$ & 0.75 \\
\hline Fatigue ductility exponent, $\mathrm{c}$ & -0.76 \\
\hline
\end{tabular}




\subsection{Fatigue life prediction-Energy density method}

The alteration of twinning and detwinning during cyclic loading and their interaction with residual twins are the reasons for the complicate fatigue deformation behavior as they affected the cyclic hardening characteristics, the stress-strain hysteresis loop, and the stabilization of material behavior [148]. Due to the above facts, using prediction models such as stress and strain-based models is difficult as those parameters typically undergo a strong variation throughout the fatigue life [148]. Compared with stress and plastic strain amplitude, plastic strain energy density exhibited a much more stable value throughout the whole fatigue life, and thus the energy-based fatigue parameter is considered suitable in predicting the low cycle fatigue life for rolled magnesium alloys [148]. Since cyclic plastic strain and cyclic plastic stress are linked to dislocation movement and their movement resistance, this energybased fatigue parameter is regarded as a comprehensive measurement of the amount of fatigue damage per cycle [154].

$$
\Delta W_{p} N_{f}^{m}=C
$$

The Morrow model is expressed in Eq. (2)[154], in which $\Delta W_{p}, N_{f}, m$ and $C$ stand for plastic strain energy density at half-life, fatigue life, fatigue exponent and material energy absorption capacity, respectively. The plastic strain energy density is calculated by integrating the area within the hysteresis loop at the mid-life of the fatigue test. Figure 4.11(a) plots the measured plastic strain energy density as a function of fatigue life and agrees well with the model

predictions. However, S. Hyuk Park et al. [148] mentioned that the material constants used in 
this model are strongly dependent on the test condition and the damage induced by tensile mean stress which is known to have a detrimental effect on fatigue life that was not included in equation (2). As seen from Figure 4.4 the tensile peak stress is always greater than the compression peak stress in each hysteresis loop, because of the early exhaustion of detwinning and the activation of the slip system, which requires a greater stress to accommodate than in the compression phase, thus tensile mean stress existed throughout the entire fatigue test [148]. Therefore, tensile mean stress effects should also be considered in the prediction of fatigue life.

The concept proposed by Ellyin and Kujawski [155] was applied in order to consider the effect of tensile mean stress and equation (2) was modified as the following:

$$
\Delta W_{t} N_{f}^{m}=C
$$

where $\Delta W_{t}=\left(\Delta W_{p}+\Delta W_{e^{+}}\right)$is the total strain energy density at midlife of fatigue test. Figure 4.11(b) shows the relationship between this total energy density with fatigue life and the prediction with this model fits the results quite well. The material constants used were $\mathrm{m}=$ 0.67 and $\mathrm{C}=114.16\left(\mathrm{MJ} / \mathrm{m}^{3}\right)$, which were calculated from Figure 4.11(b). 

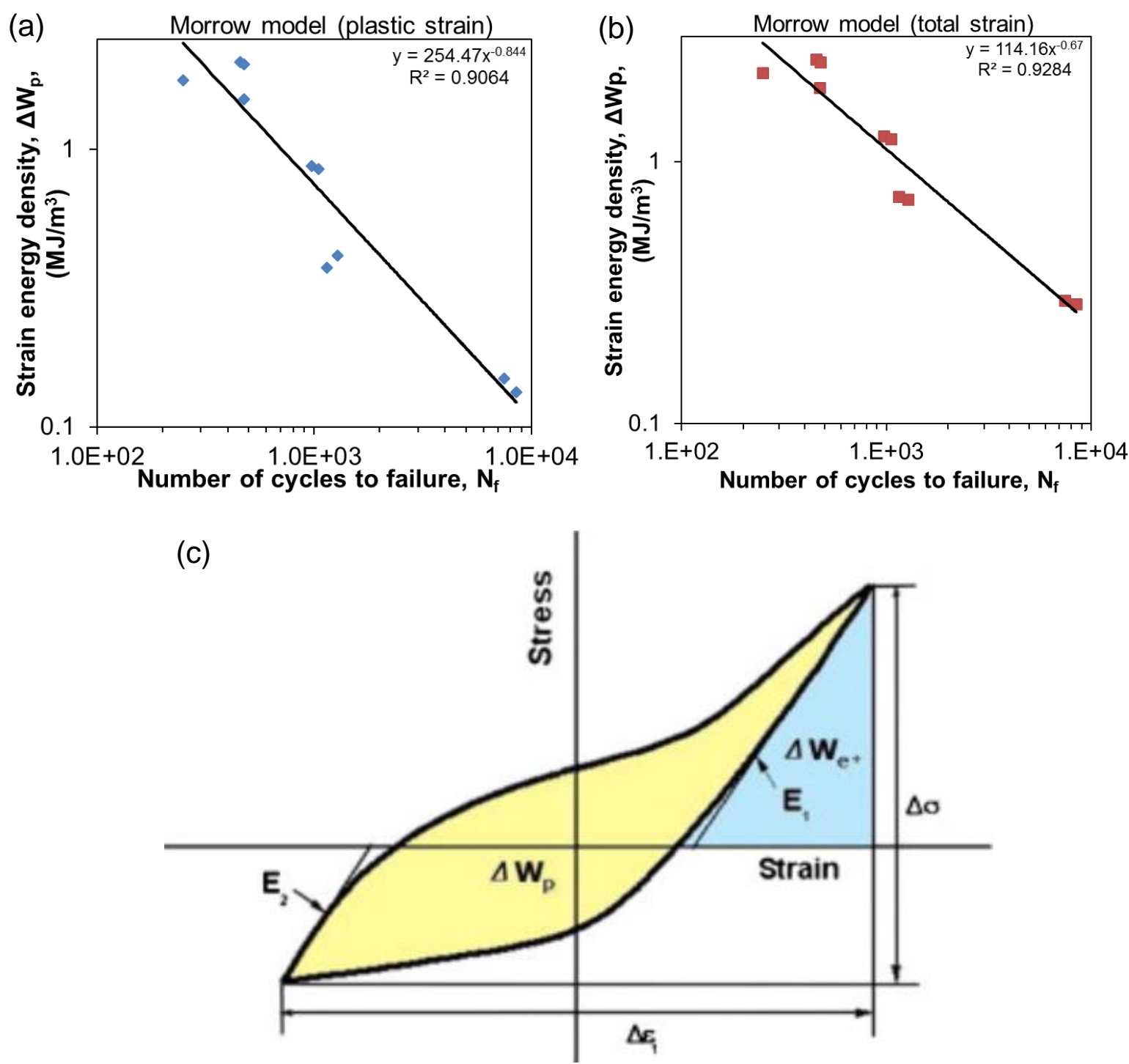

Figure 4.11: Life prediction with the energy-based models based on plastic strain energy density (a) and based on total strain (b), General definition of the hysteresis loop developed in LCF testing with $R_{\varepsilon}=-1(c)[148]$ 


\subsection{Fractography}

Fracture surfaces of fatigued specimens were examined by SEM. Figure 4.12 shows an overall view of the fracture surface at low magnifications of the rolled samples that fatigued at a total strain amplitude of $0.2 \%$ (a) and $1.0 \%$ (b), respectively. It is seen that fatigue cracks initiated basically from the specimen surface or subsurface. At the initiation site cleavagelike facets were observed. The basic differences among the fracture surfaces of samples tested at different total strain amplitudes were that the crack initiation area of low strain amplitude had a more ridges-like surface while the samples fatigued at high strain amplitude showed a smooth surface. However, both of them exhibited a striation-like surface, as shown in Figure 4.13. The fatigue propagation area is characterized by a feature of mixed mode and fatigue striation could not be clearly found under both low and high strain amplitude, as shown in Figure 4.14. The propagation area contained some fatigue striation-like features that were perpendicular to the crack propagation direction, in conjunction with secondary cracks. These characteristics were more obvious at higher strain amplitudes, as seen in Figure $4.14(b)$. 

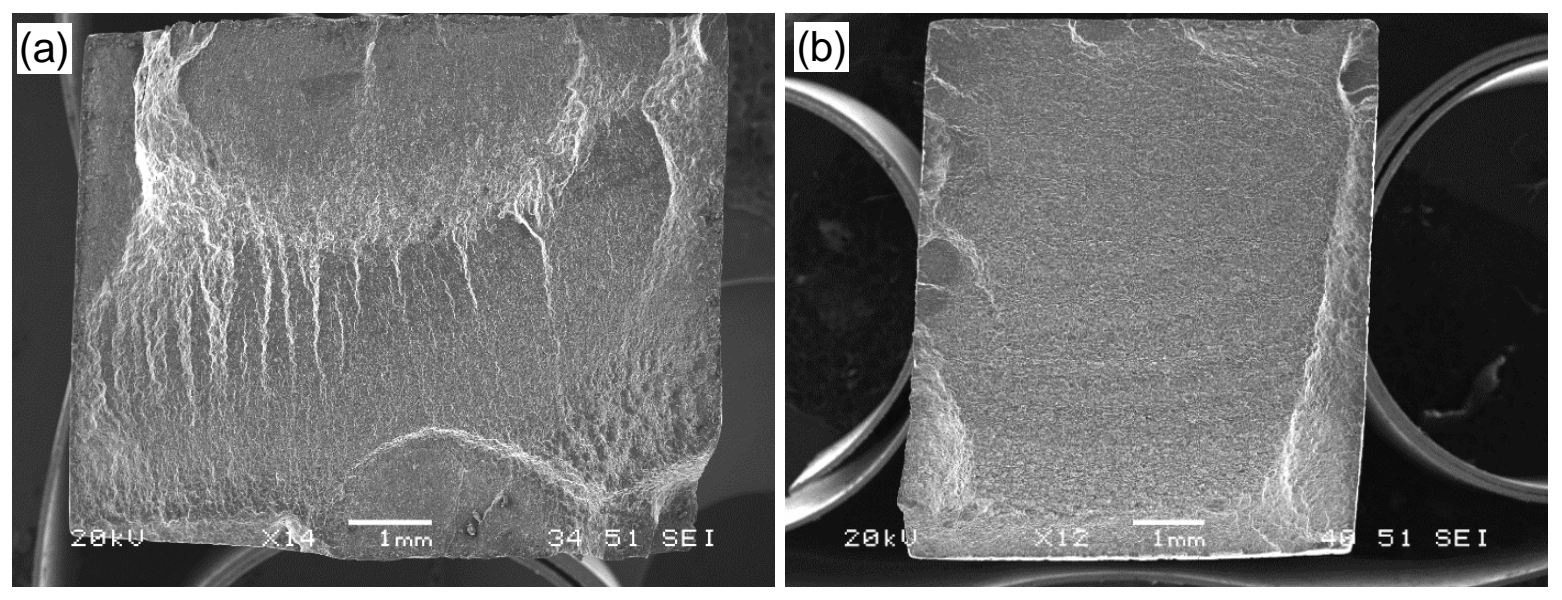

Figure 4.12: SEM images of overall fracture surfaces of the rolled specimens (RD) fatigue data total strain amplitude of (a) $0.2 \%$ and (b) $1.0 \%$.
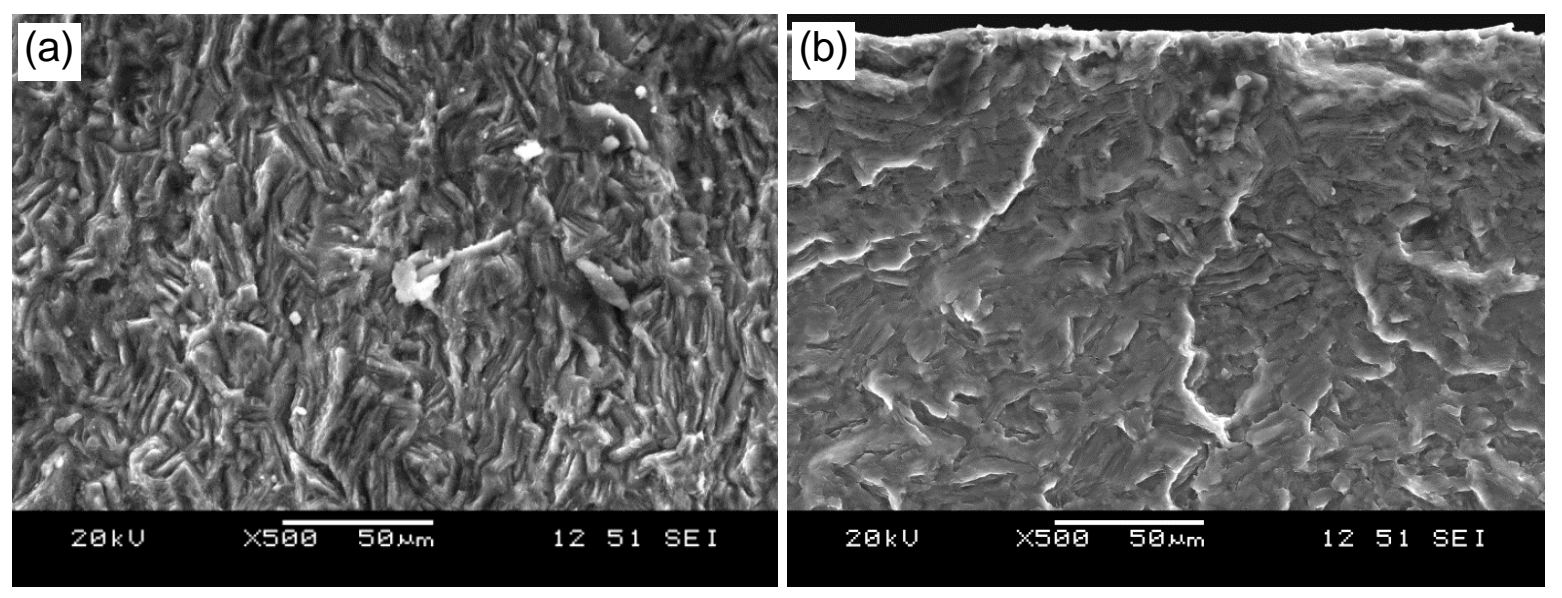

Figure 4.13: SEM micrographs of the fracture surface near crack initiation of the rolled specimens (RD) fatigued at a total strain amplitude of $0.2 \%(($ a) secondary electron image and (b) $1.0 \%$ (secondary electron image). 

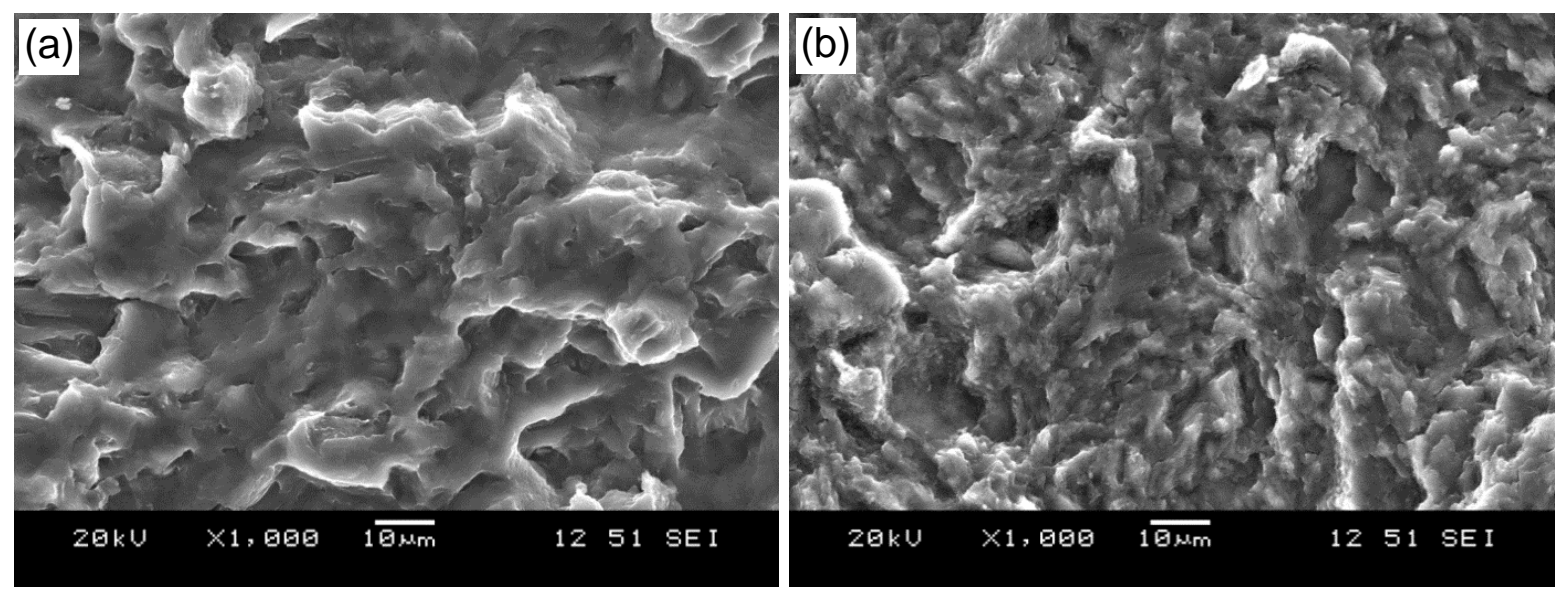

Figure 4.14: SEM micrographs of the fatigue crack propagation region of the rolled specimens (RD) fatigued at total strain amplitude of (a) $0.2 \%$ and $(b) 1.0 \%$. 


\section{COMPARISON OF FATIGUE PROPERTIES: DIFFERENT SPECIMEN ORIENTATION}

\subsection{Optical Microstructure}

Figure 5.1 (a) shows an optical image of the microstructure of the as-rolled ME20 alloy which was observed from the transverse direction. There was very little difference when compared with the microstructure observed from the rolling direction, which is shown in Figure 5.1 (b). This probably is another benefit of rare earth element addition as grain elongation was not seen, which was expected to be shown due to the hot rolling process (or other wrought processes). Grain shape change, i.e., elongation, of transverse direction from rolling direction can be found in other common wrought magnesium alloys that are without rare earth elements, such as AZ31and AM30 [8, 11-13,139]. This is due to the lack of rare earth element addition in this alloy. The grains can be prohibited from coarsening during the hot deformation process as cerium can form some dispersed and thermally stable particles [15]. Similar to Figure 5.1 (b), no twins were found in the non-deformed samples. 

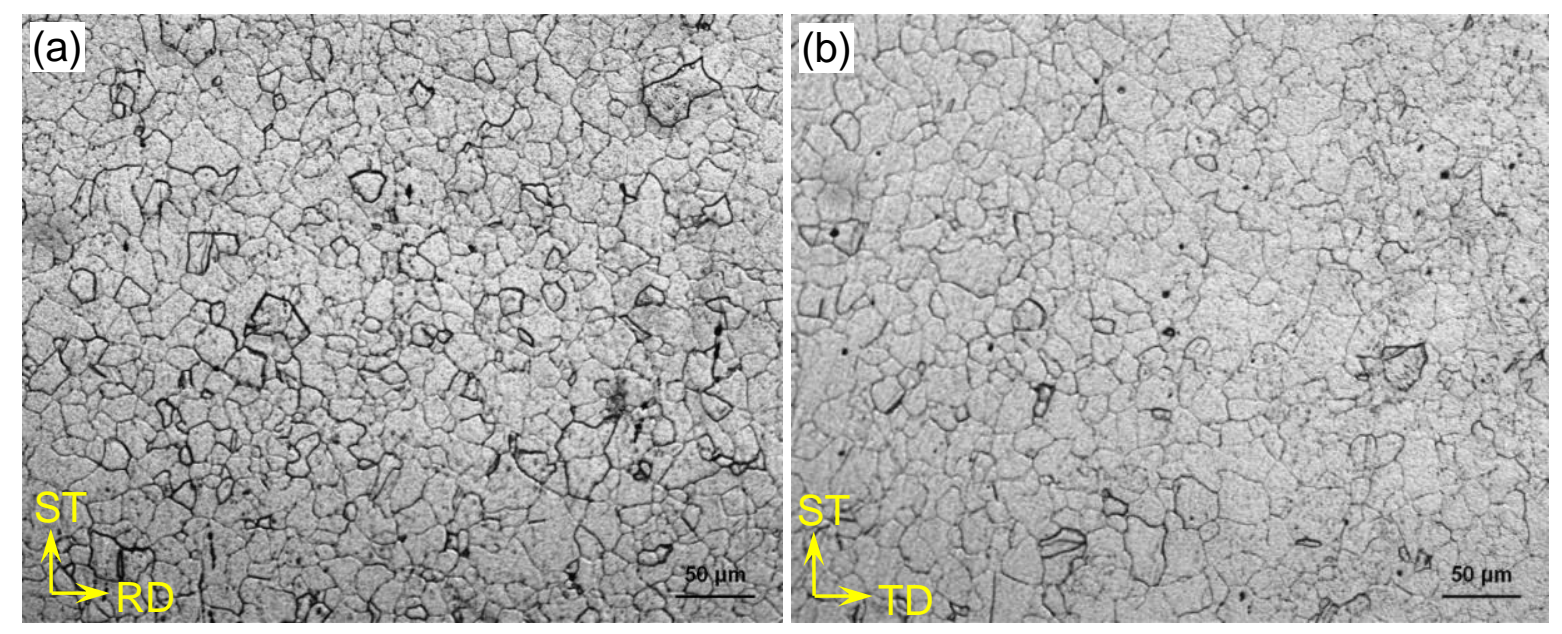

Figure 5.1: Microstructures of a ME20 base material observed from transverse direction (a) and rolling direction $(b)$.

\subsection{Tensile Properties}

The tensile stress-strain curve of the same material but cut along the transverse direction was determined at a strain rate of $1 \times 10^{-3} \mathrm{~s}^{-1}$ (room temperature) is shown in Figure 5.2, and the tensile properties obtained are listed in Table 5.1. It is clearly shown from Figure 5.2 that samples cut along the rolling direction exhibit superior mechanical properties in terms of yield strength and ultimate yield strength. However, other parameters are comparable between each other such as strain hardening exponent and strength coefficient. This showed the effect of texture on the tensile properties of ME20 samples. 


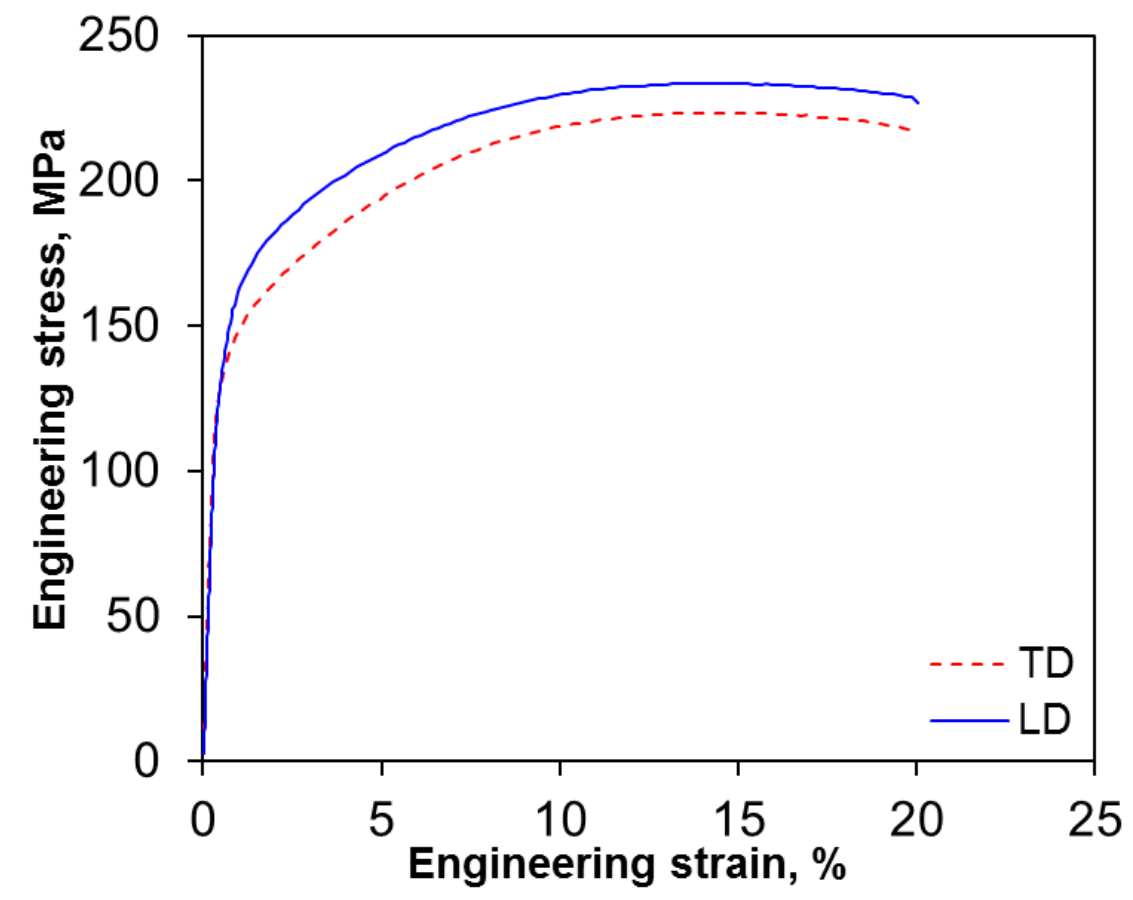

Figure 5.2: Typical tensile stress-strain curves of ME20 alloys at a strain rate of $1 \times 10^{-3} \mathrm{~s}^{-1}$ (Transverse and rolling direction).

Table 5.1: Tensile properties of rolled ME20 alloy (Transverse orientation).

\begin{tabular}{cccccc}
\hline $\begin{array}{c}\text { Yield strength, } \\
\mathrm{MPa}\end{array}$ & $\begin{array}{l}\text { Ultimate } \\
\text { tensile } \\
\text { strength, } \\
\mathrm{MPa}\end{array}$ & $\begin{array}{l}\text { Elongation, } \\
\%\end{array}$ & $\begin{array}{l}\text { Young's } \\
\text { modulus, } \\
\mathrm{GPa}\end{array}$ & $\begin{array}{l}\text { Strain } \\
\text { hardening } \\
\text { exponent } \\
(n)\end{array}$ & $K, \mathrm{MPa}$ \\
\hline 133 & 223 & 20 & 40.8 & 0.2 & 385.8 \\
\hline
\end{tabular}




\subsection{Hysteresis Loops}

Figure 5.3 shows typical stress-strain hysteresis loops for the first, second, and mid-life cycles at a total strain amplitude of $1.2 \%$ and strain ratio of $R_{\mathrm{S}}=-1$ for the as-rolled ME20 alloy samples cut along the transverse direction, as well as comparisons with samples cut along rolling direction. This specimen orientation (TD) of ME20 alloy exhibited a similar results of stress-strain hysteresis loops as specimens cut along rolling direction. The effect of specimen orientation can be seen from the figure as LD samples require higher tensile stress than TD samples in tensile loading phase, however, specimen orientation did not bring significant differences in stress-strain hysteresis loops.

The loading applied in this fatigue test is along the transverse direction. Similar to the test in chapter 4, in this test, extension twinning (in compression) and basal slip (in tension) occur more easily compared with the prismatic and pyramidal slip systems which require much higher activation stress at room temperature [149]. Intensive twinning and detwinning would be expected to happen for the sample tested under cyclic loading $[10,11]$. Residual twins can be seen from near the fracture surface on Figure 5.4. Similar to the residual twins shown in Figure 4.5, due to RE-element addition, intensive twins were not seen as well. 

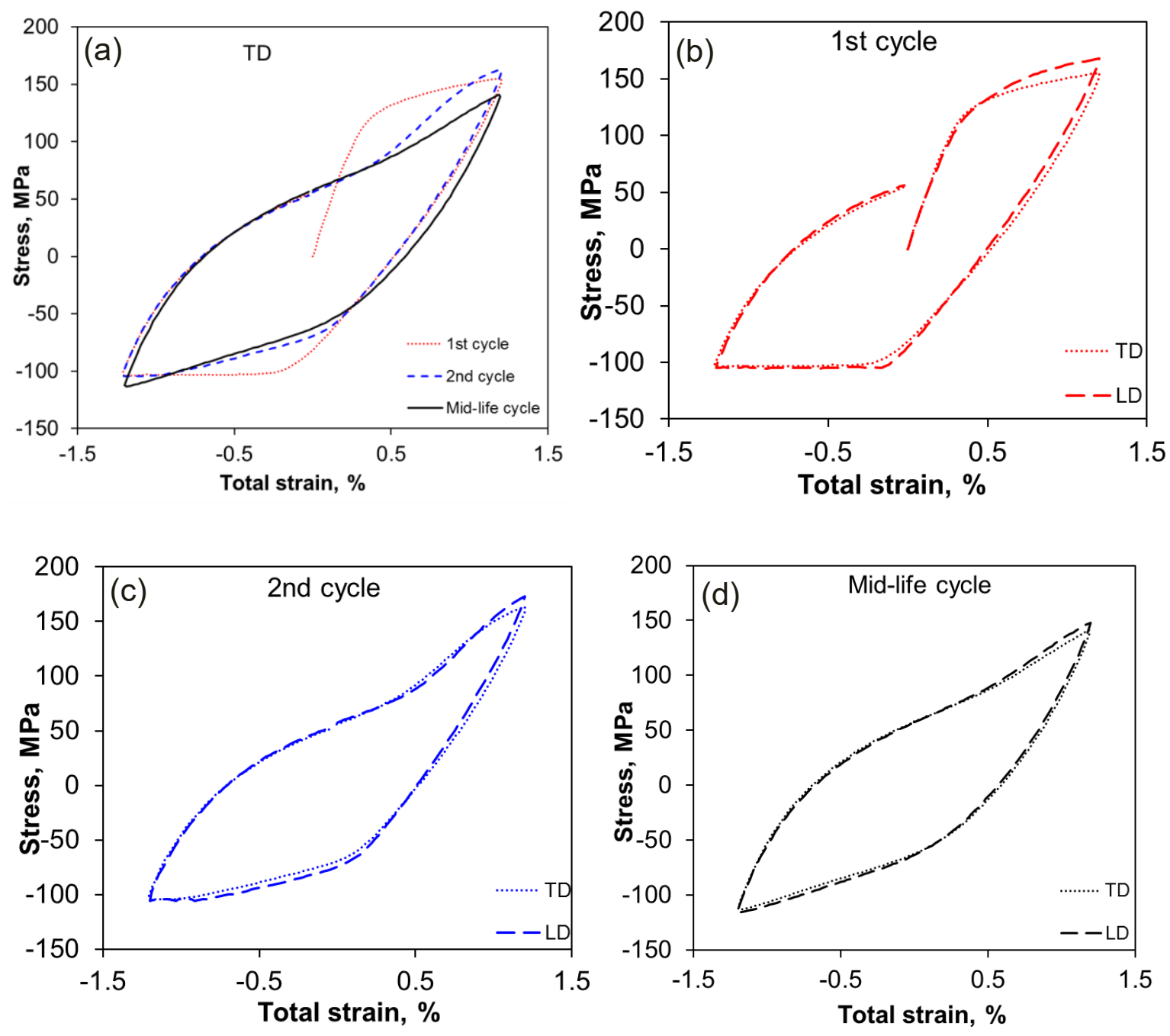

Figure 5.3: Typical stress-strain hysteresis loops of different cycles at a total strain amplitude of $1.2 \%$ and strain ratio of $R_{s}=-1$ for the rolled ME20 alloy: Transverse direction (a) and comparison with rolling direction under different cycles $(b)-(d)$. 


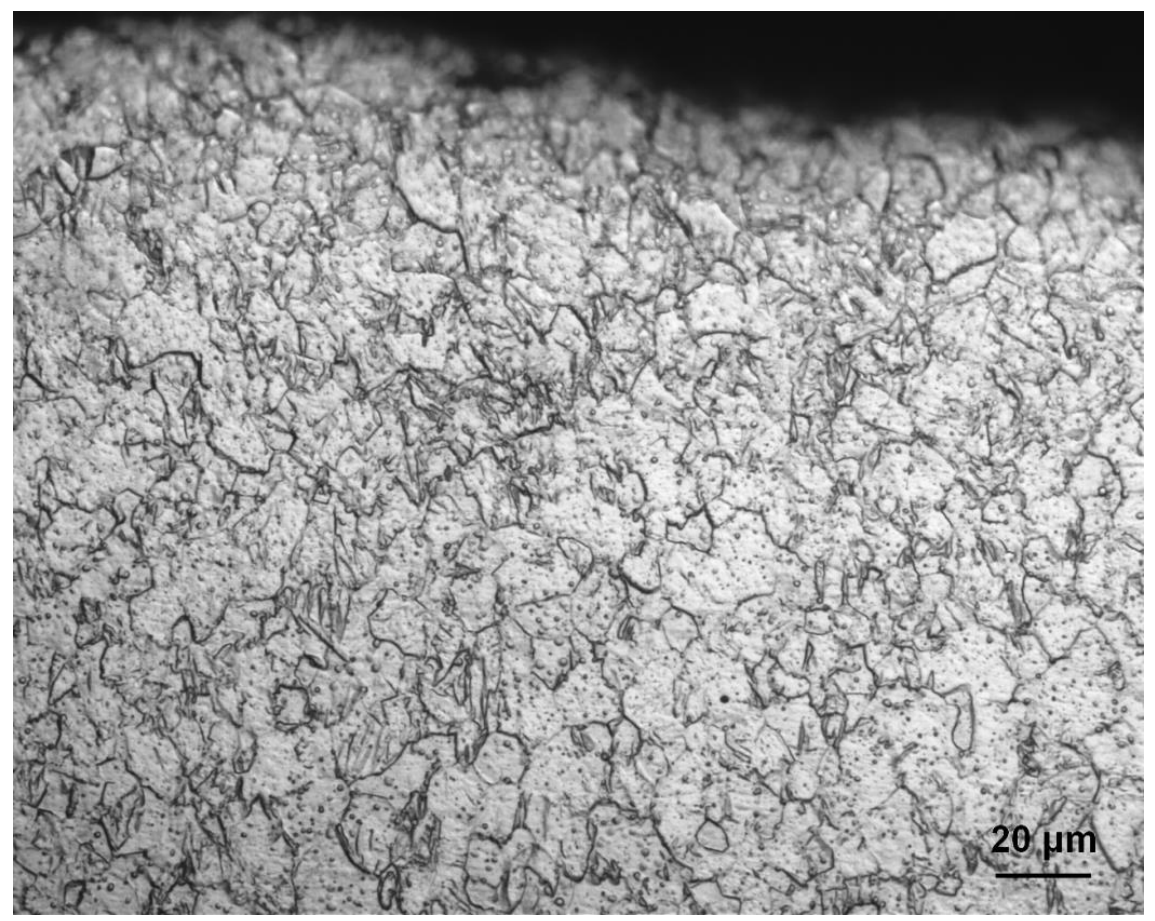

Figure 5.4: Optical micrograph in the area near the fracture surface at a total strain amplitude of $1.2 \%$, showing the distribution of residual twins in the fatigued sample of the rolled ME20 alloy (Transverse direction).

\subsection{Fatigue Behavior}

Figure 5.5 shows the trends of stress amplitude with regard to the number of cycles at different applied strain amplitudes on a semi-log scale, for both the samples cut along the transverse direction and rolling direction. Comparing with the above results it is seen that specimen orientation or texture did not make a significant difference in stress amplitude at different strain amplitudes. 

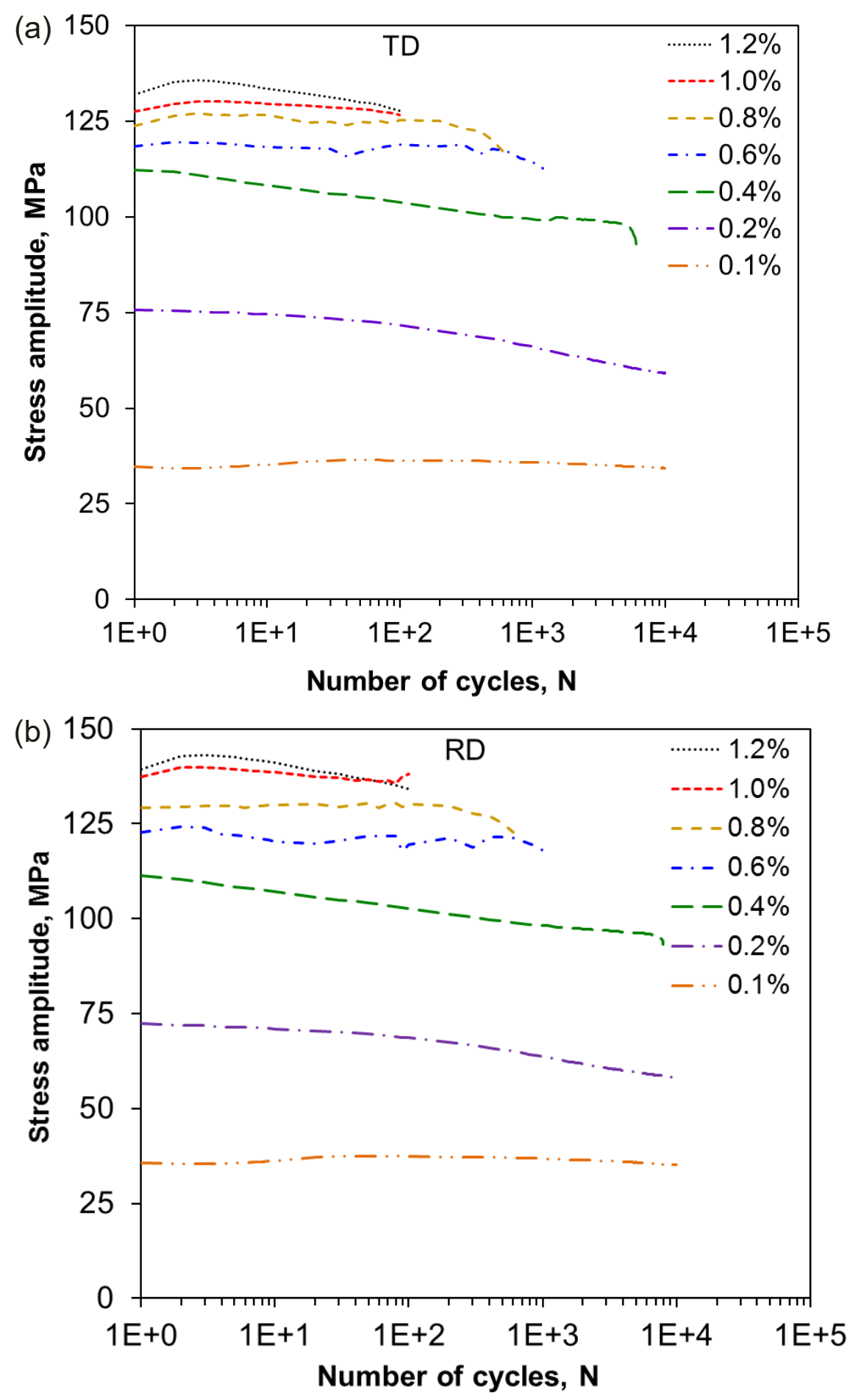

Figure 5.5: Stress amplitude vs. the number of cycles at different total strain amplitudes applied: Transverse (a) and rolling direction (b). 
Overall stress amplitudes for RD samples are slightly larger than TD samples for tests under all strain amplitudes and this agrees with the results from tensile tests. Similar to the results from samples cut along the rolling direction, the stress amplitude increased as the strain amplitude increased, while the fatigue life decreased. Cyclic stabilization occurred only at the lowest strain amplitudes of $0.1 \%$. Even under a strain amplitude of $0.1 \%$, slight cyclic hardening started at the fifth cycle until at around 30 cycles slight cyclic softening started to occur and continued up to failure. Cyclic softening occurred all the way to failure for samples tested under the strain amplitude of both $0.2 \%$ and $0.4 \%$. As far as the sample tested under the strain amplitude of $0.6 \%$, the first cycle of the test experienced hardening followed by cyclic softening for the cycles from the second to the twentieth; From 20 to 60 cycles cyclic hardening occurred and fluctuating of stress amplitude occurred all the way until 800 cycles. This fluctuation of results was probably because of disturbance and noise from the machine. However, the overall trend for stress amplitude is softening for the testing condition of $0.6 \%$ strain amplitude. As for the sample tested under the strain amplitude of $0.8 \%$, the stress amplitude was very stable from the start to 800 cycles, with cyclic softening beginning from this point. While cyclic hardening occurred for the first 3 cycles for samples tested under the strain amplitude of $1.0 \%$, and $1.2 \%$, cyclic softening kept going on until failure occurred, with the overall stress amplitude somewhat greater than for the samples cut along the rolling direction. Overall, cyclic softening happened for samples tested under all the different strain amplitudes: $0.1 \%, 0.2 \%, 0.4 \%, 0.6 \%, 0.8 \%, 1.0 \%$ and $1.2 \%$.

Figure 5.6 shows the effect of specimen orientation on the change of plastic strain amplitude with cycles of fatigue. Comparing with the above results it is seen that specimen orientation 
or texture did not make a significant difference in plastic strain amplitude as well at different strain amplitudes. Overall plastic strain amplitudes for RD samples are slightly lower than TD samples for tests under all strain amplitudes and this agrees with the differences in stress amplitudes discussed above. Similarly, for samples cut along the transverse direction, it is seen that as the total strain amplitude increased the plastic strain amplitude also increased but fatigue life decreased. Stabilization of plastic strain amplitude happened at the strain amplitude of $0.1 \%$. However, a slight increase of plastic strain amplitude can be observed over the entire fatigue life for samples tested under the strain amplitude of $0.2 \%$. As for the test under condition of $0.4 \%$ strain amplitude, a slight decrease of plastic strain amplitude occurred from the beginning until the $60^{\text {th }}$ cycle but from that point on plastic strain amplitude increased all the way to failure. At 0-200 cycles plastic strain amplitude decreased for samples tested under strain amplitudes of $0.6 \%$ and $0.8 \%$ and plastic strain amplitude started to increase at 200 cycles until failure occurred. For samples tested under the high strain amplitude of $1.0 \%$ and $1.2 \%$, a clear trend of increase of plastic strain amplitude over the full course of cyclic loading can be noticed. 

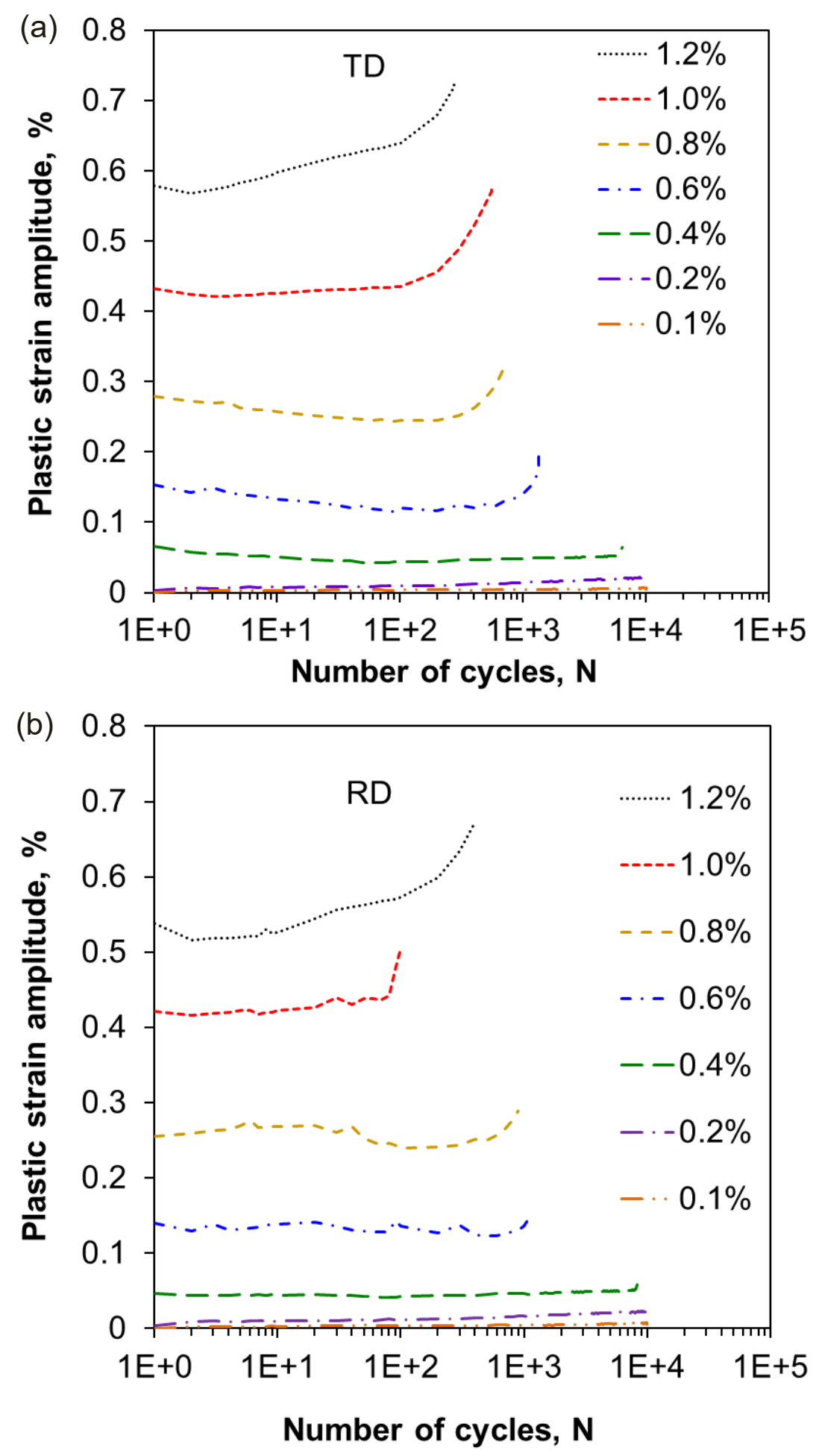

Figure 5.6: Plastic strain amplitude vs. the number of cycles at different total strain amplitudes applied: Transverse (a) and rolling direction (b). 
Under all of the different strain amplitudes the plastic strain amplitude generally showed a trend of increase with the number of cycles, which is further proof of cyclic softening, that occurred in all the tested samples. Besides, overall the curves showed smoother features for the samples cut along the transverse direction, as compared with another specimen orientation.

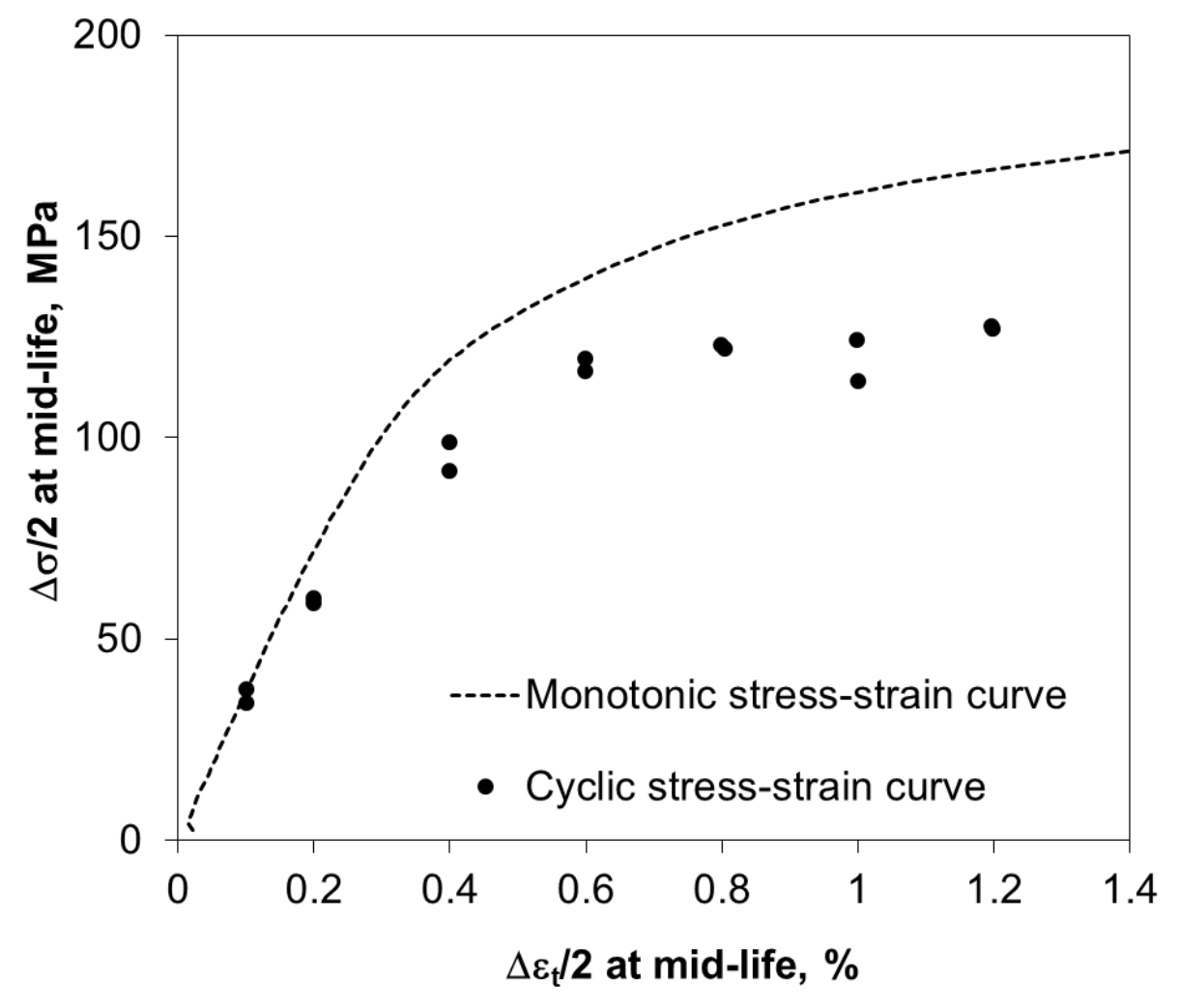

Figure 5.7: Cyclic stress-strain curve for the ME20 alloy, where the corresponding monotonic stress-strain curve is also potted for comparison (Transverse orientation). 


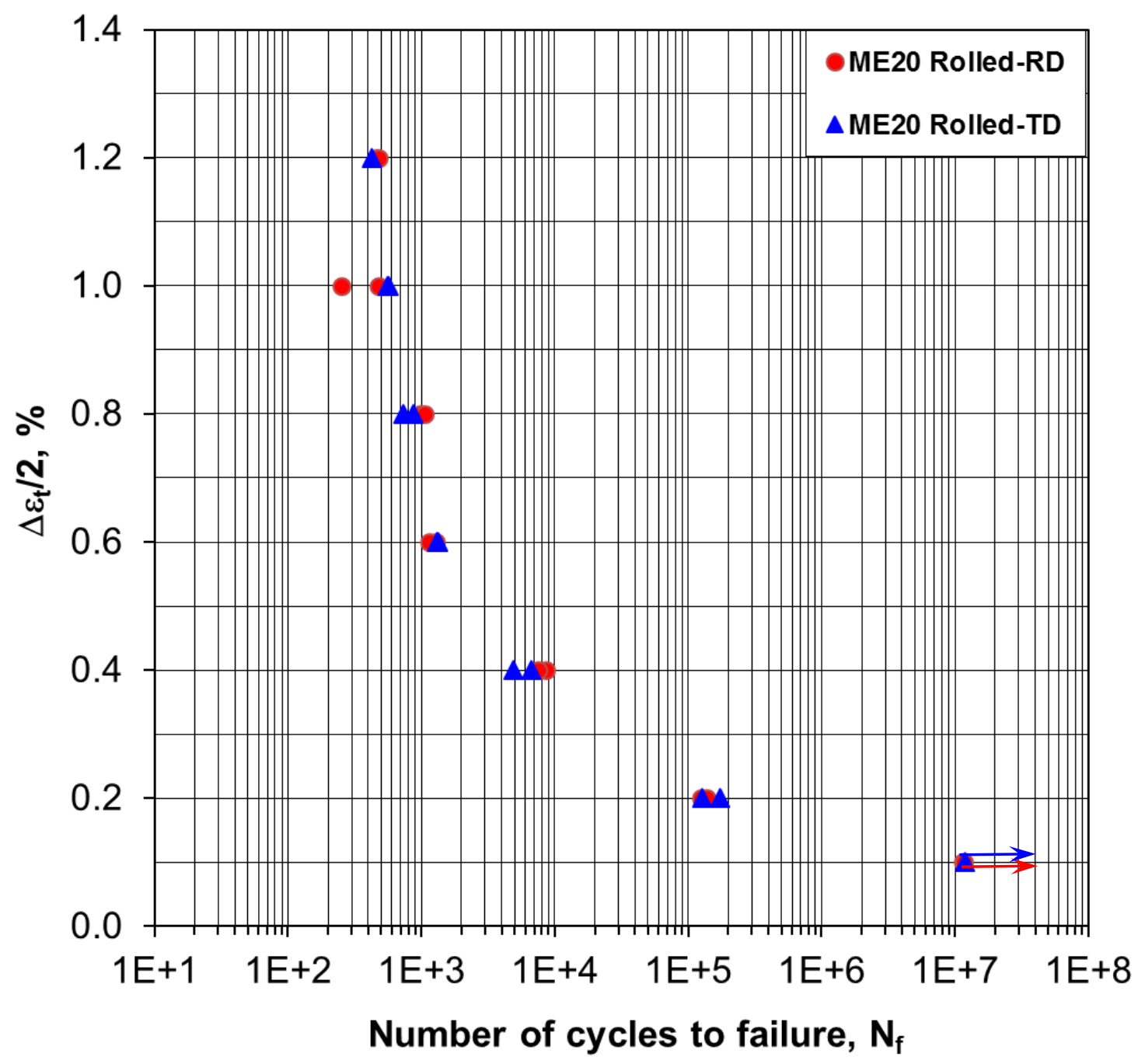

Figure 5.8: Total strain amplitude as a function of the number of cycles to failure for the rolled ME20 alloy of different specimen orientation, in comparison with the data reported in the literature for various $\mathrm{Mg}$ alloys. 
Figure 5.7 shows the cyclic stress-strain curve corresponding to the mid-life of the ME20 alloy in the transverse orientation in comparison with the corresponding monotonic tensile stress-strain curve. At a strain amplitude $0.1 \%$ the cyclic stress-strain curve is consistent with the monotonic one. However, under higher strain amplitude the stress amplitude for cyclic loading is lower than that for monotonic loading. Thus, this alloy under this orientation showed similar cyclic softening as well under the rest of strain amplitudes except for the lowest strain amplitude of $0.1 \%$.

In Figure 5.8, the number of cycles to failure $\left(N_{f}\right)$ as a function of the applied total strain amplitudes $\left(\Delta \varepsilon_{\mathrm{t}} / 2\right)$ of different specimen orientation of ME20 is plotted. Overall, the fatigue life for different specimen orientations are comparable which shows that texture plays little role in terms of fatigue life.

Figure 5.9 shows the elastic, plastic, and total strain amplitudes plotted as a function of the number of reversals to failure. The values of the strain amplitudes were taken from the midlife cycles. The fatigue life parameters obtained on the basis of Equation (1) were summarized in Table 5.2.

Although fatigue lives were comparable between the RD and TD orientations, TD samples showed superior fatigue properties in terms of some fatigue parameters. The fatigue strength coefficients underwent an increase from $665 \mathrm{MPa}$ for the RD to $815 \mathrm{MPa}$ for the TD, and fatigue ductility coefficient increased from 0.75 for the RD to 1.91 for the TD. 


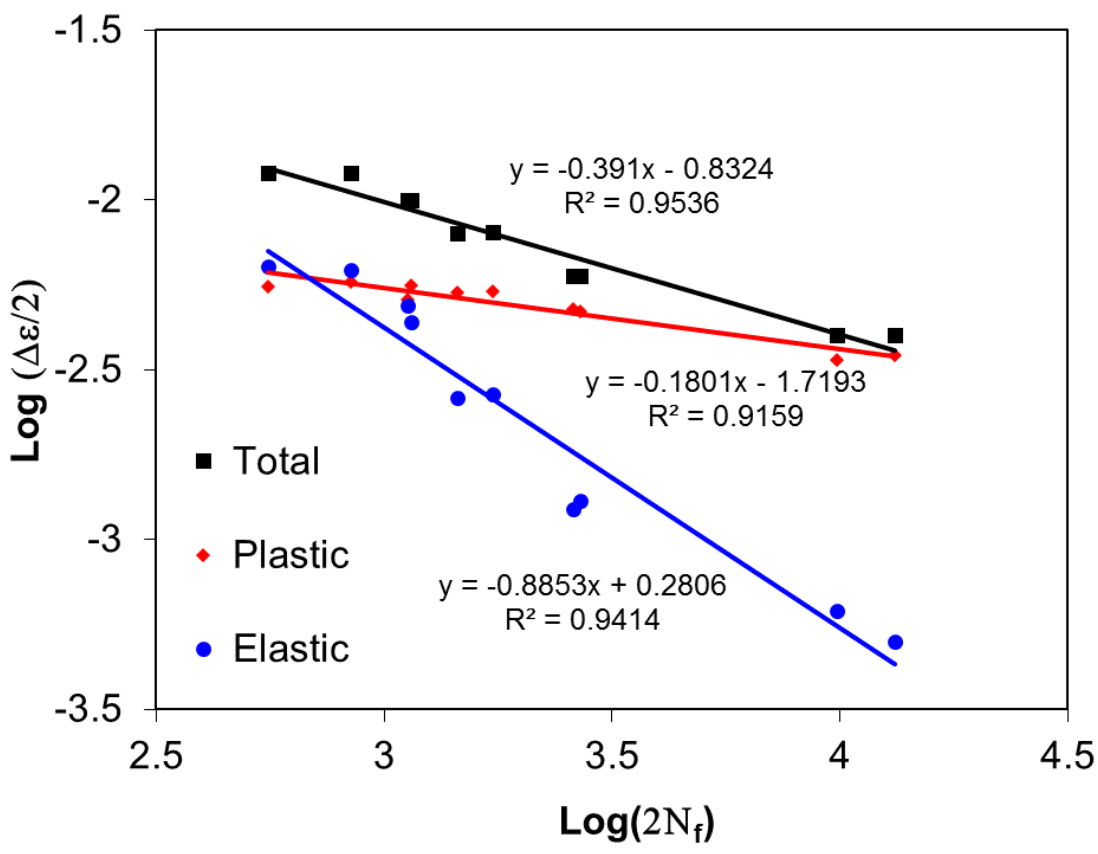

Figure 5.9: Evaluation of fatigue parameters in the form of log elastic, plastic and total strain amplitudes vs. log number of reversals to failure, respectively (TD).

Table 5.2: Low cycle fatigue parameters for the rolled ME20 alloy (TD).

\begin{tabular}{|c|c|}
\hline Low cycle fatigue parameters & \\
\hline Cyclic yield strength, $\sigma^{\prime}, \mathrm{MPa}$ & 115 \\
\hline Cyclic strain hardening exponent, $\mathrm{n}^{\prime}$ & 0.10 \\
\hline Cyclic strength coefficient, $\mathrm{K}^{\prime}, \mathrm{MPa}$ & 211 \\
\hline Fatigue strength coefficient, $\sigma^{\prime} \mathrm{f}, \mathrm{MPa}$ & 815 \\
\hline Fatigue strength exponent, $\mathrm{b}$ & -0.18 \\
\hline Fatigue ductility coefficient, $\boldsymbol{\varepsilon}^{\prime} \mathrm{f}$ & 1.91 \\
\hline Fatigue ductility exponent, $\mathrm{c}$ & -0.89 \\
\hline
\end{tabular}




\section{SUMMARY, CONCLUSIONS AND FUTURE WORK}

\subsection{Summary and Conclusions}

Cyclic deformation behavior of rolled ME20 magnesium alloys was studied by carrying out low cycle fatigue tests along the rolling direction under strain-controlled, zero mean strain conditions. The alloy has a microstructure of equiaxed grains with an average size about 15 micrometers due to dynamic recrystallization in the rolling process. The material has a fairly strong basal texture with the c-axis of many grains tilted toward the ND. The minor amount of rare earth element addition helped weaken the texture and the compression-tension yield asymmetry. Twinning played a key role in the compression loading phase and detwinning in the tensile loading phase. Cyclic softening was observed basically under all the strain amplitudes tested except for the lowest one where cyclic stabilization occurred. This cyclic softening effect is also supported by the plastic strain behavior and by comparing monotonic and cyclic stress-strain behavior. Because of a higher ductility and lower strength compared with other magnesium alloys, this alloy exhibited a better fatigue resistance at larger strain amplitudes and modest fatigue life at lower strain amplitudes. An energy density-based fatigue life prediction model was applied to this rolled magnesium alloy as plastic strain energy density is considered to be a reliable and comprehensive parameter to represent the fatigue life. By introducing a tensile elastic strain density parameter into the Morrow model the tensile mean stress effect could also be considered and those results from the life 
prediction model fit well with the experimental results. Fatigue cracks initiated from the sample surface and the fatigue propagation area was characterized by mixed-mode feature.

The specimen orientation effect on the microstructure, tensile and fatigue properties of ME20 were also investigated and results show that they were similar for both the RD and the TD samples. RD samples exhibited better tensile properties but TD showed some superior fatigue resistance due to the increase of certain fatigue parameters. Overall, the addition of RE-elements weakened the texture which was formed during the hot rolling process and the effect of specimen orientation became less prominent.

\subsection{Recommendations for Future Work}

Several things that can be done as a continuation of this research work are as follows:

1. Study the deformation behavior of ME20 compressed under different temperatures and different strain rates.

2. Study the evolution of microstructure, texture and twins during the compression process in ME20.

3. Study the microstructure, tensile properties and low cycle fatigue properties of friction stir processed ME20 samples.

4. Study the evolution of the microstructure and texture of the friction stir processed area in ME20. 


\section{REFERENCES}

[1] Gillett, N. P., Arora, V. K., Zickfeld, K., Marshall, S. J., and Merryfield, W. J. (2011) Ongoing climate change following a complete cessation of carbon dioxide emissions. Nature Geoscience, 4, 83-87.

[2] Murray, J., and King, D. (2012) Climate policy: Oil's tipping point has passed. Nature, 481, 433-435.

[3] Pollock, T.M. (2010) Weight Loss with Magnesium Alloys. Science, 328, 986-987.

[4] Wise, M., Calvin, K., Thomson, A., Clarke, L., Lamberty, B.B., Sands, R., Smith, S.J., Janetos, A., Edmonds, J. (2009) Implications of Limiting $\mathrm{CO}_{2}$ Concentrations for Land Use and Energy. Science, 324, 1183-1186.

[5] Joost, W.J. (2012) Reducing vehicle weight and improving US energy efficiency using integrated computational materials engineering. JOM, 64, 1032-1038.

[6] Luo, A.A. (2002) Magnesium: Current and potential automotive applications. JOM, 54, $42-48$.

[7] Ogarevic, V.V. and Stephens, R.I. (1990) Fatigue of Magnesium Alloys. Annu. Rev. Mater. Sci., 20, 141-177.

[8] Lin, X.Z. and Chen, D.L. (2008) Strain controlled cyclic deformation behavior of an extruded magnesium alloy. Mater. Sci. Eng. A, 496, 106-113.

[9] Mirza, F.A., Chen, D.L., in: Zhang, S., Zhao, D.L. (Eds.). (2013) Fatigue of lightweight magnesium alloys. Aerospace Materials Handbook, CRC Press, Taylor \& Francis, New York, 647-698.

[10] Begum, S., Chen, D.L., Xu, S. and Luo, A.A. (2009) Low cycle fatigue properties of an extruded AZ31 magnesium alloy. Int. J. Fatigue, 31, 726-735. 
[11] Chen, L., Wang, C., Wu, W., Liu, Z., Stoica, G.M., Wu, L. and Liaw, P.K. (2007) Low cycle fatigue behavior of an as extruded AM50 magnesium alloy. Metall. Mater. Trans. $A, \mathbf{3 8}, 2235-2241$.

[12] Begum, S., Chen, D. L., Xu, S., and Luo, A. A. (2008) Strain-controlled low-cycle fatigue properties of a newly developed extruded magnesium alloy. Metall. Mater. Trans. A, 39, 3014-3026.

[13] Begum, S., Chen, D. L., Xu, S., and Luo, A. A. (2009) Effect of strain ratio and strain rate on low cycle fatigue behavior of AZ31 wrought magnesium alloy. Mater. Sci. Eng. A, 517, 334-343.

[14] Mirza, F. A. and Chen, D. L. in: S. Zhang, D.L. Zhao (Eds.). (2013) Fatigue of lightweight magnesium alloys. Aerospace Materials Handbook, CRC Press, Taylor \& Francis, New York, 647-698.

[15] Pollock, T. M. (2010) Weight loss with magnesium alloys. Science, 328, 986-987.

[16] Agnew, W. G. (1974) Reducing automotive emissions. Science, 183(4122), 254-256.

[17] Ke, W., Han, E. H., Han, Y. F., Kainer K., and Luo, A. A. (2005) Mechanical properties and creep behavior of $\mathrm{Mg}-\mathrm{Al}-\mathrm{Ca}$ alloys. Proceedings of International Conference on Magnesium - Science, Technology and Applications. Beijing, China. Mater. Sci. Forum., 488-489.

[18] Mordike B. L. and Ebert, T. (2001) Magnesium: properties applications potential. Mater. Sci. Eng. A, 302(1), 37-45.

[19] Friedrich, H. E. and Mordike, B. L. (2006) Magnesium Technology-Metallurgy, Design Data, Applications, Springer-Verlag Berlin Heidelberg, Germany. 
[20] Eliezer, D., Aghion, E., and Froes, F. H. (1998) Magnesium science, technology and applications. Adv. Perfor. Mater., 5, 201-212.

[21] Blawert, C., Hort, N., and Kainer, K. U. (2004) Automotive applications of magnesium and its alloys. Trans. Indian Inst. Met., 57(4), 397-408.

[22] United States Automotive Materials Partnership (USAMP). 2006. Magnesium vision 2020: A North American automotive strategic vision for magnesium.

[23] Hadorn, J. P., Hantzsche, K., Yi, S., Bohlen, J., Letzig, D., and Agnew, S. R. (2012) Effects of solute and second-phase particles on the texture of Nd-containing Mg alloys. Metall. Mater. Trans. A, 43A(4), 1363-1375.

[24] He, S. M., Zeng, X. Q., Peng, L. M., Gao, X., Nie, J. F., and Ding, W. J. (2007) Microstructure and strengthening mechanism of high strength $\mathrm{Mg}-10 \mathrm{Gd}-2 \mathrm{Y}-0.5 \mathrm{Zr}$ alloy. J Alloys Comp., 427, 316-323.

[25] Hort, N., Huang, Y., Fechner, D., Stormer, M., Blawert, C., Witte, F., Vogt, C., Drucker, H., Willumeit, R., Kainer, K. U., and Feyerabend, F. (2010) Magnesium alloys as implant materials-Principles of property design for Mg-RE alloys. Acta Biomater., 6, 1714-1725.

[26] Peng, Q., Wang, J., Wu, Y., and Wang, L. (2006) Microstructures and tensile properties of $\mathrm{Mg}-8 \mathrm{Gd}-0.6 \mathrm{Zr}-\mathrm{xNd}-\mathrm{yA}(\mathrm{x}+\mathrm{y}=3$, mass\%) alloys. Mater. Sci. Eng. A, 433, 133-138.

[27] Apps, P. J., Karimzadeh, H., King, J. F., and Lorimer, G. W. (2003) Phase composition in magnesium-rare earth alloys containing yttrium, gadolinium or dysprosium. Scr. Mater., 48, 475-481. 
[28] Apps, P. J., Karimzadeh, H., King, J. F., and Lorimer, G. W. (2003) Precipitation reactions in magnesium-rare earth alloys containing yttrium, gadolinium or dysprosium. Scr. Mater., 48, 1023-1028.

[29] Chang, J., Guo, X., He, S., Fu, P., Peng, L., and Ding, W. (2008) Investigation of the corrosion for Mg-xGd-3Y-0.4Zr (x=6,8,10,12 wt.\%) alloys in a peak-aged condition. Corrosion, 50, 166-177.

[30] Cizek, J., Prochazka, I., Smola, B., Stulikova, I., and Ocenasek, V. (2007) Influence of deformation on precipitation process in Mg-15 wt.\% Gd alloy. J. Alloys Comp., 430, 92-96.

[31] Gao, L., Chen, R. S., and Han, E. H. (2009) Effects of rare-earth elements Gd and Y on the solid solution strengthening of Mg alloys. J. Alloys Comp., 481, 379-384.

[32] Gao, X., He, S. M., Zeng, X. Q., Teng, L. M., Ding, W. J., and Nie, J. F. (2006) Microstructure evolution in a $\mathrm{Mg}-15 \mathrm{Gd}-0.5 \mathrm{Zr}$ (wt.\%) alloy during isothermal aging at 250 ${ }^{\circ}$ C. Mater. Sci. Eng. A, 431, 322-327.

[33] Gao, Y., Wang, Q., Gu, J., Zhao, Y., and Tong, Y. (2007) Behavior of Mg-15Gd-5Y$0.5 \mathrm{Zr}$ alloy during solution heat treatment from 500 to $540^{\circ}$ C. Mater. Sci. Eng. A, 45, $117-123$.

[34] Liu, K., Zhang, J., Rokhlin, L. L., Elkin, F. M., Tang, D., and Meng, J. (2009) Microstructures and mechanical properties of extruded $\mathrm{Mg}-8 \mathrm{Gd}-0.4 \mathrm{Zr}$ alloys containing Zn. Mater. Sci. Eng. A, 505, 13-19.

[35] Peng, Q., Wang, L., Wu, Y., and Wang, L. (2009) Structure stability and strengthening mechanism of die-cast Mg-Gd-Dy based alloy. J. Alloys Comp., 469, 587-592. 
[36] Peng, Q., Hou, X., Wang, L., Wu, Y., Cao, Z., and Wang, L. (2009) Microstructure and mechanical properties of high performance Mg-Gd based alloys. Mater. Des., 30, 292-296.

[37] Peng, Q., Dong, H., Wang, L., Wu, Y., and Wang, L. (2008) Aging behavior and mechanical properties of Mg-Gd-Ho alloys. Mater. Charact., 59, 983-986.

[38] Peng, Q., Dong, H., Wu, Y., and Wang, L. (2008) Age hardening and mechanical properties of Mg-Gd-Er alloy. J. Alloys Comp., 456, 395-399.

[39] Peng, Q., Wu, Y., Fang, D., Meng, J., and Wang, L. (2006) Microstructures and properties of melt-spun and as-cast Mg-20Gd binary alloy. J. Rare Earths, 24, 466-470.

[40] Rokhlin, L. L. (2003) Magnesium alloys containing rare earth elements-structure and properties. Taylor \& Francis, London.

[41] Yang, Z., Li, J. P., Zhang, J. X., Lorimer, G. W., and Robson, J. (2008) Review on research and development of magnesium alloys. Acta Metall. Sin. (Engl. Lett.), 21(5), 313-328.

[42] Yang, Y., Liu, Y. B., Qin, S. Y., and Fang, Y. (2006) High cycle fatigue properties of die-cast magnesium alloy AZ91D addition of different concentrations of cerium. $J$. Rare Earths, 24, 591-595.

[43] Liu, X. B., Chen, R. S., and Han, E. H. (2008) Effects of ageing treatment on microstructures and properties of $\mathrm{Mg}-\mathrm{Gd}-\mathrm{Y}-\mathrm{Zr}$ alloys with and without $\mathrm{Zn}$ additions. $J$. Alloys Comp., 465, 232-238.

[44] Xu, Y. L., Zhang, K., Li, X. G., Lei, J., Yang, Y. S., and Luo, T. J. (2008) High cycle fatigue properties of die-cast magnesium alloy AZ91D-1\%MM. Trans. Nonferr. Met. Soc. China, 18, 306-311. 
[45] Yang, Y. and Liu, Y. B. (2008) High cycle fatigue characterization of two die-cast magnesium alloys. Mater. Charact., 59, 567-570.

[46] Yang, Y. and Li, X. S. (2010) Influence of neodymium on high cycle fatigue behavior of die cast AZ91D magnesium alloy. J. Rare Earths, 28(3), 456-460.

[47] Mokhtarishirazabad, M., Boutorabi, S. M. A., Azadi, M., and Nikravan, M. (2013) Effect of rare earth elements on high cycle fatigue behavior of AZ91 alloy. Mater. Sci. Eng. A, 587, 179-184.

[48] Bayani, H. and Saebnoori, E. (2009) Effect of rare earth elements addition on thermal fatigue behaviors of AZ31 magnesium alloy J. Rare Earths, 27(2), 255-258.

[49] Honma, T., Ohkubo, T., Hono, K., and Kamado, S. (2005) Chemistry of nanoscale precipitates in $\mathrm{Mg}-2.1 \mathrm{Gd}-0.6 \mathrm{Y}-0.2 \mathrm{Zr}$ (at.\%) alloy investigated by the atom probe technique. Mater. Sci. Eng. A, 395, 301-306.

[50] Gorsse, S., Hutchinson, C. R., Chevalier, B., and Nie, J. F. (2005) A thermodynamic assessment of the Mg-Nd binary system using random solution and associate models for the liquid phase. J. Alloys Comp., 39, 253-262.

[51] Begum, S., Chen, D. L., Xu, S., and Luo, A. A. (2009) Effect of strain ratio and strain rate on low cycle fatigue behavior of AZ31 wrought magnesium alloy. Mater. Sci. Eng. A, 517, 334-343.

[52] Begum, S., Chen, D. L., Xu, S., and Luo, A. A. (2009) Low cycle fatigue properties of an extruded AZ31 magnesium alloy. Int. J. Fatigue, 31, 726-735.

[53] Lin, X. Z. and Chen, D. L. (2008) Strain controlled cyclic deformation behavior of an extruded magnesium alloy. Mater. Sci. Eng. A, 496, 106-113. 
[54] Begum, S., Chen, D. L., Xu, S., and Luo, A. A. (2008) Strain-controlled low-cycle fatigue properties of a newly developed extruded magnesium alloy. Metall. Mater. Trans. A, 39, 3014-3026.

[55] Fan, C. L., Chen, D. L., and Luo, A. A. (2009) Dependence of the distribution of deformation twins on strain amplitudes in an extruded magnesium alloy after cyclic deformation. Mater. Sci. Eng. A, 519, 38-45.

[56] Peng, Z. -K., Zhang, X. -M., Chen, J. -M., Xiao, Y., and Jiang, H. (2005) Grain refining mechanism in Mg-9Gd-4Y alloys by zirconium. Mater. Sci. Technol., 21, $722-726$.

[57] Kainer, K. U. (2003) Magnesium - Alloys and Technology. Wiley-VCH, Cambridge.

[58] Chen, L., Wang, C., Wu, W., Liu, Z., Stoica, G. M., Wu, L., and Liaw, P. K. (2007) Low-cycle fatigue behavior of an as-extruded AM50 magnesium alloy. Metall. Mater. Trans. A, 38, 2235-2241.

[59] Lin X. Z. and Chen, D. L. (2008) Strain hardening and strain-rate sensitivity of an extruded magnesium alloy. J. Mater. Eng. Perform., 17(6), 894-901.

[60] Fairman, M., Afrin, N., Chen, D. L., Cao, X. J., and Jahazi, M. (2007) Microstructural evaluation of friction stir processed AZ31B-H24 magnesium alloy. Canadian Metall. Quarterly, 46(4), 425-432.

[61] Afrin, N., Chen, D. L., Cao, X., and Jahazi, M. (2007) Strain hardening behavior of a friction stir welded magnesium alloy. Scr. Mater., 57(11), 1004-1007.

[62] Afrin, N., Chen, D. L., Cao, X., and Jahazi, M. (2008) Microstructure and tensile properties of friction stir welded AZ31B magnesium alloy. Mater. Sci. Eng. A, 472(12), 179-186. 
[63] Sarker, D. and Chen, D. L. (2012) Detwinning and strain hardening of an extruded magnesium alloy during compression. Scr. Mater., 67, 165-168.

[64] Al-Samman, T. (2013) Modification of texture and microstructure of magnesium alloy extrusions by particle-stimulated recrystallization. Mater. Sci. Eng. A, 560, 561-566.

[65] Sarker, D. and Chen, D. L. (2013) Texture transformation in an extruded magnesium alloy under pressure. Mater. Sci. Eng. A, 582, 63-67.

[66] Ball, E. A. and Prangnell, P. B. (1994) Tensile-compressive yield asymmetries in high strength wrought magnesium alloys. Scr. Metall. Mater., 31, 111-116.

[67] Senn, J. W. and Agnew, S. R. Proc. Magnesium Technology in the Global Age, Pekguleryuz, M. O. and Mackenzie, L. W. F. eds., Montreal, PQ, Canada, 2006, pp. $115-130$.

[68] Senn, J. W. and Agnew, S. R. Magnesium Technology 2008: Proc. TMS, M.O. Pekguleryuz, N.R. Neelameggham, R.S. Beals, and E.A. Nyberg, eds., TMS, Warrendale, PA, 153-158.

[69] Li, M. Z., Wang, Y. Q., Li, C., Liu, X. G., and Xu, B. S. (2011) Effects of neodymium rich rare earth elements on microstructure and mechanical properties of as cast AZ31 magnesium alloy. Mater. Sci. Technol., 27, 1138-1142.

[70] Robson, J. D., Twier, A. M., Lorimer, G. W., and Rogers, P. (2011) Effect of extrusion conditions on microstructure, texture, and yield asymmetry in Mg-6Y-7Gd-0.5\% $\mathrm{Zr}$ alloy. Mater. Sci. Eng. A, 528, 7247-7256.

[71] Stanford, N. and Barnett, M.R. (2008) The origin of "Rare Earth" texture development in extruded Mg-based alloys and its effect on tensile ductility. Mater. Sci. Eng. A, 496, $399-408$. 
[72] Wang, F. H., Dong, J., Jiang, Y. Y., and Ding, W. J. (2013) Cyclic deformation and fatigue of extruded Mg-Gd-Y magnesium alloy. Mater. Sci. Eng. A, 561, 403-410.

[73] Stanford, N., Sha, G., Xia, J. H., Ringer, S. P., and Barnett, M. R. (2011) Solute segregation and texture modification in an extruded magnesium alloy containing gadolinium. Scr. Mater., 65, 919-921.

[74] Stanford, N. and Barnett, M. R. (2008) Effect of composition on the texture and deformation behaviour of wrought Mg alloys. Scr. Mater., 58, 179-182.

[75] Stanford, N., Atwell, D., Beer, A., Davies, C. H., and Barnett, M. R. (2008) Effect of microalloying with rare-earth elements on the texture of extruded magnesium-based alloys. Scr. Mater., 59, 772-775.

[76] Unsworth, W. (1989) The role of rare earth elements in the development of magnesium base alloys. Int. J. Mater. Prod. Technol., 4(4), 359-378.

[77] Liang, S. Q., Guan, D. K., Chen, L., Gao, Z. H., Tang, H. X., and Tong, X. T. (2011) Precipitation and its effect on age-hardening behavior of as-cast Mg-Gd-Y alloy. Mater. Des., 32, 361-364.

[78] Wang, Q., Wu, G., Zheng, H. Q., Chen, B., Zheng, Y., and Ding, W. (2010) A comparative study of Mg-Gd-Y-Zr alloy cast by metal mould and sand. China Found. $J ., 7,6-12$.

[79] Zhang, F., Zhang, K. X., Tan, C. W., Yu, X. D., Ma, H. L., Wang, F. C., and Cai, H. N. (2011) Microstructure and mechanical properties of Mg-Gd-Y-Zr alloys processed by equal channel angular pressing. Trans. Nonferr. Met. Soc. China, 21, 2140-2146.

[80] Zhu, R., Wu, Y. J., Wang, J. T., and Lu, K. C. (2011) Mechanical anisotropy of extruded Mg-10Gd-2Y-0.5Zr alloy. Adv. Mater. Res., 320, 222-227. 
[81] Stanford, N., Atwell, D., and Barnett, M. R. (2010) The effect of Gd on the recrystallisation, texture and deformation behaviour of magnesium-based alloys. Acta Mater., 58, 6773-6783.

[82] Stanford, N. (2010) Micro-alloying $\mathrm{Mg}$ with $\mathrm{Y}, \mathrm{Ce}, \mathrm{Gd}$ and $\mathrm{La}$ for texture modification-a comparative study. Mater. Sci. Eng. A, 527, 2669-2677.

[83] Bohlen, J., Nurnberg, M. R., Senn, J. W., Letzig, D., and Agnew, S. R. (2007) The texture and anisotropy of magnesium-zinc-rare earth alloy sheets. Acta Mater., 55, 2101-2112.

[84] Li, X., Al-Samman, T., Mu, S., and Gottstein, G. (2011) Texture and microstructure development during hot deformation of ME20 magnesium alloy: Experiments and simulations. Mater. Sci. Eng. A, 528, 7915-7925.

[85] Antion, C., Donnadieu, P., Perrard, F., Deschamps, A., Tassin, C., and Pisch, A. (2003) Hardening precipitation in a Mg-4Y-3RE alloy. Acta Mater., 51, 5335-5348.

[86] Nie, J. F. and Muddle, B. C. (2000) Characterisation of strengthening precipitate phases in a Mg-Y-Nd alloy. Acta Mater., 48, 1691-1703.

[87] Hantzsche, K., Bohlen, J., Wendt, J., Kainer, K. U., Yi, S. B., and Letzig, D. (2010) Effect of rare earth additions on microstructure and texture development of magnesium alloy sheets. Scr. Mater., 63, 725-730.

[88] Laser, T., Hartig, Ch., Nurnberg, M. R., Letzig, D., and Bormann, R. (2008) The influence of calcium and cerium mischmetal on the microstructural evolution of $\mathrm{Mg}$ 3Al-1Zn during extrusion and resulting mechanical properties. Acta Mater., 56, 27912798. 
[89] Li, J., Mishra, R. K., and Sachdev, A. K. (2012) Texture modification during extrusion of some Mg alloys. Metall. Mater. Trans. A, 43A(6), 2148-2157.

[90] Nie, J. F., Gao, X., and Zhu, S.M. (2005) Enhanced age hardening response and creep resistance of Mg-Gd alloys containing Zn. Scr. Mater., 53, 1049-1053.

[91] Agnew, S. R., Yoo, M. H., and Tome, C.N. (2001) Application of texture simulation to understanding mechanical behavior of $\mathrm{Mg}$ and solid solution alloys containing $\mathrm{Li}$ or $\mathrm{Y}$. Acta Mater., 49, 4277-4289.

[92] Yi, S., Bohlen, J., Heinemann, F., and Letzig, D. (2010) Mechanical anisotropy and deep drawing behaviour of AZ31 and ZE10 magnesium alloy sheets. Acta Mater., 58, $592-605$.

[93] Yang, F., Lv, F., Yang, X. M., Li, S. X., Zhang, Z. F., and Wang, Q. D. (2011) Enhanced very high cycle fatigue performance of extruded Mg-12Gd-3Y-0.5Zr magnesium alloy. Mater. Sci. Eng. A, 528, 2231-2238.

[94] Liu, W. C., Dong, J., Song, X., Belnoue, J. P., Hofmann, F., Ding, W. J., and Korsunsky, A. M. (2011) Effect of microstructures and texture development on tensile properties of Mg-10Gd-3Y alloy. Mater. Sci. Eng. A, 528, 2250-2258.

[95] Eisenmeier, G., Holzwarth, B., Hoppel, H. W., and Mughrabi, H. (2001) Cyclic deformation and fatigue behaviour of the magnesium alloy AZ91. Mater. Sci. Eng. A, 319-321, 578-582.

[96] Chen, L., Shen, J., Wu, W., Li, F., Wang, Y., and Liu, Z. (2005) Low-cycle fatigue behavior of magnesium alloy AZ91. Mater. Sci. Forum, 488-489, 725-728. 
[97] Horstemeyer, M. F., Yang, N., Gall, K., McDowell, D. L., Fan, J., and Gullett, P. M. (2004) High cycle fatigue of a die cast AZ91E-T4 magnesium alloy. Acta Mater., 52, 1327-1336.

[98] Liu, Z., Xu, Y. Y., Wang, Z. G., Wang, Y., and Liu, Z. Y. (2000) Low cycle fatigue behavior of AZ91HP alloy in as high pressure die casting. Acta Metallurgica Sinica (English Letters), 13, 961-966.

[99] Islamgaliev, R. K., Kulyasova, O. B., Mingler, B., Zehetbauer, M., and Minkow, A. (2008) Structure and fatigue properties of the Mg alloy AM60 processed by ECAP. Mater. Sci. Forum, 584-586, 803-808.

[100] Kulyasova, O. B., Islamgaliev, R., Mingler, B., and Zehetbauer, M. (2009) Microstructure and fatigue properties of the ultrafine-grained AM60 magnesium alloy processed by equal-channel angular pressing. Mater. Sci. Eng. A, 503, 176-180.

[101] El Kadiri, H., Horstemeyer, M. F., Jordon, J. B., and Xue, Y. (2008) Fatigue crack growth mechanisms in high-pressure die-cast magnesium alloys. Metall. Mat. Trans. A, 39, 190-205.

[102] Horstemeyer, M. F., Yang, N., Gall, K., McDowell, D., Fan, J., and Gullett, P. (2002) High cycle fatigue mechanisms in a cast AM60B magnesium alloy. Fat. Frac. Eng. Mater. Struct., 25, 1045-1056.

[103] Liu, Z., Ji, H., Lin, L, Chen, L., Wu, W., and Yang, L. (2007) Cyclic deformation behavior and potential automobile application of magnesium die casting alloys AZ91 and AM50. Mater. Sci. Forum, 539-543, 1626-1631. 
[104] El Kadiri, H., Xue, Y., Horstemeyer, M. F., Jordon, J. B., and Wang, P. T. (2006) Identification and modeling of fatigue crack growth mechanisms in a die-cast AM50 magnesium alloy. Acta Mater., 54, 5061-5076.

[105] Liu, Z., Wang, Z. G., Wang, Y., and Liu, Z. Y. (1999) Cyclic deformation behavior of high pressure die casting alloy AM50. J. Mater. Sci. Lett., 18, 1567-1569.

[106] Brown, D. W., Jain, A., Agnew, S. R., and Clausen, B. (2007) Twinning and detwinning during cyclic deformation of Mg alloy AZ31B. Mater. Sci. Forum, 539543, 3407-3413.

[107] Noster, U. and Scholtes, B. (2003) Isothermal strain-controlled quasi-static and cyclic deformation behavior of magnesium wrought alloy AZ31. Mater. Res. Adv. Tech. (Zeitschrift fuer Metallkunde), 94, 559-563.

[108] Hasegawa, S., Tsuchida, Y., Yano, H., and Matsui, M. (2007) Evaluation of low cycle fatigue life in AZ31 magnesium alloy. Int. J. Fatigue, 29, 1839-1845.

[109] Chamos, A. N., Pantelakis, Sp. G., Haidemenopoulos, G. N., and Kamoutsi, E. (2008) Tensile and fatigue behaviour of wrought magnesium alloys AZ31 and AZ61. Fat. Frac. Eng. Mater. Struct., 31(9), 812-821.

[110] Chamos, A. N., Charitidis, C. A., Skarmoutsou, A., and Pantelakis, Sp. G. (2010) An investigation on the high stress sensitivity of fatigue life of rolled AZ31 magnesium alloy under constant amplitude fatigue loading. Fat. Frac. Eng. Mater. Struct., 33(4), 252-265.

[111] Wu, L., Jain, A., Brown, D. W., Stoica, G. M., Agnew, S. R., Clausen, B., Fielden, D. E., and Liaw, P. K. (2008) Twinning-detwinning behavior during the strain-controlled 
low-cycle fatigue testing of a wrought magnesium alloy, ZK60A. Acta Mater., 56, 688-695.

[112] Wu, L., Agnew, S. R., Brown. D. W., Stoica, G. M., Clausen, B., Jain, A., Fielden, D. E., and Liaw, P. K. (2008) Internal stress relaxation and load redistribution during the twinning-detwinning-dominated cyclic deformation of a wrought magnesium alloy, ZK60A. Acta Mater., 56, 3699-3707.

[113] Dong, J., Liu, W. C., Song, X., Zhang, P., Ding, W. J., and Korsunsky, A.M. (2010) Influence of heat treatment on fatigue behavior of high-strength Mg-10Gd-3Y alloy. Mater. Sci. Eng. A, 725, 6053-6063.

[114] Yang, Y. and Liu, Y. B. (2007) The effect of cerium on high-cycle fatigue properties of die-cast magnesium alloy. Fat. Frac. Eng. Mater. Struct., 30(12), 1149-1157.

[115] Nascimento, L., Yi, S., Bohlen, J., Fuskova, L., Letzig, D., and Kainer, K. U. (2010) High cycle fatigue behaviour of magnesium alloys. Procedia Eng., 2, 743-750.

[116] Yang, X. M., Yang, H. J., Yang, F., Yin, S. M., Wang, W., Li, S. X., and Wang, Q. D. (2009) Tensile and isothermal fatigue behaviors of Mg-12Gd-3Y-0.5Zr alloy at high temperature. J. Mater. Sci. Technol., 25(6), 731-737.

[117] Song, X., Liu, W. C., Belnoue, J. P., Dong, J., Wu, G. H., Ding, W. J, Kimber, S. A. J., Buslaps, T., Lunt, A. J. G., and Korsunsky, A.M. (2012) An eigenstrain-based finite element model and the evolution of shot peening residual stresses during fatigue of GW103 magnesium alloy. Int. J. Fatigue, 42, 284-295.

[118] Fu, Q. Q., Li, Y. S., Liu, G. W., and Li, H. (2012) Low cycle fatigue behavior of AZ91D magnesium alloy containing rare-earth Ce element. Procedia Eng., 27, 17941800. 
[119] Wu, L., Yang, Z., Xia, W., Chen, Z., and Yang, L. (2012) The cyclic softening and evolution of microstructures for Mg-10Gd-2.0Y-0.46Zr alloy under low cycle fatigue at 573 K. Mater. Des., 36, 47-53.

[120] Yin, S. M. and Li, S. X. (2013) Low-cycle fatigue behaviors of an as-extruded Mg12\%Gd-3\%Y-0.5\%Zr alloy. J. Mater. Sci. Technol., 29(8), 775-780.

[121] Zhu, R., Cai, X. T., Wu, Y. J., Liu, L. G., Ji, W. Q., and Hua, B. (2014) Low-cycle fatigue behavior of extruded Mg-10Gd-2Y-0.5Zr alloys. Mater. Des., 53, 992-997.

[122] Dieter, G. E. (1986) Mechanical Metallurgy, SI metric ed., McGraw-Hill, Boston, USA.

[123] Potzies, C. and Kainer, K. U. (2004) Fatigue of magnesium alloys. Adv. Eng. Mater., 6(5), 281-289.

[124] Yang, F., Yin, S. M., Li, S. X., and Zhang, Z. F. (2008) Crack initiation mechanism of extruded AZ31 magnesium alloy in the very high cycle fatigue regime. Mater. Sci. Eng. A, 491, 131-136.

[125] Suresh, S. (1998) Fatigue of materials, second ed., Cambridge University Press, Cambridge.

[126] Patel, H. A., Chen, D. L., Bhole, S. D., and Sadayappan, K. (2013) Low cycle fatigue behavior of a semi-solid processed AM60B magnesium alloy. Mater. Des., 49, 456464.

[127] Patel, H. A., Rashidi, N., Chen, D. L., Bhole, S. D., and Luo, A. A. (2012) Cyclic deformation behavior of a super-vacuum die cast magnesium alloy. Mater. Sci. Eng. A, 546, 72-81. 
[128] Goodenberger, D. L. and Stephens, R. I. (1993) Fatigue of AZ91E-T6 Cast Magnesium Alloy. J. Eng. Mater. Tech., 115, 391-397.

[129] Patel, H. A., Chen, D. L., Bhole, S. D., and Sadayappan, K. (2010) Cyclic deformation and twinning in a semi-solid processed AZ91D magnesium alloy. Mater. Sci. Eng. A, 528, 208-219.

[130] Jordon, J. B., Gibson, J. B., Horstemeyer, M. F., El Kadiri, H., Barid, J. C., and Luo, A. A. (2011) Effect of twinning, slip, and inclusions on the fatigue anisotropy of extrusion-textured AZ61 magnesium alloy. Mater. Sci. Eng. A, 528, 6860-6871.

[131] Lv, F., Yang, F., Duan, Q. Q., Yang, Y. S., Wu, S. D., Li, S. X., and Zhang, Z. F. (2011) Fatigue properties of rolled magnesium alloy (AZ31) sheet: Influence of specimen orientation. Int. J. Fatigue, 33, 672-682.

[132] Yu, Q., Zhang, J., Jiang, Y., and Li, Q. (2012) An experimental study on cyclic deformation and fatigue of extruded ZK60 magnesium alloy. Int. J. Fatigue, 36, 47-58.

[133] Luo, T. J., Yang, Y. S., Tong, W. H., Duan, Q. Q., and Dong, X. G. (2010) Fatigue deformation characteristic of as-extruded AM30 magnesium alloy. Mater. Des., 31, $1617-1621$.

[134] Lee, S. G., Patel, G. R., and Gokhale, A. M. (2005). Inverse surface macro-segregation in high-pressure die-cast AM60 magnesium alloy and its effects on fatigue behavior. Scr. Mater., 52, 1063-1068.

[135] Vinogradov, A., Washikita, A., Kitagawa, K., and Kopylov, V. I. (2003) Fatigue life of fine-grain Al-Mg-Sc alloys produced by equal-channel angular pressing. Mater. Sci. Eng. A, 349, 318-326. 
[136] Bachmann, F., Hielscher, R., and Schaeben, H. (2010) Texture analysis with MTEX free and open source software toolbox. Solid State Phenom., 160, 63-68..

[137] Standard test methods of tension testing of metallic materials, ASTM E8 / E8M-13a.

[138] Standard test method for strain-controlled fatigue testing, ASTM E606 / E606M-12.

[139] Fan, C. L., Chen, D. L., and Luo, A. A. (2009) Dependence of the distribution of deformation twins on strain amplitudes in an extruded magnesium alloy after cyclic deformation. Mater. Sci. Eng. A, 519, 38-45.

[140] Yu, K., Rui, S. T., Song, J. M., Li, W. X., and Guo, L. (2008) Effects of grain refinement on mechanical properties and microstructures of AZ31 alloy. Trans. Nonferrous Met. Soc. China, 18, s39-s43.

[141] Li, X., Al-Samman, T., Mu, S., and Gottstein, G. (2011) Texture and microstructure development during hot deformation of ME20 magnesium alloy: Experiments and simulations. Mater. Sci. Eng. A, 528, 7915-7925.

[142] Sarker, D. and Chen, D. L. (2012) Detwinning and strain hardening of an extruded magnesium alloy during compression. Scr. Mater., 67, 165-168.

[143] Lv, F., Yang, F., Duan, Q. Q., Yang, Y. S., Wu, S. D., Li, S. X., and Zhang, Z. F. (2011) Fatigue properties of rolled magnesium alloy (AZ31) sheet: Influence of specimen orientation. Int. J. Fatigue, 33, 672-682.

[144] Stanford, N. and Barnett, M. R. (2008) Effect of composition on the texture and deformation behaviour of wrought Mg alloys. Scr. Mater., 58, 179-182.

[145] Mirza, F.A., Chen, D.L., Li, D.J. and Zeng, X.Q. (2013) Low cycle fatigue of a rareearth containing extruded magnesium alloy. Mater. Sci. Eng. A, 575, 65-73. 
[146] Jain, J., Poole, W. J., Sinclair, C. W., and Gharghouri, M. A. (2010) Reducing the tension-compression yield asymmetry in a $\mathrm{Mg}-8 \mathrm{Al}-0.5 \mathrm{Zn}$ alloy via precipitation. Scr. Mater., 62, 301-304.

[147] Hong, S. G., Park, S. H. and Lee, C. S. (2010) Enhancing the fatigue property of rolled AZ31 magnesium alloy by controlling $\{10-12\}$ twinning-detwinning characteristics. $J$ Mater Res, 25, 784-792.

[148] Park, S. H., Hong, S. G., Lee, B. H., Bang, W. and Lee, C. S. (2010) Low-cycle fatigue characteristics of rolled $\mathrm{Mg}-3 \mathrm{Al}-1 \mathrm{Zn}$ alloy. International Journal of Fatigue, 32, $1835-1842$.

[149] Barnett, M. R. (2003) A taylor model based description of the proof stress of magnesium AZ31 during hot working. Metall. Mater. Trans. A, 34, 1799-1806.

[150] Barnett, M. R. (2007) Twinning and ductility of magnesium alloys: part I "tension" twins. Mater Sci Eng A, 464, 1-7.

[151] Xu, S., Gertsman, V.Y., Li, J., Thompson, J.P. and Sahoo, M. (2005) Role of mechanical twinning in tensile compressive yield asymmetry of die cast Mg alloys. Can Metall Quart, 44 (2), 155-166.

[152] Kalidindi, S.R., Salem, A.A. and Doherty, R.D. (2003) Role of Deformation Twinning on Strain Hardening in Cubic and Hexagonal Polycrystalline Metals. Advanced Eng. Mater., 5, 229-232.

[153] Chowdhury, S. H., Chen, D. L., Bhole, S. D. , Powidajko, E. , Weckman, D. C. and Zhou, Y. (2012) Fiber laser welded AZ31 magnesium alloy: Effect of welding speed on microstructure and mechanical properties. Metall. Mater. Trans. A, 43, 2133-2147.

[154] Morrow JD. ASTM STP 1964; 378:45-87. 
[155] Ellyin F, Kujawski D. ASTM STP 1993; 1191: 55-56. 